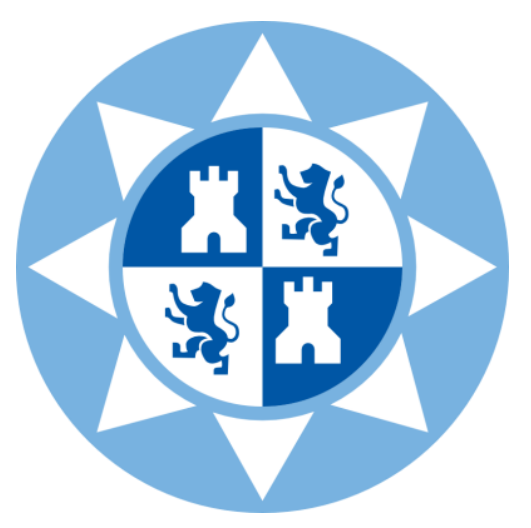

Universidad Politécnica de Cartagena

Unidad Predepartamental de Ingeniería Civil

\title{
Evaluación de la variabilidad hidroclimática desde modelos climáticos regionales a escala de cuenca
}

Patricia Olmos Giménez 


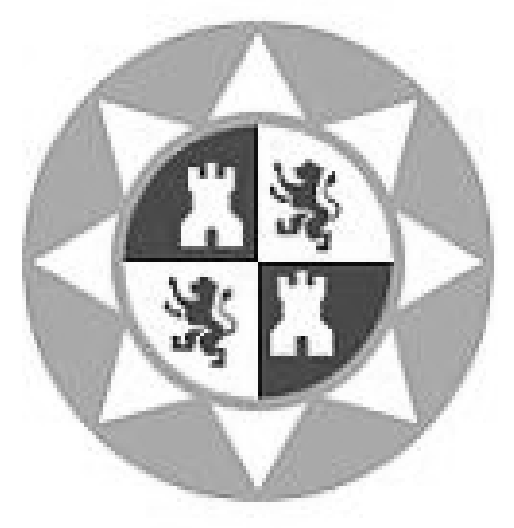

Universidad Politécnica de Cartagena

Unidad Predepartamental de Ingeniería Civil

\title{
Evaluación de la variabilidad hidroclimática desde modelos climáticos regionales a escala de cuenca
}

Patricia Olmos Giménez

\author{
Directora \\ Dra. Sandra G. García Galiano
}

2015 


\section{CONFORMIDAD DE SOLICITUD DEAUTORIZACIÓN DE DEPÓSITO DE TESIS DOCTORAL POR EL/LA DIRECTOR/A DE LA TESIS}

D". Sandra G. García Galiano, Director/a de la Tesis doctoral "Evaluación de la variabilidad hidroclimática desde modelos climáticos regionales a escala de cuenca".

\section{INFORMA:}

Que la referida Tesis Doctoral, ha sido realizada por Da . Patricia Olmos Giménez, dentro del Programa de Doctorado Técnicas Avanzadas en Investigación y Desarrollo Agrario y Alimentario (TAIDA), dando mi conformidad para que sea presentada ante la Comisión de Doctorado para ser autorizado su depósito.

La rama de conocimiento en la que esta tesis ha sido desarrollada es:

Ciencias

Ciencias Sociales y Jurídicas

$\checkmark$ Ingeniería y Arquitectura

En Cartagena, a 09 de Octubre de 2015

LA DIRECTOR/A DE LA TESIS

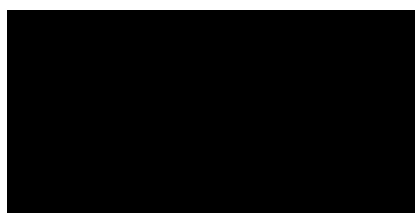

Fdo.: Sandra G. García Galiano 


\section{CONFORMIDAD DE DEPÓSITO DE TESIS DOCTORAL POR LA COMISIÓN ACADÉMICA DEL PROGRAMA}

D. Francisco Artés Hernández, Presidente de la Comisión Académica del Programa Técnicas Avanzadas en Investigación y Desarrollo Agrario y Alimentario (TAIDA)

\section{INFORMA:}

Que la Tesis Doctoral titulada, "Evaluación de la variabilidad hidroclimática desde modelos climáticos regionales a escala de cuenca", ha sido realizada, dentro del mencionado programa de doctorado, por $\mathrm{D}^{\mathrm{a}}$. Patricia Olmos Giménez, bajo la dirección y supervisión de la Dra. Sandra García Galiano.

En reunión de la Comisión Académica de fecha 14/10/2015, visto que en la misma se acreditan los indicios de calidad correspondientes y la autorización del Director de la misma, se acordó dar la conformidad, con la finalidad de que sea autorizado su depósito por la Comisión de Doctorado.

La Rama de conocimiento por la que esta tesis ha sido desarrollada es:

Ciencias

Ciencias Sociales y Jurídicas

$\mathrm{X}$ Ingeniería y Arquitectura

En Cartagena, a 15 de octubre de 2015

EL PRESIDENTE DE LA COMISIÓN ACADÉMICA DEL PROGRAMA
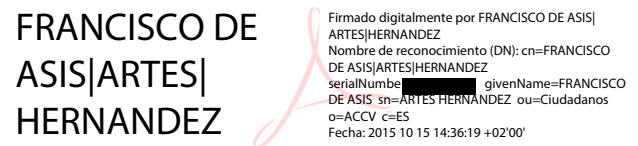

Fdo: Dr. Francisco Artés Hernández

\section{COMISIÓN DE DOCTORADO}




\section{AGRADECIMIENTOS}

A la Secretaría Nacional de Investigación del Ministerio de Economía y Competitividad por el apoyo financiero recibido con el Proyecto Nacional I+D CGL2012-39895-C0201 HYDROCLIM ", y a los Fondos FEDER.

Al Grupo de I+D Gestión de Recursos Hídricos de la UPCT que ha suministrado la información correspondiente del Proyecto Europeo ENSEMBLES, y a la Confederación Hidrográfica del Segura por la cesión de información, que ha permitido llevar a cabo este trabajo.

A mi directora, la Dra. Sandra García Galiano por su dirección para poder llevar a cabo esta Tesis, y por darme el impulso que me faltaba para poder finalizar este trabajo.

A mi compañero José Ángel, que tanto me ha ayudado y animado en los buenos y malos momentos.

A mi compañero Ángel, que aunque no ha estado durante todos estos años de tesis, me ha hecho pasar muy buenos momentos.

Al Dr. Juan Diego Giraldo Osorio por su apoyo en el desarrollo informático.

A mis padres, por su inmensa paciencia en todos estos años de estudio.

Y al gran merecedor de una mención en esta página, a Nacho, por ser mi mayor apoyo, por sufrir conmigo y por alegrarse de cada una de mis metas alcanzadas. 


\section{Índice}

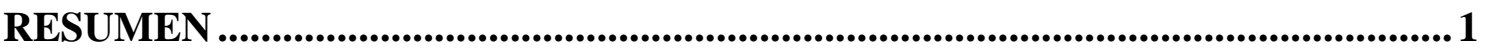

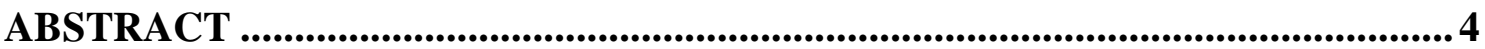

1. MOTIVACIÓN Y OBJETIVOS ..................................................................... 7

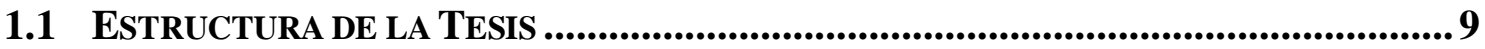

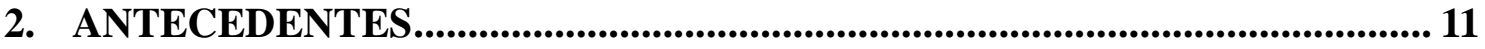

2.1 ESCENARIOS DE EMISIONES DE EFECTO INVERNADERO .................................... 11

2.2 MODELOS CLIMÁTICOS REGIONALES (RCM) .................................................... 13

2.3 ESTUDIOS DE IMPACTOS DEL CAMBIO CLIMÁTICO EN LOS RECURSOS HÍDRICOS: MODELOS DE IMPACTOS

3. CARACTERIZACIÓN DE LA ZONA DE ESTUDIO: ESPAÑA PENINSULAR Y CUENCA DEL RÍO SEGURA ....................................................... 21

4. PROCESAMIENTO DE INFORMACIÓN........................................................... 26

4.1 INFORMACIÓN METEOROLÓGICA............................................................... 26

4.2 INFORMACIÓN HIDROLÓGICA .............................................................................. 28

4.3 CARTOGRAFÍA TEMÁTICA-INFORMACIÓN GEOGRÁFICA.........................................30

5. METODOLOGÍAS DE COMBINACIÓN DE RCMS.......................................... 32

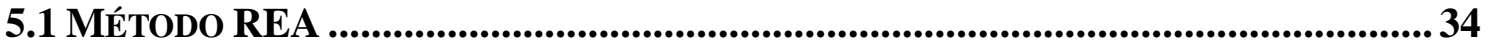

5.2 NUEVAS FORMULACIONES EN LA ESTIMACIÓN DE CONFIABILIDAD DE LOS RCMS 35 5.3 EVALUACIÓN DE SENSIBILIDAD DEL FACTOR DE CONFIABILIDAD: CASO DE ESTUDIO

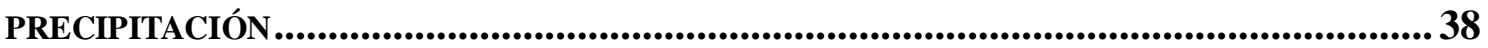


6.1 METODOLOGÍA DE CALIBRACIÓN Y VALIDACIÓN .................................................41

6.2 ESTIMACIÓN DE LAS ENTRADAS AL MODELO...................................................46

7. ANÁLISIS DE RESULTADOS Y DISCUSIÓN ....................................................48

7.1 ANÁlisis DE SENSIBILIDAD PROBABILÍSTICO A LA METODOLOGÍA DE CONSTRUCCIÓN DE ENSEMbLes PDF Y A LA MÉTRICA DE PROYECCIONES DE

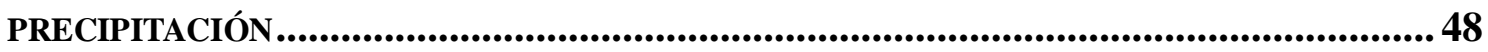

7.1.1 EVALUACIÓN DE METODOLOGÍAS PROPUESTAS PARA GENERACIÓN DEL ENSEMBLE DE

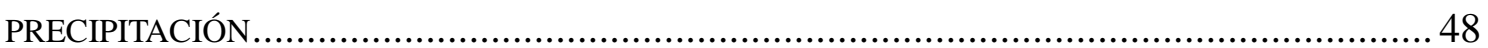

7.1.2 EVALUACIÓN DE LA SENSIBILIDAD DEL ENSEMBLE A LA SELECCIÓN DE LA MÉTRICA 57 7.2 ANÁlisis DE TENDENCIAS DE PRECiPitación, TEMPERATURA MÁXiMA Y

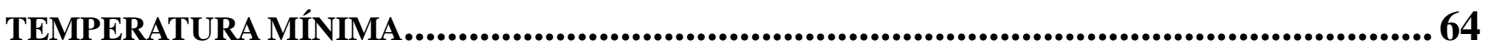

7.3 RESUlTAdOS: MODELIZACión HIDROLÓGICA EN LA CUENCA DE LA FUENSANTA . 69

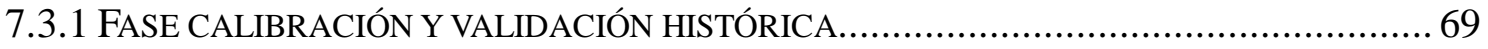

7.3.2 FASE GENERACIÓN DE ESCENARIOS HIDROLÓGICOS FUTUROS ................................ 71

8. CONCLUSIONES …............................................................................................. 81

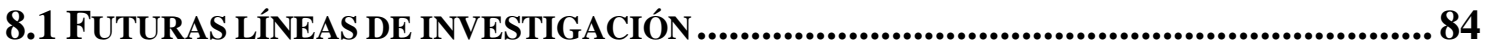

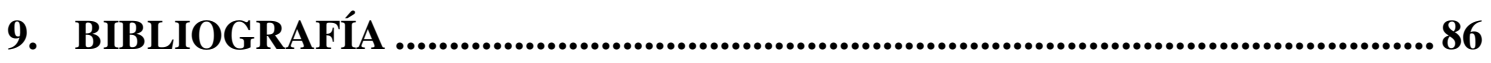

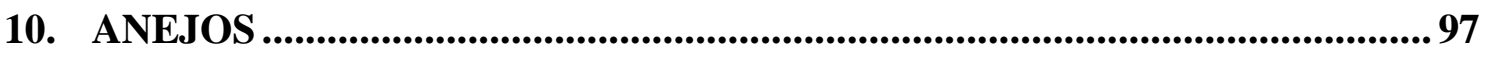

A. P DEL TEST DE BONDAD DE AJUSTE SMIRNOV-KOLMOGOROV ............................97

B. SSCORE. MÉTRICA PROPUESTA POR PERINS ................................................98

C. ECUACIONES DEL MODELO TÉMEZ ................................................................ 99 


\section{Índice de figuras}

Figura 2.1 Dominio espacial común de los RCMs en los distintos experimentos. (Fuente: http://clone.www.clm-community.eu/index.php?menuid=1)

Figura 3.1. Distribución espacial de la precipitación media anual ( $\mathrm{mm}$ ) desde datos observados (Spain02) en la España Peninsular, para el periodo 1961-1990. 21 Figura 3.2. Localización de la cuenca del río Segura, y mapa de la precipitación media anual (mm) desde datos observados (base de datos Spain02) para el periodo 1961-1990

Figura 3.3. Cuenca del río Segura y cuenca de la Fuensanta . 24

Figura 4.1. Ubicación de los 906 sitios de análisis al interior del territorio continental español, basados en la malla del Proyecto ENSEMBLES. 27

Figura 4.2. Hidrograma de aportación ( $\mathrm{hm}^{3} / \mathrm{mes}$ ) en régimen natural para el Embalse de Fuensanta en el periodo 1961-1990, frente a la media.

Figura 4.3. Mapa geológico para la cuenca de la Fuensanta (Fuente: IGME, 2013). .... 30 Figura 4.4. Mapa de usos del suelo para la cuenca de la Fuensanta (Fuente: IGN, 2010)

Figura 4.5. Mapa de unidades hidrogeológicas para la cuenca de la Fuensanta (Fuente: CHS, 2013) 31

Figura 5.1. Diagrama de flujo de la metodología en cada sitio para la construcción del ensemble PDF. .36

Figura 6.1. Esquema simplificado del modelo Témez. 40

Figura 6.2. Mapa de la cuenca de estudio de: a) Infiltración del suelo (mm); b) Capacidad máxima de humedad del suelo ( $\mathrm{mm}$ ); y c) Mapa de coeficiente de agotamiento del acuífero (mes ${ }^{-1}$ ).

Figura 7.1. Mapas de los valores de $R_{i}$ estimados con la combinación 1.1 (Método $1 \mathrm{y}$ métrica $p$ del TSSK) de cada RCM para la precipitación.

Figura 7.2. Mapas de los valores de $R_{i}$ estimados con la combinación 2.1 (Método 2 y métrica $p$ del TSSK) de cada RCM para la precipitación.

Figura 7.3. Mapas de los valores de $R_{i}$ estimados con la combinación 1.2 (Método $1 \mathrm{y}$ métrica Sscore) de cada RCM para la precipitación. .51

Figura 7.4. Mapas de los valores de $R_{i}$ estimados con la combinación 2.2 (Método 2 y 
métrica Sscore) de cada RCM para la precipitación.

Figura 7.5. Mapas de valores medios del factor de confiabilidad para el Método 1 y 2 , evaluados usando las métricas: a) $p$ del TSSK; y b) Sscore.

Figura 7.6. Mapas de los valores de Pm estimados con la combinación 1.1 (Método 1 y métrica $p$ del TSSK) de cada RCM para la precipitación.

Figura 7.7. Mapas de los valores de Pm estimados con la combinación 2.1 (Método 2 y métrica $p$ del TSSK) de cada RCM para la precipitación. .55

Figura 7.8. Mapas de los valores de Pm estimados con la combinación 1.2 (Método 1 y métrica Sscore) de cada RCM para la precipitación. 56

Figura 7.9. Mapas de los valores de Pm estimados con la combinación 2.2 (Método 2 y métrica Sscore) de cada RCM para la precipitación.

Figura 7.10. Ubicación de los 906 sitios, cuencas y sitios de estudio seleccionados en la España continental. .58

Figura 7.11. CDFs anuales de precipitación de datos observados (en negro), RCMs (en color) y ensemble de RCMs (negro discontinua) en seis sitios diferentes para el período $1961-1990$ .59

Figura 7.12. Mapas de diferencias de medias de precipitaciones calculados para el período 1961-1990. Los mapas ensembles fueron construidos con el Método 1 usando: Sscore (derecha) y $p$ del TSSK (izquierda).

Figura 7.13. Mapas de diferencias de medias de precipitaciones calculados para el período 1961-1990. Los mapas ensembles fueron construidos con el Método 2 usando: Sscore (derecha) y $p$ del TSSK (izquierda).

Figura 7.14. Mapas de precipitación media anual $(\mathrm{mm})$ y variación de la precipitación (\%) para 2021-2050 en contraste para dos periodos distintos de datos observados (19611990 у 1971-2000).

Figura 7.15. Mapas de temperatura máxima media anual $\left({ }^{\circ} \mathrm{C}\right)$ y variación de la temperatura máxima (\%), para 2021-2050 en contraste para dos periodos distintos de datos observados (1961-1990 y 1971-2000). .66

Figura 7.16. Mapas de temperatura mínima media anual $\left({ }^{\circ} \mathrm{C}\right)$ y variación de la temperatura mínima (\%), para 2021-2050 en contraste para dos periodos distintos de datos observados (1961-1990 y 1971-2000).

Figura 7.17. Resultados de la calibración del modelo de Témez. Periodo 2000-2005... 69

Figura 7.18. Validación del modelo. Aportaciones simuladas y observadas $\left(\mathrm{hm}^{3}\right)$ con el 
modelo de Témez para el periodo 2006-2012. 70

Figura 7.19. (a) Diagrama de cajas de la escorrentía media mensual para el período 2000-2005 desde datos observados, simulada a partir de datos históricos y simulada con ensembles de RCMs; y (b) anomalías proyectadas para 2021-2050 de las precipitaciones y escorrentía en relación con la media del periodo 1961-1990. 71 Figura 7.20. Mapas de precipitación media anual $(\mathrm{mm})$ y variación de la precipitación (\%) en la cuenca de la Fuensanta, para el escenario 2021-20150 en contraste con dos periodos distintos de datos observados 1961-1990 y 1971-2000. .73

Figura 7.21. Mapas de evapotranspiración potencial media anual $(\mathrm{mm})$ y variación de la evapotranspiración (\%) en la cuenca de la Fuensanta, para el escenario 2021-20150 en contraste con dos periodos distintos de datos observados 1961-1990 y 1971-2000 ...... 74 Figura 7.22. Mapas de aportación media anual (mm) y variación de la aportación (\%) en la cuenca de la Fuensanta, para el escenario 2021-20150 en contraste con dos periodos distintos de datos observados 1961-1990 y 1971-2000. 75 Figura 7.23. Diagrama de cajas de la precipitación media mensual (mm) a escala de cuenca para cada estación, simulada para el período 2021-2050 y para los periodos de control 1961-1990 y 1971-2000. .77

Figura 7.24. Diagrama de cajas de la ETP media mensual $(\mathrm{mm})$ a escala de cuenca para cada estación, simulada para el período 2021-2050 y para los periodos de control 19611990 y $1971-2000$. 77

Figura 7.25. Diagrama de cajas de la temperatura media mensual $\left({ }^{\circ} \mathrm{C}\right)$ para cada estación a escala de cuenca, simulada para el período 2021-2050 y para los periodos de control 1961-1990 y 1971-2000. .78

Figura 7.26. Diagrama de cajas de la aportación media mensual $\left(\mathrm{hm}^{3}\right)$ para cada estación simuladas a escala de cuenca para el período 2021-2050 y para los periodos de control 1961-1990 y 1971-2000. 78 Figura 10.1 Métrica definida por Perkins et al. (2007). El Sscore es la medida del área bajo ambas curvas $f_{1}(x)$ y $f_{2}(x)$ (área sombreada). 98 Figura 10.2. Ley de excedentes (izq.) y ley de infiltración (derecha) 100 


\section{Índice de tablas}

Tabla 2.1. Familias de escenarios de GEI del SRES. Se presenta el rango proyectado de aumento de las temperaturas para el año 2100 (IPCC SRES, 2000)............................ 12 Tabla 2.2. Escenarios del 5to informe del IPCC. Se presenta rango del aumento proyectado de las temperaturas para el año 2100 (IPCC, 2013) ................................. 13

Tabla 4.1. Resumen de RCMs utilizados, junto con la base de datos observados.......... 27 Tabla 5.1. Diferentes combinaciones para analizar la sensibilidad del factor de

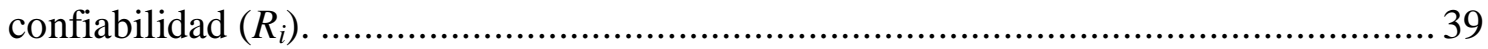

Tabla 6.1. Regionalización de la capacidad máxima de infiltración a partir de la

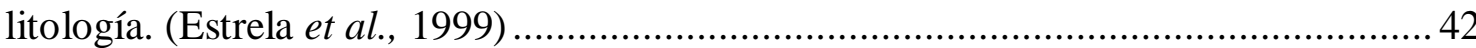

Tabla 6.2. Regionalización de la capacidad máxima de humedad del suelo en $\mathrm{mm}$ a partir de los usos del suelo (Estrela et al., 1999)....

Tabla 6.3. Criterio para la evaluación de la bondad de ajuste de Nash-Sutcliffe (Molnar, 2011) 46

Tabla 7.1. $p$ del TSSK y Sscore para las combinaciones 1.1 y 1.2 en el período 19611990. .58

Tabla 7.2. Datos de aportaciones medias anuales en la cuenca de aporte al embalse de Fuensanta. 


\section{Índice de acrónimos}

\begin{tabular}{|c|c|}
\hline Acrónimo & Descripción \\
\hline$\alpha$ & Coeficiente de recesión de los acuíferos \\
\hline ECMWF & Centro Europeo de Predicción Meteorológica a Medio Plazo \\
\hline$C$ & Coeficiente de excedente \\
\hline CDFs & $\begin{array}{l}\text { Funciones de Distribución Acumulativas } \text { (Cumulative } \text { Distribution } \\
\text { Functions en inglés) }\end{array}$ \\
\hline CEDEX & Centro de Estudios y Experimentación de Obras Públicas \\
\hline CHS & Confederación Hidrográfica del Segura \\
\hline CMIP & Proyecto de Intercomparación de Modelos Acoplados \\
\hline ETP & Evapotranspiración potencial \\
\hline ETR & Evapotranspiración real \\
\hline FR & Forzamiento Radiativo \\
\hline GCMs & Modelos Climático Globales (Global Climate Models en inglés) \\
\hline GEI & Gases de efecto invernadero \\
\hline GRASS & $\begin{array}{l}\text { Sistema de apoyo y análisis de Recursos Geográficos (Geographic } \\
\text { Resources Analysis Support System en inglés) }\end{array}$ \\
\hline$H_{0}$ & Humedad inicial en el suelo \\
\hline$H_{\text {máx }}$ & Capacidad máxima de almacenamiento de humedad en el suelo \\
\hline IGME & Instituto Geológico y Minero de España \\
\hline IGN & Instituto Geográfico Nacional \\
\hline$I_{\text {máx }}$ & Capacidad máxima de infiltración \\
\hline IPCC & Panel Intergubernamental del Cambio Climático \\
\hline IVIA & Instituto Valenciano de Investigaciones Agrarias \\
\hline LIC & Lugar de Importancia Comunitaria \\
\hline LSM & Modelo de superficie terrestre (Land Surface Model en inglés) \\
\hline NSE & Coeficiente de Eficiencia de Nash-Sutcliffe \\
\hline PDF & $\begin{array}{l}\text { Funciones de densidad de probabilidad (Probability density functions en } \\
\text { inglés) }\end{array}$ \\
\hline $\mathrm{P}$ & Precipitación \\
\hline$P m$ & Factor de confiabilidad normalizado \\
\hline$R_{i}$ & Factor de confiabilidad \\
\hline REA & Reliability Ensemble Average \\
\hline RCMs & Modelos Climáticos Regionales (Regional Climate Models en inglés) \\
\hline RCPs & $\begin{array}{l}\text { Trayectorias de Concentración } \\
\text { Concentration Pathway en inglés) }\end{array}$ \\
\hline SIAM & Sistema de Información Agraria de Murcia \\
\hline SIAR & Servicio Integral de Asesoramiento al Regante de Castilla la Mancha \\
\hline SIG & Sistema de Información Geográfica \\
\hline
\end{tabular}




\begin{tabular}{|l|l|}
\hline SRES & $\begin{array}{l}\text { Informe especial sobre escenarios de emisiones (Special Report on } \\
\text { Emissions Scenarios en inglés) }\end{array}$ \\
\hline Sscore & Métrica propuesta por Perkins (skill score en inglés) \\
\hline TSSK & Test de bondad de ajuste Smirnov-Kolmogorov \\
\hline$V_{0}$ & Almacenamiento inicial en el acuífero \\
\hline
\end{tabular}




\section{Resumen}

La situación geográfica y las características socioeconómicas de la España Peninsular, la hacen vulnerable al cambio y variabilidad climática. Estudios recientes identifican el Mediterráneo como una región particularmente vulnerable al cambio climático. El aumento de la población y los usos consuntivos intensos, generan presiones sobre los recursos hídricos de muchas cuencas. Tal es el caso de la cuenca del río Segura, una cuenca que se puede considerar deficitaria, donde el $85 \%$ de sus recursos totales de agua están orientados a la agricultura.

Los Modelos Climáticos Regionales (RCMs por sus siglas en inglés) constituyen una valiosa herramienta para analizar, comprender y predecir las tendencias a medio y largo plazo de los plausibles impactos del cambio climático en los componentes del ciclo hidrológico.

Sin embargo, las proyecciones divergentes obtenidas a partir de diferentes RCMs implican que los resultados tienen muchas incertidumbres asociadas. Las metodologías de combinación (o ensemble en inglés) de múltiples RCMs, permiten la cuantificación y reducción de incertidumbres en las proyecciones.

Considerando que la precipitación es la entrada principal al ciclo hidrológico, se debe tener una atención especial en su estimación. Por lo tanto aumentar la confiabilidad en las proyecciones de la precipitación es un requisito previo en la obtención de proyecciones hidrológicas precisas.

En este trabajo, se ha realizado un análisis de sensibilidad con la precipitación ensemble de RCMs considerando dos formulaciones diferentes del factor de confiabilidad $\left(R_{i}\right)$, basadas en el método REA (Reliability Ensemble Average). Las formulaciones propuestas se basan en Funciones de Distribución Acumulativas (CDFs por sus siglas en inglés) de la variable (precipitación por ejemplo), a escala estacional y anual en un caso; o CDFs mensuales en el otro caso. El análisis de sensibilidad también ha considerado el impacto del uso de dos métricas distintas al construir el ensemble.

De este análisis se ha obtenido cual es el método más robusto en la representación de la variable seleccionada para el periodo histórico 1961-1990 en la España Peninsular. Se ha trabajado para ello, tanto con bases de datos meteorológicas observadas, como simuladas por RCMs provistos por el Proyecto Europeo ENSEMBLES. Se han 
considerado mallas de datos observados meteorológicos de alta resolución, para evaluar las habilidades de los RCMs en la simulación de las variables seleccionadas y aumentar así la confiabilidad de las proyecciones climáticas e hidrológicas.

Ensembles de RCMs de las variables temperatura máxima, mínima y media, así como de precipitación se han generado.

Desde las proyecciones climáticas, se han discernido las tendencias espacio-temporales de las diferentes variables estudiadas al horizonte 2021-2050, considerando como periodo de control 1961-1990. Adicionalmente, se ha estudiado la influencia en las proyecciones debido a la selección del periodo de contraste o de control, considerando como periodo de referencia el 1971-2000.

Desde los resultados obtenidos para el horizonte 2021-2050, se identifican las tendencias espacio-temporales de las precipitaciones, con aumentos en la mayor parte de la España Peninsular, mientras que en zonas como el Suroeste de Andalucía o Galicia, se esperan reducciones de precipitación. En el caso de la temperatura, se identificaron tendencias crecientes usando ambos periodos de referencia. Un aumento de las temperaturas máximas y mínimas es previsto para el periodo 2021-2050 de forma generalizada.

En orden a no generar más incertidumbre en las proyecciones hidrológicas a escala de cuenca, se ha seleccionado un modelo hidrológico de simulación continua a escala mensual distribuido espacialmente, que destaca por su reducido número de parámetros. El modelo hidrológico se ha forzado con los ensembles de variables meteorológicas desde los RCMs. Las ecuaciones que definen el modelo se aplican a escala de celda en que se discretiza la cuenca, realizando así una modelización espacio-temporal de entradas, procesos y parámetros en un entorno de Sistemas de Información Geográfica (SIG), lo que ha permitido simular los flujos medios mensuales en cualquier punto de la red hidrográfica.

Para realizar la modelización hidrológica, se ha seleccionado la cuenca de aporte al embalse de Fuensanta (en adelante cuenca de la Fuensanta), localizada en la cabecera del río Segura. La misma se trata de una de las principales cuencas generadoras de recursos hídricos en la cuenca del río Segura, de allí el carácter estratégico de conocer y mejorar las proyecciones de sus aportaciones, dado el impacto en la economía y medios de vida de la Región. 
En consecuencia, se han identificado las proyecciones de escorrentía de la cuenca de la Fuensanta para el período 2021-2050 en contraste con los períodos de control 19611990 y 1971-2000. Los resultados se han visto fuertemente afectados por la selección del período de control de contraste. Para el horizonte 2021-2050, las proyecciones hidrológicas demuestran una disminución de la escorrentía del $20 \%$ si se contrasta con el período 1961-1990, que está motivada por una disminución de las precipitaciones y un aumento de la evapotranspiración potencial. Mientras que si el periodo de contraste corresponde al 1971-2000, se proyecta un incremento en la escorrentía del $2 \%$ basado en un aumento importante de las precipitaciones. La selección del periodo observacional para el contraste es un tema importante debido a la variabilidad natural.

En conclusión, el uso de modelos hidrológicos distribuidos forzados por ensembles de RCMs constituye un enfoque válido y sólido para aumentar la confiabilidad tanto de las proyecciones climáticas como hidrológicas.

El aumentar el conocimiento sobre los impactos plausibles en las distintas variables, especialmente con las distribuciones espaciales, haciendo uso del estado del arte en modelización climática e hidrológica, ayudará a construir capacidad adaptativa en la Región, para hacer frente al cambio climático. Los gestores y responsables de la toma de decisión en planificación y gestión del uso del agua, requieren de mensajes claros de la comunidad científica para alcanzar un uso sostenible de los recursos.

Palabras clave: modelización; ensembles; proyecciones hidrológicas; cambio climático; confiabilidad; impactos; España. 


\section{Abstract}

The geographic situation and socioeconomic characteristics of Spain, make it vulnerable to climate change and variability. Recent studies have identified the Mediterranean as a region particularly vulnerable to climate change. The growth in population and intense consumptive uses generate pressures on the water resources of many river basins. This is true of the Segura River Basin, a basin that can be considered deficient, where $85 \%$ of its total water resources are orientated to agriculture.

The Regional Climate Models (RCMs) are a valuable tool to analyze, understand and predict trends of plausible impacts of climate change on the components of the hydrological cycle in the medium and long term.

However, divergent projections obtained from different RCMs imply that the results have a great deal of associated uncertainties. Methodologies combining multiple RCMs (or ensemble) allow the quantification and reduction of uncertainty in the projections.

Considering that the rainfall is the principal input to the hydrological cycle, special attention should be taken in its estimation. Therefore, increasing the confidence in projections of rainfall is a prerequisite for obtaining precise hydrological projections.

In this paper, a sensitivity analysis with rainfall ensemble of RCMs has been carried out, considering two different formulations of the reliability factor $\left(R_{i}\right)$, based in the REA (Reliability Ensemble Average) method. The proposed formulations are based on Cumulative Distribution Functions (CDFs), of the variable (e. g. precipitation), to seasonal and annual scale in one case; or monthly CDFs in the other case. The sensitivity analysis has also considered the impact of using two different metrics to build the ensemble.

The most robust method in the representation of the selected variable for the historical period 1961-1990 in mainland Spain has been obtained from this analysis. Observed meteorological data as well as that simulated by Regional Climate Models provided by the European project ENSEMBLES were considered. High resolution meteorological observed data grids were considered to evaluate the skills of RCMs in the simulation of the selected variables and increase the reliability of climate and hydrological projections. 
The ensemble of different RCMs has been generated for the variables of maximum, minimum and mean temperature, and rainfall.

From climate projections, the spatio-temporal trends have been discerned from different variables studied for the horizon 2021-2050, considering the control period of 19611990. In addition, the influence on projections due to the selection period or contrast control has been studied, considering the 1971-2000 reference period.

From the results obtained for the 2021-2050 horizon, spatio-temporal precipitation trends are identified, with increases in most of mainland Spain, while in areas such as the Southwest of Andalusia and Galicia, reductions in precipitation are expected. Regarding temperature, increasing trends were identified using the two reference periods. An increase in the maximum and minimum temperatures is expected across the board for the future period 2021-2050.

In order to not create more uncertainty in hydrological projections at basin scale, a hydrological model of continuous simulation which is spatially distributed on a monthly scale that is remarkable for its low number of parameters has been selected. The hydrological model has been forced with ensembles of meteorological variables from RCMs. The equations defining the model are applied to cell scale in which the basin is discretized, making a spatio-temporal modeling of inputs, processes and parameters in an environment of Geographic Information Systems; this allowed average monthly flows at any point of the hydrological network to be simulated.

To carry out the hydrological modeling, the Fuensanta Reservoir's basin (hereinafter Fuensanta basin) located in the headwaters of the River Segura was selected. It is one of the main generator basins of water resources in the Segura River basin; hence the strategic importance of knowing and improving projections of its runoff, given its impact on the economy and livelihood of the region.

Consequently, runoff projections have been identified in the Fuensanta basin for the 2021-2050 period in contrast to the 1961-1990 and 1971-2000 control periods. The results have been strongly affected by the selection of the contrast control period. For the 2021-2050 horizon, hydrological projections show a decrease in runoff of $20 \%$ if contrasted with the period 1961-19990, which is motivated by a decrease in rainfall and an increase in potential evapotranspiration. However, if the contrast period corresponds to $1971-2000$, then an increase of $2 \%$ in runoff is projected based on a significant 
increase in precipitation. The selection of the observational period for contrast is an important issue, due to natural variability.

In conclusion, the use of distributed hydrological models forced by ensembles of RCMs is a valid and strong approach to increase the reliability of both climate as well as hydrological projections.

Increasing knowledge about plausible impacts on the different variables, especially spatial distributions, using state of the art climate and hydrological modeling will help to build the adaptive capacity in the Region to deal with climate change. Managers and decision makers responsible for the planning and management of water use require clear messages from the scientific community to achieve a sustainable use of resources.

Keywords: modeling; ensembles; hydrological projections; climate change; reliability; impacts; Spain. 


\section{Motivación y Objetivos}

La Península Ibérica es un área crítica para el estudio de impactos de cambio climático en la precipitación, debido a su posición marginal de la cuenca Mediterránea (entre el océano Atlántico y el mar Mediterráneo), el gradiente latitudinal de Norte a Sur y su orografía. Esta zona está sometida a contrastes estacionales extremos, y como resultado de las emisiones antropogénicas de gases de efecto invernadero, y su localización geográfica, grandes cambios en la temperatura y precipitaciones se esperan a lo largo del siglo (IPCC, 2007).

Particularmente en el área mediterránea, estas tendencias podrían exacerbar las condiciones existentes en las regiones que ya son vulnerables a la variabilidad climática, reduciendo así la disponibilidad hídrica (Ramos et al., 2012).

Desde informes del Panel Intergubernamental del Cambio Climático (IPCC, 2014) se prevé que: la temperatura superficial aumente durante el siglo XXI en todos los escenarios de emisiones evaluados, las olas de calor se produzcan con más frecuencia y duren más tiempo, los eventos extremos de precipitación sean más intensos y frecuentes en muchas regiones, el océano continúe calentándose y se acidifique, y que el nivel medio global del mar aumente.

Pero no sólo el cambio climático afecta a los recursos hídricos, también otras presiones tales como el aumento de la demanda urbana, agrícola e hidroeléctrica, la intensificación de ciertos procesos de deterioro de la calidad de agua y el incremento de la intervención humana, generan impactos negativos en la disponibilidad y calidad del recurso hídrico (Giraldo y García, 2011).

Según el IPCC (2014), la influencia humana en el sistema climático es clara, y emisiones antropogénicas recientes de gases de efecto invernadero son las más altas de la historia. Muchos aspectos del cambio climático y los impactos asociados continuarán durante siglos, incluso si se detienen las emisiones antropogénicas de gases de efecto invernadero (IPCC, 2014)

Huntington (2006) destaca que existe evidencia robusta sobre la intensificación actual y futura del ciclo hidrológico, y puntualiza la necesidad de mejorar la habilidad para la monitorización y predicción de impactos asociados con el cambio de los regímenes hidrológicos.

Es prioritario disponer de los mejores escenarios regionalizados posibles de cambio 
climático futuro considerando los escenarios de emisiones (estimaciones plausibles de cómo podrían evolucionar las emisiones de gases de efecto invernadero o GEI), con objeto de poder realizar análisis de riesgos e impactos.

Pero aún se observan dispersiones importantes entre los resultados de los Modelos Climáticos Regionales (RCMs por sus siglas en inglés), lo cual incrementa la incertidumbre de las predicciones. Por lo que, el uso de una aproximación ensemble desde las diferentes simulaciones de RCMs es un modo de aumentar la confiabilidad de las proyecciones climáticas y estimar las incertidumbres asociadas (Paeth et al., 2011).

Es necesario, entonces, avanzar en la mejora de las proyecciones de cambio climático desde RCMs, para reducir las incertidumbres en los datos de entrada a los modelos hidrológicos y en consecuencia en las proyecciones hidrológicas.

El aumentar el conocimiento sobre los riesgos climáticos permitirá el desarrollo de estrategias encaminadas a construir "capacidad adaptativa" a los mismos. La capacidad adaptativa es considerada una condición necesaria para diseñar e implementar estrategias efectivas de adaptación, y puede ser lograda incrementando el conocimiento sobre los riesgos climáticos potenciales que se ciernen sobre las diferentes cuencas (European Commission, 2009).

Considerando la motivación, los objetivos de la Tesis son los siguientes:

1. Proponer una metodología robusta de combinación (ensembles) de RCMs que permita reducir las incertidumbres asociadas, en los escenarios plausibles de precipitación mensual.

2. Evaluar la confiabilidad de las metodologías, que constituyen una variante del método REA (Reliability Ensemble Averaging), teniendo en cuenta distintos niveles de información que consideran la variabilidad mensual de la precipitación en un caso, y la variabilidad anual y estacional de la precipitación en el otro caso.

3. Identificar la metodología más robusta para la construcción de escenarios plausibles de las variables meteorológicas seleccionadas, que constituyen el input a los modelos hidrológicos.

4. Mejorar las proyecciones hidrológicas, considerando los ensembles de RCMs de las variables precipitación, temperatura máxima, media y mínima, como forzamiento a los modelos hidrológicos.

En el caso de los objetivos 1, 2 y 3 el dominio espacial seleccionado corresponde a la España Peninsular. Mientras que el objetivo 4 se aborda en la cuenca del río Segura, 
Subcuenca del aporte al Embalse de Fuensanta.

\subsection{Estructura de la Tesis}

Este documento de Tesis (en adelante Tesis) está estructurado en diez capítulos, considerando la bibliografía y un apartado de anejos.

El capítulo de antecedentes (capítulo 2) se inicia realizando una introducción al tema objeto de estudio, por medio de la descripción de los fundamentos y los conceptos teóricos que son importantes en la evaluación de la variabilidad hidroclimática. Se continúa con una reseña de los estudios de impactos del cambio climático en los recursos hídricos, y los modelos hidrológicos más ampliamente empleados para ello. Asimismo, se pretende justificar el porqué del planteamiento parsimonioso propuesto en esta Tesis.

En el capítulo 3, se realiza la descripción de las dos zonas de estudio establecidas en la Tesis, de acuerdo a los distintos objetivos. A continuación en el capítulo 4, se resume cómo se ha obtenido y procesado la información requerida (meteorológica, hidrológica y cartográfica).

Tanto el capítulo 5 como el capítulo 6, introducen al lector en la metodología aplicada. En el capítulo 5, se presentan los planteamientos matemáticos propuestos para llevar a cabo las distintas combinaciones de RCMs. El capítulo 6 presenta la conceptualización del modelo hidrológico distribuido Témez, utilizado como herramienta para simular los procesos del ciclo hidrológico. Al mismo tiempo, se describen las entradas al modelo, la metodología aplicada en la parametrización del modelo y la métrica utilizada en las fases de calibración y validación del modelo.

El capítulo de resultados (capítulo 7) se ha estructurado en tres apartados diferentes, en función de los objetivos principales de la Tesis. En primer lugar se hace referencia al análisis de sensibilidad de las diferentes formulaciones planteadas para la construcción de los ensembles de RCMs de variables meteorológicas. En segundo lugar, una vez seleccionada la mejor metodología, se estudian los escenarios plausibles de estas variables. Finalmente, se consideran los ensembles espacio-temporales de RCMs como forzamiento del modelo hidrológico, estimándose y analizándose las proyecciones hidrológicas a escala de cuenca. 
El capítulo 8 recoge las conclusiones y recomendaciones más destacadas de la Tesis. Se cierra el trabajo planteándose interesantes líneas de investigación futuras. 


\section{Antecedentes}

\subsection{Escenarios de emisiones de efecto invernadero}

Los modelos climáticos permiten realizar proyecciones del cambio climático relacionado con la creciente acumulación en la atmósfera de gases de efecto invernadero (GEI), y son la única herramienta de que se dispone para derivar objetivamente las futuras alteraciones del clima debido a estas emisiones (Abanades et al., 2007). El rango y la probabilidad asociada con las tendencias climáticas es mejor entendido si se ejecutan múltiples experimentos, con diferentes modelos climáticos, considerando distintos escenarios GEI.

Los GEI fueron definidos por el Informe Especial sobre Escenarios de Emisión (Special Report on Emissions Scenarios, SRES) del Panel Intergubernamental del Cambio Climático (IPCC SRES, 2000), establecidos por forzamientos tales como el desarrollo demográfico, socioeconómico y tecnológico (Tabla 2.1). La evolución futura es altamente incierta, y ninguno de estos escenarios es considerado, por ahora, más probable de ocurrir.

Analizando los distintos escenarios de emisión desde la Tabla 2.1, la familia A1 supone integración global, caracterizada por un rápido crecimiento económico. Dentro de la familia A1, se presenta el escenario A1B considerado en la presente Tesis. La familia A2, se corresponde con incremento constante de la población y desarrollos económicos y tecnológicos enfocados regionalmente. La familia B1 se caracteriza por un rápido crecimiento económico, pero con énfasis en sostenibilidad ambiental global. Finalmente, en la familia B2 de escenarios se imponen las soluciones locales para garantizar la sostenibilidad económica, social y ambiental. 
Tabla 2.1. Familias de escenarios de GEI del SRES. Se presenta el rango proyectado de aumento de las temperaturas para el año 2100 (IPCC SRES, 2000).

\begin{tabular}{c|cc}
\hline & Enfoque económico & Enfoque ambiental \\
\hline Globalización & $\mathbf{A 1}$ & $\mathbf{B 1}$ \\
(homogeneidad global) & Rápido crecimiento económico & Sostenibilidad ambiental global \\
& $(\mathrm{A} 1 \mathrm{~T}, \mathrm{~A} 1 \mathrm{~B}, \mathrm{~A} 1 \mathrm{FI})$ & {$[1,1 ; 2,9]^{\circ} \mathrm{C}$} \\
& {$[1,4 ; 6,4]^{\circ} \mathrm{C}$} & \\
\hline Regionalización & $\mathbf{A 2}$ & $\mathbf{B 2}$ \\
(heterogeneidad global) & Desarrollo económico regional & Sostenibilidad ambiental a nivel \\
& {$[2,0 ; 5,4]^{\circ} \mathrm{C}$} & local \\
& & {$[1,4 ; 3,8]^{\circ} \mathrm{C}$} \\
\hline
\end{tabular}

Líneas evolutivas estimadas para cada escenario fueron presentadas en el Informe Resumido del 4to Informe de Valoración del IPCC (IPCC, 2007), donde se representó la evolución promedio del calentamiento superficial (relativo al periodo 1980-1999) como una continuación de la simulación para el siglo XX.

Posteriormente, en el 5to Informe del IPCC (2013) se definieron cuatro nuevos escenarios denominados Trayectorias de Concentración Representativas (Representative Concentration Pathway, RCPs por sus siglas en inglés). Los RCPs no especifican escenarios socioeconómicos, se caracterizan por su Forzamiento Radiativo (FR) total al final del siglo XXI relativo a las condiciones pre-industriales. Este forzamiento oscila entre 2.6 y $8.5 \mathrm{~W} / \mathrm{m}^{2}$ (Tabla 2.2). Por ejemplo, el escenario RCP8.5 asume un incremento en el forzamiento radiativo de $8.5 \mathrm{~W} / \mathrm{m}^{2}$.

Las cuatro RCPs comprenden un escenario en el que los esfuerzos en mitigación conducen a un nivel de forzamiento muy bajo (RCP2.6), dos escenarios de estabilización (RCP4.5 y RCP6.0) y un escenario con un nivel muy alto de emisiones de GEI (RCP8.5). El escenario RCP2.6 asume que se van a reducir los gases de efecto invernadero a corto plazo (antes de 2030 se habrán reducido todas las emisiones). El escenario RCP4.5 considera que se comenzarán a reducir los gases de efecto invernadero antes de 2050. El escenario RCP6.5 considera que dentro de dos generaciones, los nacidos en torno al año 2030 empezarán a tomar decisiones, reduciendo las emisiones de manera efectiva y de forma apresurada. El último escenario, el RCP8.5 considera que no se tomarán medidas, y seguirán las emisiones de gases de efecto invernadero al mismo nivel de hoy en día. 
Tabla 2.2. Escenarios del 5to informe del IPCC. Se presenta rango del aumento proyectado de las temperaturas para el año 2100 (IPCC, 2013)

\begin{tabular}{l|cccc}
\hline & FR $\left(\mathbf{W} / \mathbf{m}^{2}\right)$ & Tendencia FR en 2100 & $\mathbf{C O}_{2}$ en 2100 & Aumento T ${ }^{\mathbf{a}}(\mathbf{C})$ \\
\hline RCP2.6 & 2.6 & Decreciente & $421 \mathrm{ppm}$ & $0.3-1.7$ \\
RCP4.5 & 4.5 & Estable & $538 \mathrm{ppm}$ & $1.1-2.6$ \\
RCP6.0 & 6.0 & Creciente & $670 \mathrm{ppm}$ & $1.4-3.1$ \\
RCP8.5 & 8.5 & Creciente & $936 \mathrm{ppm}$ & $2.6-4.8$
\end{tabular}

Los nuevos RCPs pueden contemplar los efectos de las políticas orientadas a limitar el cambio climático del siglo XX, frente a los escenarios de emisión utilizados en el cuarto informe del IPCC (IPCC, 2007) que en contraposición no los contemplaban.

Una comparación entre los efectos climáticos de los escenarios SRES y los escenarios RCPs indica que el escenario A1B, que considera un incremento medio anual de la temperatura global en el rango 2.8-4.2 grados centígrados, se aproxima al RCP6.0 y claramente queda entre el RCP4.5 y RCP8.5 (Jacob et al., 2014).

\subsection{Modelos climáticos regionales (RCM)}

Según la comunidad científica, los Modelos Climáticos Globales (GCM) tienen capacidades para simular la distribución sinóptica de las principales variables climáticas y aspectos del cambio climático observado. Pero presentan deficiencias a escalas regionales debido a su gruesa resolución espacial (generalmente del orden de cientos de kilómetros). A pesar de que la capacidad computacional se ha incrementado, los GCM no simulan adecuadamente características climáticas de mesoescala. Además, algunas veces estos modelos simplifican o parametrizan inadecuadamente procesos climáticos no lineales complejos. Estas desventajas, que se atribuyen principalmente a la baja resolución espacial, se han intentado superar mediante la construcción de RCMs con resoluciones más finas, anidados en los GCMs. De esta manera, los GCMs imponen las condiciones de frontera (o contorno) a los RCMs.

Los RCMs son herramientas muy útiles para entender la dinámica del clima y realizar estudios de impactos a escala de cuenca. Los RCMs corresponden a una reducción de escala (“downscaling”) de GCMs, una práctica común para obtener información de alta resolución acerca de los escenarios de cambio climático proyectado. Las técnicas de downscaling pueden considerarse estadísticas o dinámicas (Rummukainen, 2010). En 
esta Tesis, se trabajará con downscaling dinámico, que de acuerdo con Herrera et al. (2010), consiste en solucionar las ecuaciones de la física climática con una resolución espacial mejorada para una región particular, utilizando algún GCM como condición de contorno.

Sin embargo, las proyecciones de los RCMs exhiben una gran variabilidad, incluso los resultados obtenidos son divergentes o contradictorios en algunos casos, lo que incrementa la incertidumbre de las predicciones. Además, los RCMs exhiben niveles de "habilidad" desiguales en la simulación de los procesos, sobre diferentes regiones y considerando variables hidrometeorológicas distintas, haciendo difícil identificar los modelos más confiables (Giraldo Osorio, 2011). Por ello, se justifica la construcción de conjuntos de RCMs que consideren la variabilidad simulada por todos los modelos climáticos. Las proyecciones climáticas y la estimación de las incertidumbres asociadas están mejor basadas en la combinación de la información suministrada utilizando una aproximación ensemble desde las diferentes simulaciones de RCMs (Giorgi y Mearns, 2002; Paeth et al., 2011).

A diferencia de la mayoría de regiones de la Tierra, para Europa existen varios proyectos coordinados de conjuntos de simulaciones climáticas regionales de alta resolución espacial. En la Figura 2.1 se puede observar el dominio espacial de los distintos experimentos existentes en Europa.

El experimento PRUDENCE (Christensen et al., 2007) fue un proyecto que buscaba reducir al mínimo las incertidumbres en la evaluación de los impactos del cambio climático en la agricultura en las zonas del Mediterráneo. Desarrolló escenarios climáticos que proporcionaban una resolución de hasta 25 kilómetros y se basaban en la generación de escenarios de emisiones del SRES.

Otra iniciativa de relevancia fue el Proyecto Europeo ENSEMBLES (Christensen et al., 2009), que siguió distintas líneas de investigación (RT0, RT1, RT2A, RT2B, RT3, RT4, RT5, RT6, RT7 y RT8). La línea RT2B desarrolló la producción de escenarios Climáticos Regionales para las evaluaciones de impacto, mientras que la línea RT3 se orientó a la formulación de alta resolución de RCMs para Europa. La diferencia entre ambas líneas consistió en que los modelos de RT3 estaban forzados en el periodo histórico con datos reales del reanálisis ERA-40 del Centro Europeo de Predicción Meteorológica a Medio Plazo (ECMWF), sin embargo los modelos de RT2B eran modelados y estaban forzados por diferentes GCMs. 
El experimento RT2B del Proyecto ENSEMBLES (Christensen et al., 2009) ofrece modelos climáticos regionales del sistema terrestre, con una alta resolución espacial de 25 a $50 \mathrm{~km}$ para el periodo 1951-2050, y en algunos casos 1951-2100 para escenarios de emisión de GEIs del SRES. En esta Tesis se emplearon dieciséis RCMs correspondientes al experimento RT2B del Proyecto ENSEMBLE, con $25 \mathrm{~km}$ de resolución espacial y simulaciones para el periodo temporal 1951-2050. La selección de los RCMs empleados se basó en la alta resolución espacial y disponibilidad de datos en el periodo temporal seleccionado. Las características de los diferentes RCMs utilizados, junto con las bases de datos observados, se presentarán más adelante.

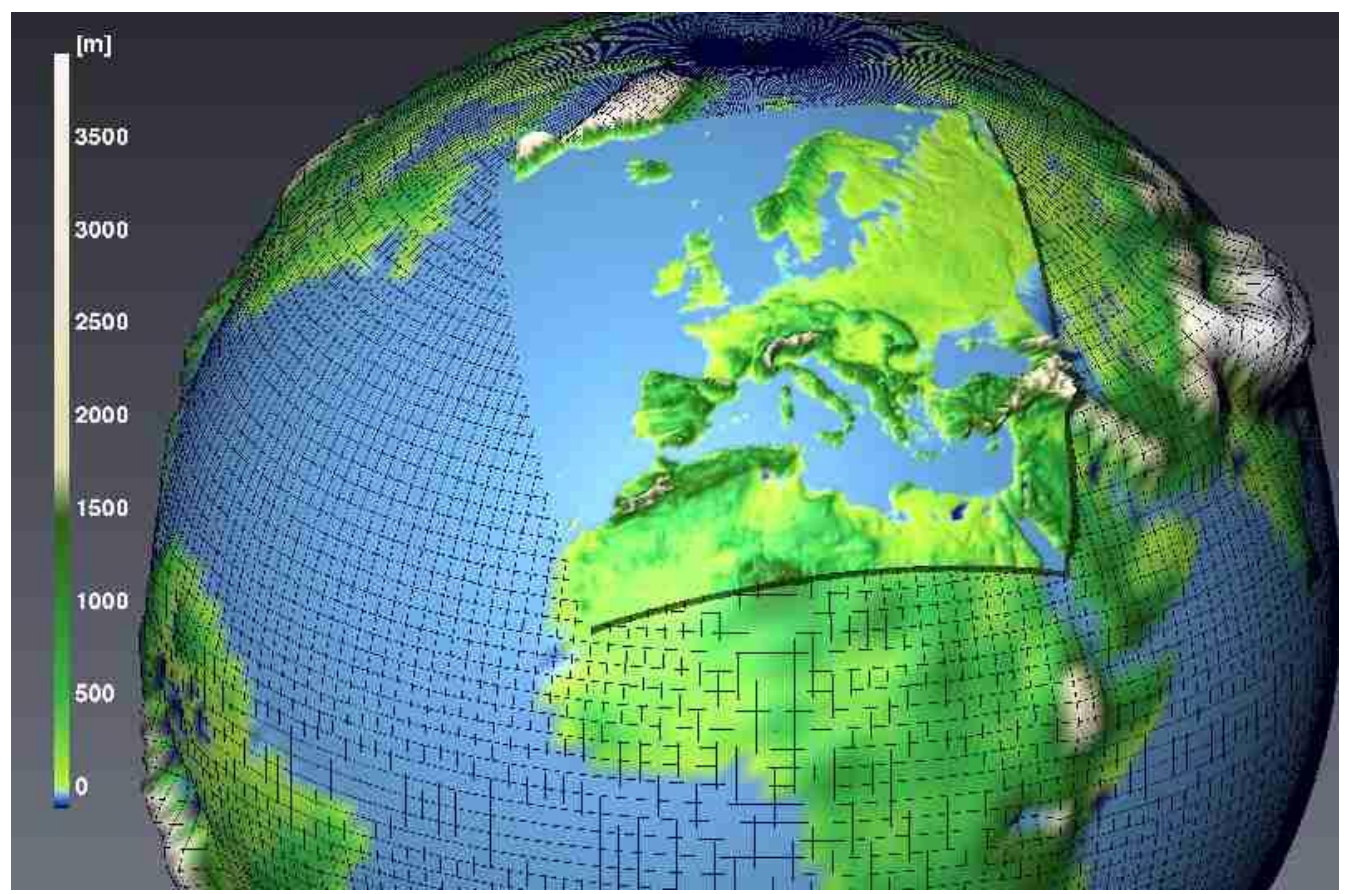

Figura 2.1 Dominio espacial común de los RCMs en los distintos experimentos. (Fuente: http://clone.www.clm-community.eu/index.php?menuid=1)

Recientemente, el experimento CORDEX para el dominio de Europa (EUROCORDEX; Jacob et al., 2014) ha llevado a cabo sus simulaciones de RCMs en varias resoluciones espaciales diferentes. Inicialmente, se ha trabajado con 0.44 grados (EUR44, 50 kilómetros) y 0.11 grados (EUR-11, 12.5 kilómetros), si bien actualmente se disponen de ejecuciones en la resolución 0.22. Las simulaciones EURO-CORDEX para el dominio espacial de Europa, consideran las simulaciones climáticas globales de los experimentos a largo plazo del Proyecto de Intercomparación de Modelos Acoplados fase 5 (CMIP5 por sus siglas en inglés) hasta el año 2100 y los nuevos escenarios de 
emisiones RCPs.

En el caso de España, también existe un conjunto de cuatro RCMs de alta resolución, PROMES, REMO, MM5 y WRF, proporcionados por el proyecto español ESCENA (Jiménez-Guerrero et al., 2013). Los RCMs de ESCENA fueron primero forzados por reanálisis (ERA-Interim) del ECMWF en el periodo observado. El proyecto se centró en el futuro cercano, con la simulación del periodo presente (1950-2000) forzada por el escenario histórico 20C3M y continuada por un período de 50 años (2001-2050) bajo los escenarios de emisión del SRES. Su dominio está centrado sobre la Península Ibérica y abarca todo el territorio español con una resolución horizontal de $25 \mathrm{~km}$.

\subsection{Estudios de impactos del cambio climático en los recursos hídricos: modelos de impactos}

Los recursos hídricos en España constituyen una fuente de preocupación y controversia debido al estrés hídrico histórico y a la afirmación reconocida de que el país está experimentando una disminución en precipitaciones y escorrentías (Houghton et al., 2001). Sin embargo, el impacto del cambio climático puede variar de región a región.

En este sentido, la proyección de las variaciones de las precipitaciones se ha convertido en un objetivo importante en España. Distintos trabajos se encuentran en la materia. A modo de ejemplo mencionar el trabajo de Paredes et al. (2006) que analizó y caracterizó la disminución de alrededor del $50 \%$ de precipitación de marzo durante el periodo 1960-1997 sobre la Península Ibérica. Así como el trabajo de Herrera et al. (2010), que empleó simulaciones de RCMs forzadas por ERA40 y proporcionadas por el Proyecto Europeo ENSEMBLES para evaluar la capacidad de los RCMs de reproducir los regímenes medios y extremos de precipitación sobre España.

Numerosos autores prevén impactos negativos en nuestro país debido a la reducción de las precipitaciones. Según Osca et al. (2013), se vaticina un secado sustancial de aproximadamente el $30 \%$ al final del siglo en comparación con la actualidad, aunque con un patrón no uniforme en el espacio y el tiempo a medida que avanza el siglo. De Luis et al. (2010) identificó una reducción de precipitación de invierno a verano y un aumento en otoño del porcentaje de precipitación. Por otro lado, Argüeso et al. (2012) indicaron que España podría estar expuesta a una disminución sustancial de la precipitación anual que oscila entre el $18 \%$ y el $42 \%$ dependiendo de la simulación, 
con una reducción particularmente severa durante el verano, entre el $32 \%$ y $72 \%$. Un plausible aumento significativo y generalizado en toda la España continental del valor medio de las longitudes de rachas secas máximas anuales entre los años 1990 y 2050, es proyectado por Giraldo y García (2013).

En la región del Mediterráneo, algunos autores han encontrado también cambios significativos en los patrones de precipitación con tendencias decrecientes (Goubanova, 2007; De Luis et al., 2009; Touhami et al., 2015). Por ejemplo, según los resultados de García et al. (2015), se identifica una intensificación de las sequías extremas en algunas cuencas de cabecera de la cuenca del río Segura.

En concordancia con la opinión de Sun et al. (2015), se considera que la evaluación de los impactos del cambio climático en las futuras variaciones del ciclo del agua es urgente y necesaria para la exploración y utilización de los recursos hídricos. Un aspecto importante al evaluar el impacto del cambio climático sobre la disponibilidad de agua es disponer de series temporales mensuales representativas de la situación actual (Gonzalez-Zeas et al., 2012).

En las últimas décadas, muchos estudios han evaluado el impacto potencial del cambio climático en los recursos hídricos y la escorrentía. Los resultados de Arnell (1999) sugieren que la escorrentía media anual aumentará en las latitudes altas, en África ecuatorial, Asia y Asia Sur-Oriental, y disminuirá en latitudes medias y las regiones más subtropicales. Mientras Vörösmarty et al. (2000) demostraron que el aumento de la demanda de agua supera con creces el calentamiento por el efecto invernadero, al definir el estado de los sistemas de agua a nivel mundial para el año 2025. De acuerdo con Labat et al. (2004), en el último siglo se incrementó un 4 \% la escorrentía global debido a un aumento de $1{ }^{\circ} \mathrm{C}$ de la temperatura global. Para Gedney et al. (2006), el aumento de la escorrentía continental es consistente con una supresión de la transpiración de las plantas debido al cierre de los estomas inducido por el $\mathrm{CO}_{2}$. Durante la última mitad del siglo XX, la descarga acumulada de muchos ríos de latitudes medias se redujo en un $60 \%$, mientras que los ríos de latitudes altas experimentaron un aumento de descarga (Milliman et al., 2008).

La mayoría de los estudios que investigan el impacto futuro del cambio climático emplean un modelo hidrológico forzado por un RCM específico o un GCM, o por varios modelos. Hoy en día se encuentran distintos enfoques al momento de aplicar un 
modelo hidrológico para estudios de impactos. Cabe citar el trabajo de Kilsby et al. (2007) que utilizan un único RCM (HadRM3H) como entrada a un modelo hidrológico distribuido para evaluar impactos a escala mensual, en dos cuencas de España (cuenca del río Tajo y cuenca del río Guadiana). Estos autores corrigen el sesgo, que estiman presenta el modelo climático, a escala mensual. El modelo hidrológico considerado corresponde al modelo conceptual precipitación-aportación UP2, que es una simplificación del modelo UP (Ewen et al., 1999).

Touhami et al. (2015) utilizan el modelo climático HadCM3 (con dos escenarios de emisión A2 y B2) como entrada al modelo hidrológico determinístico HYDROBAL (Bellot y Chirino, 2013) en una región semiárida de Alicante. El modelo simula la dinámica temporal del balance hídrico del suelo con una resolución diaria integrando las condiciones meteorológicas, las características de la vegetación y del suelo, a escala de parcela y cuenca hidrológica.

En el trabajo de Candela et al. (2012) el análisis de los regímenes de flujo se evaluó mediante el modelo hidrológico semidistribuido HEC-HMS (USACE, 1998), un modelo de base física para evaluar lluvia-escorrentía en una cuenca. Mientras que la recarga se estimó con el modelo distribuido VisualBALAN (Samper et al., 1999), que estima las recargas naturales en una cuenca no aforada (Siurana, NE España). Para ello se trabaja con el GCM ECHAM5 para dos escenarios de GEIs (A2 y B1) y dos intervalos de tiempo 2013-2037 y 2038-2062.

El modelo hidro-ecológico RHESSys (Regional Hydro-Ecologic Simulation System; Tague y Band, 2004) ha sido utilizado para simular los caudales en una cuenca de montaña de los Pirineos centrales españoles considerando diferentes escenarios de cambio climático y de uso del suelo (López-Moreno et al., 2014). RHESSys está diseñado para simular el ciclo del agua, del carbono y de los nutrientes sobre terreno complejo, a escalas de análisis pequeñas y medianas.

Milano et al. (2013) emplearon una versión modificada del modelo conceptual GR2M (Makhlouf y Michel, 1994) para simular las descargas en la cuenca del río Ebro, tanto con datos de la Confederación Hidrográfica del Ebro, como con salidas de cuatro GCMs extraídos del IPCC Data Distribution Center (escenario A2). El GR2M es un modelo hidrológico mensual de dos parámetros, desarrollado por el CEMAGREF (Centro de Investigación Agrícola e Ingeniería Ambiental Francia), que requiere como datos de entrada la precipitación mensual y la evapotranspiración potencial. 
El modelo Soil and Water Assessment Tool (SWAT; Engel et al., 1993) se utilizó para evaluar los impactos potenciales del cambio climático en la recarga de agua subterránea en el distrito hidrológico de Galicia Costa, con proyecciones climáticas a partir de dos GCMs y ocho RCMs, y para dos escenarios de cambio climático del SRES (Raposo et $a l .$, 2013). SWAT es un modelo físicamente basado, continuo, y distribuido, que fue desarrollado por el Departamento de Agricultura de los Estados Unidos (USDA), y se basa en un balance hídrico para determinar la entrada, la salida y el almacenamiento de agua en la cuenca.

En el último estudio publicado de impactos del cambio climático en los recursos hídricos realizado por el Centro de Estudios y Experimentación de Obras Públicas (CEDEX, 2012) se empleó el modelo SIMPA (Simulación Precipitación-Aportación, Estrela y Quintas, 1996; Álvarez et al., 2005), con escenarios climáticos regionalizados (resultados de GCMs mejorados con técnicas de regionalización) elaborados por la Agencia Estatal de Meteorología para escenarios de emisión A2 y B2 del IPCC SRES. SIMPA es un modelo distribuido a escala mensual ampliamente utilizado en España. Si bien, las proyecciones hidrológicas publicadas oficialmente hasta el momento en España con este modelo, no han hecho uso del estado del arte en RCMs (como los escenarios provistos por el Proyecto Europeo ENSEMBLES o EURO-CORDEX).

Al tratar la problemática de los modelos de impactos, se debe resaltar una tendencia muy válida basada en el uso de los Modelos de Superficie Terrestre (LSMs por sus siglas en inglés), que describen los intercambios entre el suelo, la planta y la atmósfera de acuerdo con los procesos físicos y fisiológicos que ocurren en cada compartimiento, con un paso de tiempo generalmente fino (menos de una hora). Los LSMs pueden ser acoplados a un GCM o forzados por datos climáticos. Pero el uso de LSMs en grandes áreas es limitado debido a la capacidad para proporcionar las variables de entrada necesarias y los parámetros relativos al suelo, planta o atmósfera. Tanguy (2012) empleó el LSM JULES (Best et al., 2011; Clark et al., 2011) para calcular las estimaciones del flujo de calor latente (o evapotranspiración) en la cuenca del río Segura. El modelo JULES reconoce nueve tipos de superficie: árboles latifoliados, árboles de coníferas, hierba C3 (templada), hierba C4 (tropical), arbustos, aguas continentales, hielo, suelo urbano y suelo desnudo.

Loaiza y Pauwels (2008) emplearon el modelo TOPMODEL que forma parte del LSM TOPLATS (Famiglietti y Wood, 1994), utilizando los valores de humedad observados 
del suelo en una cuenca montañosa del Mediterráneo, para mejorar su calibración. TOPLATS es un modelo de base física, distribuido espacialmente, que por cada píxel dentro de la cuenca resuelve la ecuación de balance de energía de la superficie a través de una iteración para la temperatura superficial del suelo.

El LSM ORCHIDEE fue empleado por Verant et al. (2004) con el fin de analizar los impactos del cambio de resolución sobre el balance hídrico simulado, forzado con el RCM PROMES (resolución espacial 20 km) sobre la Península Ibérica. Este modelo es el resultado del acoplamiento del modelo SECHIBA (Ducoudré et al., 1993), que calcula los procesos físicos en la interfase suelo, vegetación y atmósfera y los flujos de agua en el suelo, el modelo de ciclo de carbono (STOMATE; Viovy, 1996), que simula los procesos bioquímicos en la superficie, y el modelo Lund-Potsdam-Jena (LPJ), que representa la evolución dinámica de la vegetación y el presupuesto de carbono (Sitch et al., 2000). Los dos últimos componentes de ORCHIDEE no se utilizaron en este estudio.

Como conclusión, se destaca que, si bien las distintas aproximaciones al uso de modelos hidrológicos en estudios de impactos son muy variadas (modelos conceptuales o basados físicamente, modelos a escala diaria o a escala mensual, distribuidos o discretos), en la presente Tesis se optará por el forzamiento de un modelo hidrológico que permita reducir las incertidumbres asociadas y obtener así proyecciones hidrológicas más robustas. 


\section{Caracterización de la zona de estudio: España Peninsular y cuenca del río Segura}

Como se ha comentado previamente, se han considerado dos dominios espaciales diferentes, seleccionados de acuerdo a los objetivos planteados en la Tesis.

Se ha trabajado con la España Peninsular a la hora de identificar, proponer y evaluar la confiabilidad de las dos metodologías que se proponen para la construcción de los ensembles de RCMs de variables meteorológicas a escala mensual (objetivos 1 y 2), así como para identificar de forma justificada la metodología más robusta (objetivo 3).

La mejora de las proyecciones hidrológicas (se focaliza en escorrentía), considerando los ensembles de RCMs identificados previamente como forzamiento del modelo hidrológico, se ha centrado en la cuenca del Segura (cuenca de la Fuensanta).

España se encuentra en el Suroeste de Europa, presenta una extensión de $492175 \mathrm{~km}^{2}$ y abarca una región con una compleja orografía, influenciada por ambos climas Atlántico y Mediterráneo. Estos factores producen una variabilidad del clima local marcado con un gradiente significativo de precipitación Noreste-Sureste, con valores mayores de $1400 \mathrm{~mm} /$ año en el Oeste de los Pirineos, la costa cantábrica y la región de Galicia, hasta valores menores de $250 \mathrm{~mm} /$ año en el Sureste (Figura 3.1).

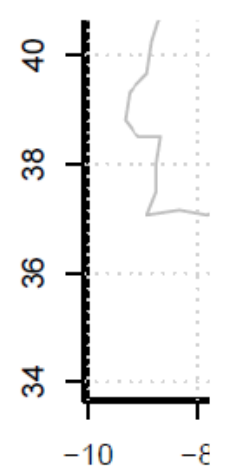

$\mathrm{P}(\mathrm{mm})$

Figura 3.1. Distribución espacial de la precipitación media anual (mm) desde datos observados (Spain02) en la España Peninsular, para el periodo 1961-1990. 
El clima de la mayor parte de España es continental y se caracteriza por un período seco en julio y agosto, que es particularmente intenso en la mitad Sur de la Península Ibérica, y un período de precipitaciones durante los meses de invierno (diciembre, enero y febrero), principalmente en la costa cantábrica (Comunidades Autónomas de Galicia, Asturias, Cantabria y País Vasco). La zona de Levante (regiones autónomas de Murcia y Valencia) presenta un ciclo de lluvias bimodal, con valores altos en los meses de abril a mayo y octubre a noviembre, y los períodos secos en invierno y sobre todo en verano. Las temperaturas en España aumentan de Norte a Sur, y en el interior del país, los valores descienden de Oeste a Este. Enero es el mes con la temperatura media más baja, mientras que agosto es el mes con el promedio más alto. Su topografía tiene como principal característica que la mayor parte de su superficie está configurada como una meseta, con ligera pendiente hacia poniente y una altura media de $600 \mathrm{~m}$ sobre el nivel del mar. El litoral es rocoso y con acantilados al Norte, Nordeste, Noroeste y Sureste, siendo más suave la mayor parte del litoral Este y Sur.

El Sureste de España se caracteriza por un clima Mediterráneo. La cuenca del río Segura, localizada en el Sureste de España (Figura 3.2) cubre un área de $18930 \mathrm{~km}^{2}$, repartida en cuatro Comunidades Autónomas (Región de Murcia, Castilla-La Mancha, Comunidad Valenciana y Andalucía).

La variabilidad de las precipitaciones puede llegar en el Sureste español a una irregularidad extrema. La precipitación media en la cuenca del Segura oscila entre valores casi de $1000 \mathrm{~mm} / \mathrm{año}$ en las secciones de cabecera a $250 \mathrm{~mm} / \mathrm{año}$ en las tierras bajas más secas (Figura 3.2), mientras que las medias de evapotranspiración potencial son del orden de $1400 \mathrm{~mm} / \mathrm{año}$.

La influencia climática dominante es de tipo mediterráneo y es considerada semiárida en la cuenca y árida en la costa. Esta zona es una de las regiones más deficitarias en la cuenca del Mediterráneo. 
Figura 3.2. Localización de la cuenca del río Segura, y mapa de la precipitación media anual (mm) desde datos observados (base de datos Spain02) para el periodo 1961-1990

Al final de la sección de cabecera, el río Segura contribuye con la descarga natural más alta del sistema (391 $\mathrm{hm}^{3} /$ año) (ASSET, 2015). Este es el motivo por el que se ha escogido la cuenca de la Fuensanta como la zona de estudio en el caso de generación y análisis de proyecciones hidrológicas.

En esta subcuenca, el clima es Mediterráneo, suave y templado lo que conlleva a un régimen moderado de las temperaturas y una alternancia climática estacional muy contrastada. El régimen anual de temperaturas presenta un mínimo invernal en los meses de diciembre y enero, siendo más frecuente que los valores más bajos sean en este último. Los máximos anuales corresponden a los meses de julio y agosto, aunque por término general, el primero es algo más caluroso. Las lluvias son más frecuentes en otoño, es decir, entre los meses de octubre y diciembre. En las montañas situadas en el suroeste de la cuenca de estudio, y sometidas a la acción de los vientos húmedos de las borrascas atlánticas del frente polar, los registros pluviométricos alcanzan sus máximos valores, llegando a los $1000 \mathrm{~mm} /$ año como media.

La cuenca de la Fuensanta (Figura 3.3) ocupa una extensión de $1220.6 \mathrm{~km}^{2}$, tiene una 
altitud media de $1263 \mathrm{~m}$ y se extiende por las provincias de Albacete, Jaén y Granada. Los principales afluentes del río Segura en la cuenca corresponden al río Zumeta, que une sus aguas al Segura antes de abandonar Jaén, y al río Tus, que confluye con el Segura en el Embalse de la Fuensanta (CHS, 2015).

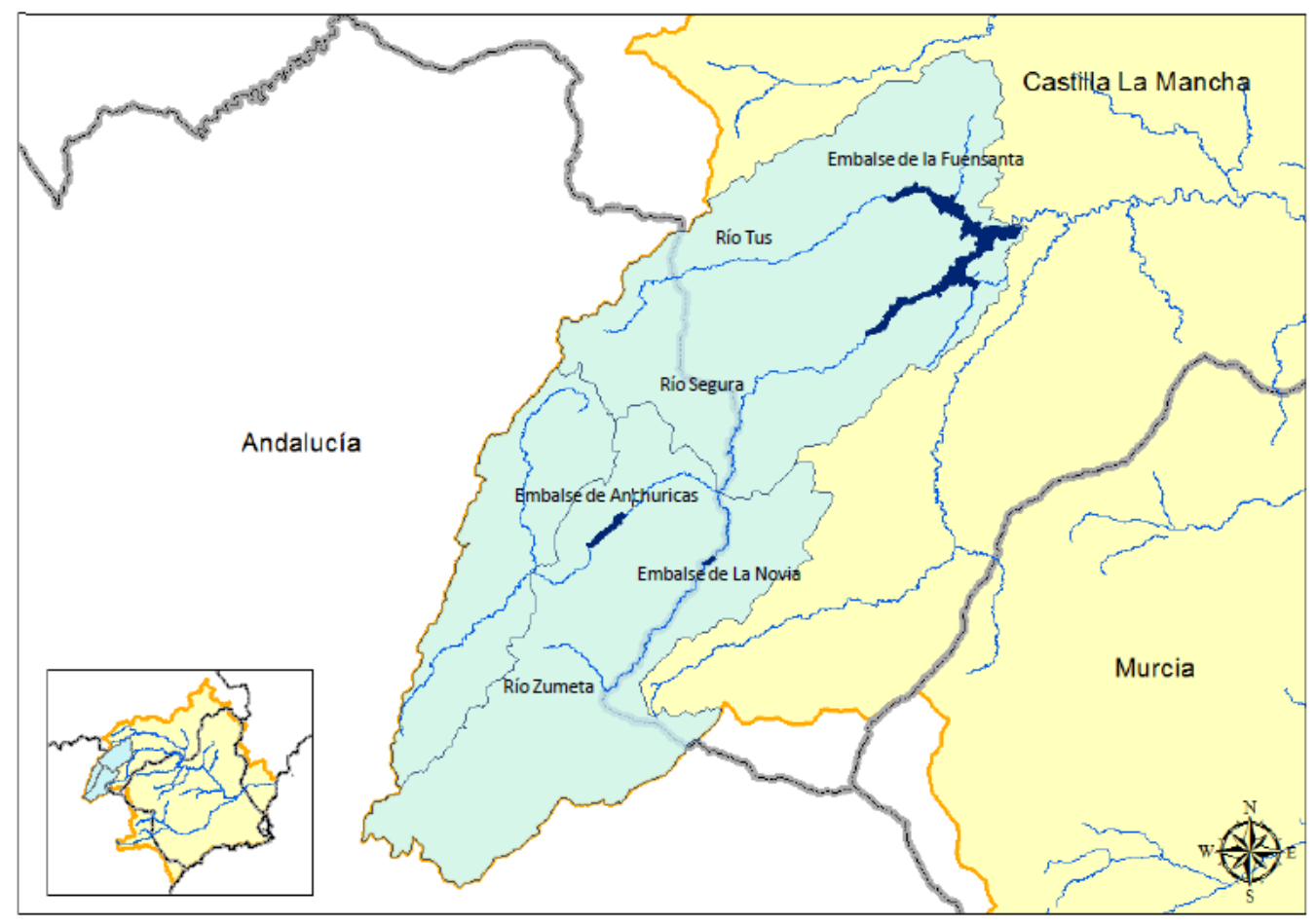

Figura 3.3. Cuenca del río Segura y cuenca de la Fuensanta

La cuenca de la Fuensanta presenta a su vez la presa de La Novia y la presa de Anchuricas, ambas en la provincia de Jaén. La presa de Anchuricas se encuentra en el cauce del río Segura y posee un volumen de agua embalsada de $6 \mathrm{hm}^{3}$. Mientras, la presa de La Novia, también conocida como La Vieja, es una pequeña presa que embalsa las aguas del río Zumeta. Su capacidad es de $0.6 \mathrm{hm}^{3}$. El agua desembalsada se une a la que procede del embalse de Anchuricas para su aprovechamiento hidroeléctrico en la Central Hidroeléctrica de Miller (CHS, 2015).

El embalse de la Fuensanta se ubica en la confluencia de los ríos Segura y Tus, en el denominado estrecho de la Carrizosa. Tanto la presa como la totalidad del embalse por ella creado se encuentran en el término municipal de Yeste, provincia de Albacete. La capacidad de embalse es de $224.7 \mathrm{hm}^{3}$.

La presa y el embalse de la Fuensanta están incluidos en el Lugar de Importancia 
Comunitaria (LIC) de "Sierra de Alcaraz y Segura y cañones del Segura y del Mundo". El LIC en cuestión ocupa una superficie de unos $1750 \mathrm{~km}^{2}$ de la provincia de Albacete e integra un conjunto de alineaciones montañosas intercaladas con angostos valles fluviales que conforman un paisaje de singular belleza.

Por otro lado, han sido numerosas las actuaciones de repoblación forestal de los márgenes del embalse promovidas por la Confederación Hidrográfica del Segura a lo largo de una larga serie de años. Estas se llevaron a cabo en zonas como Paraje de Toril, Arroyo Morote, Paraje Umbría, etc. Evidentemente, se ha producido un cambio importante de los usos del suelo en la zona de estudio.

En cuanto a condicionantes de tipo medioambiental en la explotación de la presa, debe mencionarse que el Plan hidrológico de la cuenca del Segura establece un caudal mínimo para el tramo de cauce del río Segura comprendido entre los embalses de la Fuensanta y del Cenajo de $2.3 \mathrm{hm}^{3} / \mathrm{mes}\left(0.90 \mathrm{~m}^{3} / \mathrm{s}\right)$.

A esto se le suma un marco geológico muy atormentado, con numerosas formaciones acuíferas de tipo kárstico y con notable complejidad estructural y tectónica. 


\section{Procesamiento de información}

\subsection{Información meteorológica}

Se ha trabajado con la base de datos meteorológicos observados denominada Spain02 (período 1950-2007) de la Península Ibérica, que provee datos de precipitaciones, y temperaturas máximas y mínimas diarias con una resolución espacial de $0.2^{\circ}(\sim 20 * 20$ km) (Herrera et al., 2012). Esta base de datos se ha generado mediante una interpolación aplicando el método de Kriging (ordinary krigging) desde más de 2500 pluviómetros con registros consistentes.

La base de datos observacional fue extendida en la cuenca del Segura, para el periodo 2008-2013, mediante la recolección y procesado de datos de las estaciones meteorológicas de la cuenca del Segura provistas por: - el Sistema de Información Agraria de Murcia (SIAM, 2013), - el Instituto Valenciano de Investigaciones Agrarias (IVIA, 2013) y - el Servicio Integral de Asesoramiento al Regante de Castilla la Mancha (SIAR, 2013).

Como se ha mencionado previamente, los datos de precipitación, temperatura máxima y temperatura mínima mensual simulados corresponden a los proporcionados por el experimento RT2B del Proyecto Europeo ENSEMBLES (Christensen et al., 2009). Se destaca que en la presente Tesis se han seleccionado dieciséis RCMs (Tabla 4.1) provistos por ENSEMBLES. Esta selección se basó en la resolución espacial (sólo aquellos con tamaño de celda $25 * 25 \mathrm{~km}$ ), el periodo temporal (con datos en el periodo 1961-2050), y evitar sesgar los ensembles. Se ha trabajado con simulaciones de RCMs anidados en distintos GCMs para el escenario A1B. 
Tabla 4.1. Resumen de RCMs utilizados, junto con la base de datos observados.

\begin{tabular}{cccc}
\hline Name & Institute & GCM & RCM \\
\hline Spain02/v2.1 & UC & Observed data & RCA3 \\
C4IRCA3 & C4I & HadCM3Q16 & Aladin \\
CNRM/RM5.1 & CNRM & ARPEGE_RM & \\
DMI/HIRHAM5 & DMI & ARPEGE & HIRHAM \\
DMI/HIRHAM5 & DMI & ECHAM5-r3 & DMI-HIRHAM5 \\
DMI/HIRHAM5 & DMI & BCM & DMI-HIRHAM5 \\
ETHZ/CLM & ETHZ & HadCM3Q0 & CLM \\
ICTP/REGCM3 & ICTP & ECHAM5-r3 & RegCM \\
KNMI/RACMO2 & KNMI & ECHAM5-r3 & RACMO \\
METNOHIRHAM & METNO & BCM & HIRHAM \\
METNOHIRHAM & METNO & HadCM3Q0 & HIRHAM \\
MPI-M/REMO & MPI & ECHAM5-r3 & REMO \\
OURANOSMRCC4.2.1 & OURANOS & CGCM3 & CRCM \\
SMHIRCA & SMHI & BCM & RCA \\
SMHIRCA & SMHI & ECHAM5-r3 & RCA \\
SMHIRCA & SMHI & HadCM3Q3 & RCA \\
UCLM/PROMES & UCLM & HadCM3Q0 & PROMES \\
\hline
\end{tabular}

Basados en la discretización espacial correspondiente a los RCMs, se establecieron 906 celdas (sites) para la España Peninsular (Figura 4.1).

ल

Figura 4.1. Ubicación de los 906 sitios de análisis al interior del territorio continental español, basados en la malla del Proyecto ENSEMBLES. 
Debe destacarse que tanto los datos de los RCMs como los procedentes de las bases de datos observadas, han sido integrados en el Sistema de Información Geográfica (SIG) GRASS (Geographic Resources Analysis Support System) en trabajos previos del Grupo de I+D Gestión de Recursos Hídricos (Giraldo y García, 2011; Giraldo y García, 2013). El procesamiento de la información meteorológica observada, en cuanto a determinación de distribuciones espacio-temporales de temperaturas máximas, mínimas y medias mensuales se ha realizado con el Toolbox EXTREMES (García Galiano, 2011) bajo el SIG GRASS.

\subsection{Información hidrológica}

Los datos mensuales históricos hidrológicos (aportaciones al Embalse de Fuensanta), para el período 1958-2013, fueron provistos por la Confederación Hidrográfica del Segura.

En esta Tesis se han empleado datos hidrológicos para el periodo 2000-2005 para llevar a cabo la calibración del modelo hidrológico, y de 2006 a 2012 para realizar la validación. Además, se emplearon datos de aportaciones del periodo 1961-1990, y 1971-2000, para contrastar los valores simulados con proyecciones de escorrentía en la cuenca.

La Figura 4.2 siguiente representa el hidrograma de aportaciones al embalse de Fuensanta para uno de los periodos de datos observados de 30 años considerados en la Tesis. Desde la misma, se puede apreciar el salto que existe entre las medias de las aportaciones mensuales de los periodos 1961-1975 y 1975-1990 fundamentado en la disminución de los caudales máximos a partir de 1975. 
Figura 4.2. Hidrograma de aportación ( $\left.\mathrm{hm}^{3} / \mathrm{mes}\right)$ en régimen natural para el Embalse de Fuensanta en el periodo 1961-1990, frente a la media.

En el Plan Hidrológico de la cuenca del Segura (CHS, 2014) se consideraron los recursos en régimen natural de series completas de 50 años (1940/41-1989/90) para cada una de las estaciones. Para el Embalse de la Fuensanta, la CHS define una aportación media de $282 \mathrm{hm}^{3} / a$ ño, con $576 \mathrm{hm}^{3} /$ año de máxima, y $111 \mathrm{hm}^{3} /$ año de mínima.

El Plan de cuenca de 1998 procedió a la revisión de las asignaciones establecidas por la Orden Ministerial que desarrollaba el Decreto del 53, determinando las disponibilidades hídricas reales en el momento de redacción del Plan. Al emplear la serie hidrológica de aportaciones a los embalses de cabecera en régimen natural para el periodo 1940/411989/90 (50 años hidrológicos completos), y no la serie de 10 años empleada en el Decreto de 1953, la regulación en cabecera disminuía de $533 \mathrm{hm}$ /año a $340 \mathrm{hm}^{3} /$ año, 
empleando el mismo método

En conclusión, se recomienda la consideración de series completas de aportaciones de periodos suficientemente largos (al menos 30 años) para que sean lo suficientemente representativos.

\subsection{Cartografía temática-Información geográfica}

En el cálculo de los parámetros del modelo hidrológico se ha utilizado información geográfica, geológica, del suelo (usos y tipos de suelo), y de las unidades hidrogeológicas para la zona de estudio.

El mapa geológico (1994) ha sido obtenido desde el Instituto Geológico y Minero de España (IGME) a escala 1:1000000 (formato shapefile que ha sido importado a formato ráster GRASS). En la Figura 4.3 se presenta el mapa geológico utilizado de la cuenca de la Fuensanta.

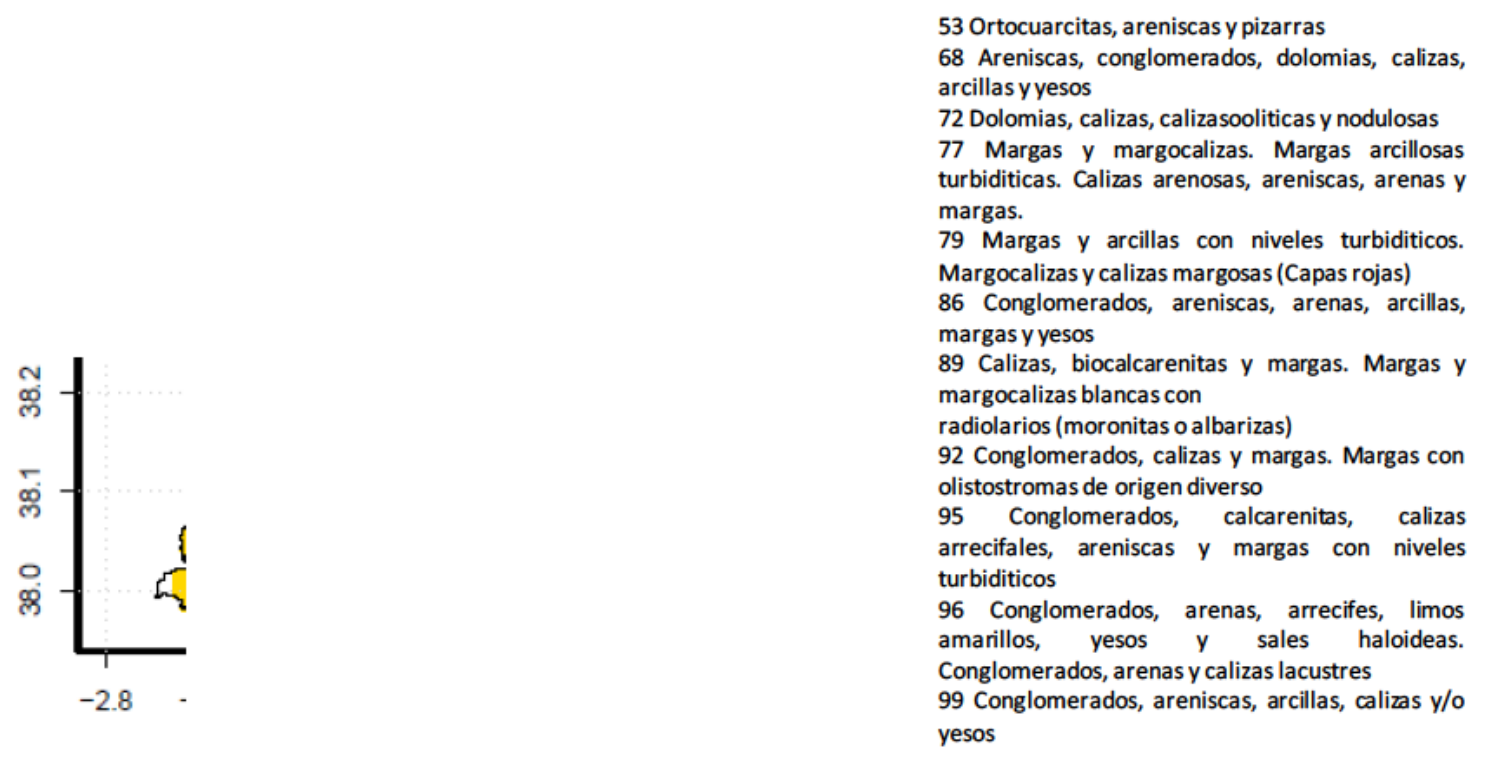

Figura 4.3. Mapa geológico para la cuenca de la Fuensanta (Fuente: IGME, 2013).

En el caso de los usos del suelo, se han considerado los datos provistos por el proyecto CORINE Land Cover 2006 a través del Instituto Geográfico Nacional (IGN, 2010). La base de datos de Ocupación del Suelo (IGN, 2010) presenta una escala de referencia 1:100000 a nivel europeo, basada en una nomenclatura jerárquica de 44 clases, con un tamaño mínimo de polígonos de 25 ha. En la Figura 4.4 se presenta el mapa de usos de suelo considerado para la cuenca de la Fuensanta. 


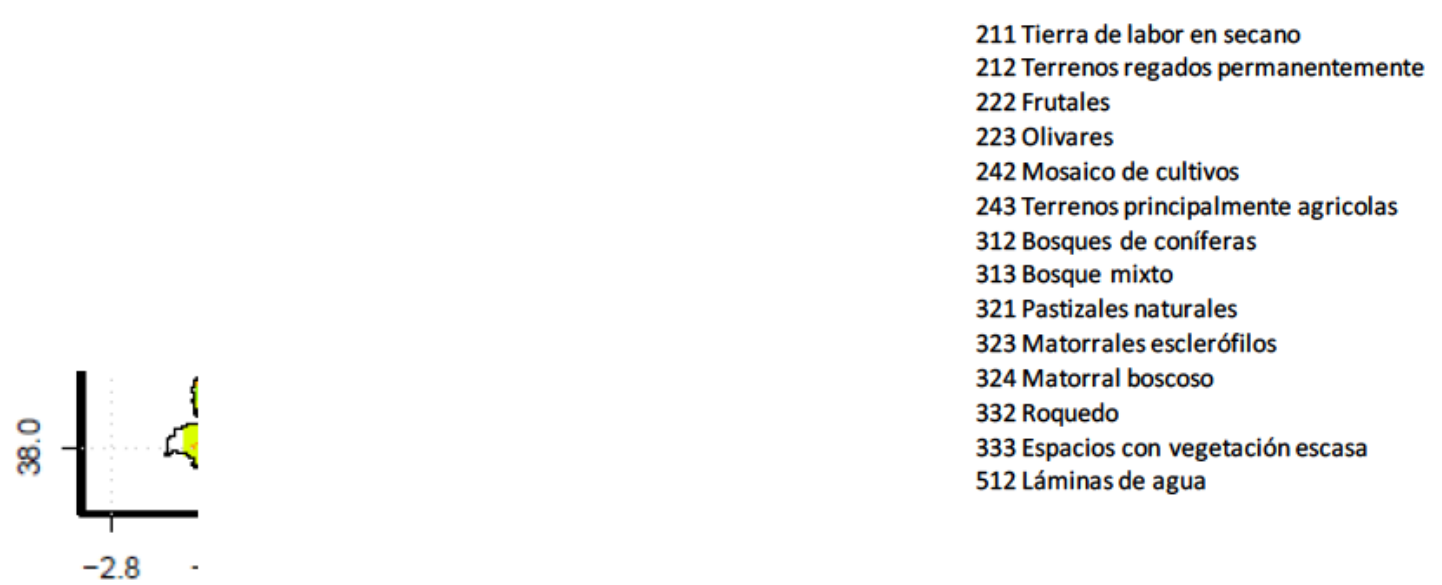

Figura 4.4. Mapa de usos del suelo para la cuenca de la Fuensanta (Fuente: IGN, 2010)

Por último, el mapa de las unidades hidrogeológicas y acuíferos ha sido provisto por la Confederación Hidrográfica del Segura, a escala 1:250000 (formato shapefile importado al SIG GRASS en formato ráster). En la Figura 4.5 se observa el mapa de las unidades hidrogeológicas considerado para la cuenca de la Fuensanta.

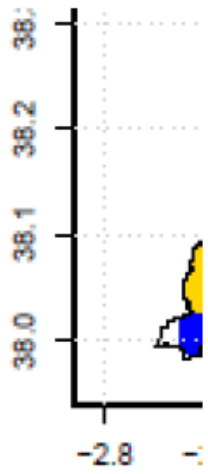

\author{
36 Calar del Mundo \\ 04 Pliegues Jurásicos del \\ Mundo \\ 07 Fuente Segura-Fuensanta \\ 14 Segura-Madera-Tus \\ 39 Castril
}

Figura 4.5. Mapa de unidades hidrogeológicas para la cuenca de la Fuensanta (Fuente:

CHS, 2013) 


\section{Metodologías de combinación de RCMs}

Durante las últimas décadas se ha invertido un gran esfuerzo en mejorar la parametrización de los RCMs, así como su resolución espacial, y acceso a ingentes bases de datos, incluyendo diferentes modelos para evaluar la incertidumbre de las proyecciones de cambio climático. Pero aún hoy persisten incertidumbres asociadas a algunos parámetros físicos, a la resolución espacio-temporal y a la variabilidad interna de los modelos (Giraldo Osorio, 2011).

Varios esfuerzos se han llevado a cabo para generar bases de datos climáticas fiables de alta resolución para evaluar el desempeño de los RCMs y GCMs. Cabe destacarse la base de datos E-OBS sobre Europa (Haylock et al., 2008), Regnie sobre Alemania (Rauthe et al., 2013), o Spain02 sobre España y Baleares (Herrera et al., 2012).

En la literatura se ha argumentado con frecuencia que una combinación (o ensemble por su terminología en inglés) de RCMs, que suele ser la media o la mediana, es un mejor estimador que un resultado obtenido con un modelo único, debido a la gran incertidumbre inherente a los modelos climáticos (Palmer et al., 2005; Tebaldi y Knutti, 2007; Rauscher et al., 2010; Herrera et al., 2010; Sillmann et al., 2013). Paeth et al. (2011) indican que una aproximación ensemble es necesaria para obtener información robusta sobre el cambio climático, y para estimar adecuadamente las incertidumbres asociadas. Diallo et al. (2012) observaron que un conjunto de RCMs forzado por diferentes GCMs, ayuda a compensar los errores sistemáticos tanto de los modelos que se usan como forzamiento, como de los anidados. Según Sunyer et al. (2013), las salidas de precipitación de los RCMs del Proyecto ENSEMBLES (Christensen et al., 2009) no pueden considerarse independientes, por lo que deben usarse conjuntos de RCMs. Si la interdependencia entre los RCMs no se tiene en cuenta, la incertidumbre en las simulaciones de RCMs en proyecciones de precipitación futura puede ser subestimada (Sunyer et al., 2013). Por otra parte, Giorgi y Coppola (2010) indicaron que se requiere un mínimo de cuatro modelos para obtener estimaciones sólidas de cambio de las precipitaciones regionales. Los resultados de Lim et al (2014) demostraron que el método ensemble propuesto mejoró significativamente la proyección de precipitación estacional en comparación con la proyección del GCM. 
Una ponderación de los modelos, basada en datos observados, puede mejorar este problema (Sánchez et al., 2009). Pero, para asignar los factores de ponderación (o pesos) a los diferentes RCMs de un ensemble, es necesario comparar diferentes estadísticos con los calculados desde los datos observados. No obstante, el uso de estadísticos como la media y la desviación estándar no permite la comparación completa de la distribución de los datos.

Por ello, en los últimos años se están aplicando metodologías que permitan identificar ensembles de RCMs consistentes, mediante funciones de densidad de probabilidad (PDFs por sus siglas en inglés) o funciones de distribución acumulada empíricas (CDFs por sus siglas en inglés), para así aumentar la confiabilidad de las proyecciones hidrológicas y climáticas. Distintos autores (Tebaldi et al. 2004; Buser et al., 2009; Boberg et al., 2010; Xu et al., 2010; Giraldo y García, 2013; Domínguez et al., 2013) han abordado la estimación de PDFs de variables hidrometeorológicas en base a proyecciones climáticas y datos históricos.

Focalizando en España, diferentes estudios se han llevado a cabo utilizando ensembles de RCMs para identificar y evaluar períodos de sequías, detección de cambio climático y eventos de precipitación extrema (Giraldo y García, 2013; Domínguez et al., 2013; López-Franca et al., 2015). En el caso de ensembles de temperaturas, Domínguez et al. (2013) analizaron la capacidad de un ensembles medio de cinco RCMs del proyecto ESCENA, para representar las temperaturas extremas de toda España, aunque este ensembles no presentó mejoras, comparadas con los resultados de los modelos individuales. Merece mencionarse los esfuerzos realizados en algunas regiones españolas, para llevar a cabo evaluaciones de las proyecciones de temperatura con ensembles de RCMs (López-Moreno et al., 2008; González-Aparicio e Hidalgo, 2012; López-Moreno et al., 2014; El Kenawy et al., 2015).

Por otro lado, se han encontrado pocos análisis con ensembles de RCMs de precipitación media en la Península Ibérica. Herrera et al. (2010) utilizaron un ensemble medio de nueve RCMs proporcionados por el Proyecto ENSEMBLES para evaluar su capacidad en reproducir los regímenes de precipitación media anual y extrema en España para el periodo 1960-2000. El uso del ensembles de precipitación permitió mejorar los resultados de los modelos individuales, descartando así los modelos con peor desempeño para un área en particular. 
Ello, por tanto, justifica abordar la estimación de ensembles de PDFs asociadas a variables climáticas como precipitaciones medias, temperaturas máximas, mínimas y medias a distinta escala temporal para toda España.

A nuestro saber y entender, ninguna investigación de análisis de sensibilidad, que combine la influencia de la metodología de construcción de ensembles de RCMs y la métrica en los patrones espaciales de precipitación, se ha desarrollado en España, por lo que constituye un aporte significativo de esta Tesis. El análisis de sensibilidad probabilístico permite evaluar el impacto que los cambios en un determinado parámetro (en este caso la métrica y la metodología de ensembles) tendrán sobre los resultados de los modelos (precipitación simulada por ejemplo).

\subsection{Método REA}

Estudios previos han usado el método REA (Reliability Ensemble Average) para evaluar el desempeño de modelos climáticos (Moise y Hudson, 2008; Domínguez et al., 2010; Giraldo y García, 2011; Sun et al., 2015). Este método ha sido aplicado recientemente en otros campos, como por ejemplo para mejorar la confiabilidad de las predicciones de flujos de nitrógeno a escala de cuenca (Exbrayat et al., 2013); para el cálculo de balances hídricos y su interacción con los usos del suelo (Huisman et al., 2009); y para predecir demandas de riego (Multsch et al., 2015) por ejemplo.

El método REA permite calcular el cambio medio, la confiabilidad general del cambio estimado, la media y el rango de incertidumbre del cambio climático simulado con ensembles de diferentes GCMs atmósfera-océano, así como desde RCMs (Giorgi y Mearns, 2002).

La formulación original del método REA, propuesta por Giorgi y Mearns (2002) considera dos factores para calcular el factor de confiabilidad $\left(R_{i}\right)$ de cada modelo (Ecuación 1). El factor de desempeño $R_{B}$ es una medida del desvío del modelo en base a datos observados y el factor de convergencia $R_{D}$ mide la confiabilidad de cada modelo en base a la distancia al "mejor estimado" de la respuesta del clima futuro, que es construido con las proyecciones climáticas de todos los RCMs considerados.

$$
R_{i}=\left(R_{B, i}\right)^{m} \cdot\left(R_{D, i}\right)^{n}
$$

donde $i=1,2, \ldots N$, siendo $N$ el número de modelos considerados para construir el ensemble. Los parámetros $b$ y $d$ son la ponderación de cada criterio. 
La dificultad en la estimación del factor $R_{D}$ estriba en que la PDF de referencia para el clima futuro no es conocida, por lo que debe ser estimada mediante un proceso iterativo (Giorgi y Mearns, 2002).

Finalmente, la probabilidad asociada con el cambio simulado por el RCM es proporcional a $R_{i}$. El factor de confiabilidad normalizado $P_{m}$ (Ecuación 2) se puede interpretar como la probabilidad asociada a cada RCM y se define como (Giorgi y Mearns, 2003):

$$
P m_{i}=\frac{R_{i}}{\sum_{j=1}^{N} R_{j}}
$$

donde $i=1,2, \ldots N$, siendo $N$ el número de modelos considerados para construir el ensemble.

\subsection{Nuevas formulaciones en la estimación de confiabilidad de los RCMs}

El método propuesto para el cálculo del ensemble PDF se presenta esquemáticamente en la Figura 5.1. Sintéticamente, siguiendo el diagrama de flujo (Figura 5.1), en primer lugar se leen las series temporales de las variables observadas, así como simuladas por los RCMs. A continuación, se estiman las PDFs desde las series temporales para el periodo de control (1961-1990 en este caso). Se aplica el resultado del análisis sesgo como criterio de rendimiento del modelo $\left(R_{i}\right)$. Empleando los valores de $R_{i}$ estimados para cada RCM, se obtiene el factor de confiabilidad normalizado (Pm) que se emplea como el factor de ponderación para construir el ensemble PDF. 


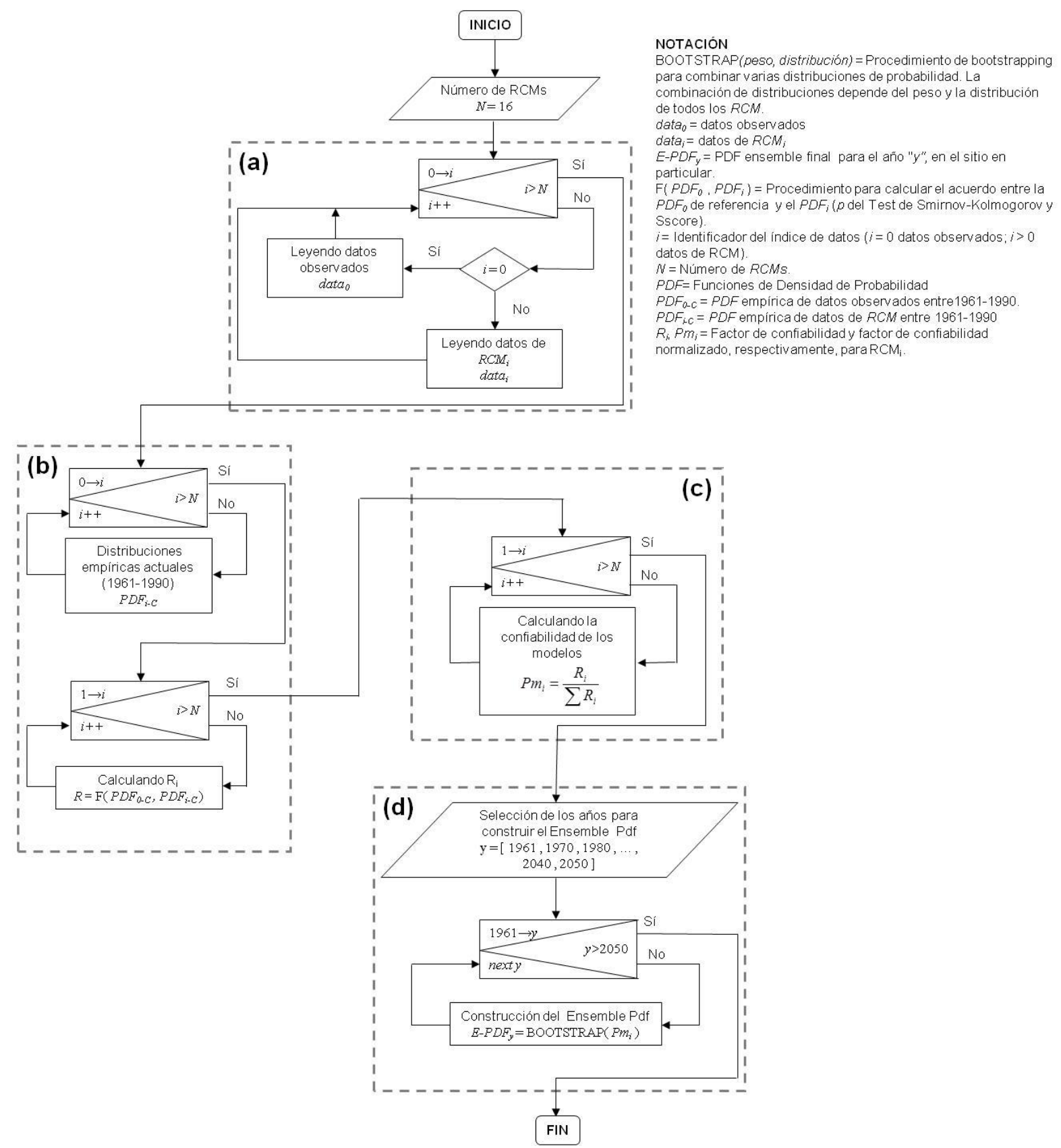

Figura 5.1. Diagrama de flujo de la metodología en cada sitio para la construcción del ensemble PDF.

En esta Tesis, dos nuevos métodos de cálculo del factor de confiabilidad $R_{i}$ de la metodología REA, son propuestos para eliminar algunas limitaciones del método original. Las nuevas formulaciones abandonan el uso del criterio de convergencia del método original, por lo tanto dejan todo el peso al factor de desempeño. Al igual que opinan $\mathrm{Xu}$ et al. (2010), se eliminan así las incertidumbres que genera el desconocimiento de la PDF de referencia para el clima futuro. 
El peso que se asocia a cada RCM en el ensemble implica que se asume que un modelo es más idóneo para simular la PDF observada de una variable que el resto, por lo que se tendrá una mayor confianza en las proyecciones futuras de este modelo (Perkins et al., 2007; Sánchez et al., 2009).

La metodología propuesta se basa en dos aproximaciones para el análisis del sesgo, que es evaluado desde datos a escala anual y estacional en un caso; y a escala mensual en el otro, en busca de la mejor bondad del ajuste entre CDFs de RCMs y datos observados. En concreto, los dos nuevos métodos de cálculo de $R_{i}$ con distinto nivel de información que fueron considerados son:

- Método $1 . R_{i}$ se estima en base a CDFs estacionales y anuales.

$$
R_{i}=\left(R_{\text {Invierno }} R_{\text {Primavera }} R_{\text {Verano }} R_{\text {Otoño }} R_{\text {Anual }}\right)^{1 / 5}
$$

- Método 2. $R_{i}$ se estima en base a CDFs mensuales.

$$
R_{i}=\left(R_{E n e} R_{F e b} R_{M a r} R_{A b r} R_{M a y} R_{J u n} R_{J u l} R_{\text {Ago }} R_{\text {Sep }} R_{\text {Oct }} R_{\text {Nov }} R_{D i c}\right)^{1 / 12}
$$

donde $i=1,2, \ldots N$, siendo $N$ el número de modelos considerados para construir el ensemble.

Las Ecuaciones (3) y (4) establecen que el peso del modelo viene dado por la multiplicación de los factores funcionales. Las funciones $R_{\text {Invierno, }} R_{\text {Primavera }}, R_{\text {Verano, }}$ $R_{\text {Otoño }}$ y $R_{\text {Anual }}$ miden la capacidad del modelo para reproducir las variables medias estacionales y la variabilidad media anual del clima actual. Las funciones $R_{E n e}, R_{F e b}$, $R_{M a r}, R A_{b r}, R_{M a y}, R_{J u n}, R_{J u l}, R_{A g o}, R_{S e p}, R_{O c t}, R_{N o v}$ y $R_{D i c}$ miden la capacidad del modelo para reproducir las variables medias de cada mes.

Como se ha comentado previamente, la evaluación del factor $R_{i}$ se basa en CDFs y una medida cuantitativa (o métrica) del grado de ajuste entre las funciones de probabilidad. Las CDFs empíricas fueron construidas tanto desde datos observados como desde los RCMs, en el periodo 1961-1990, para realizar el contraste en cada pixel (o sitio). Las CDFs de los datos observados se consideran las de referencia para este periodo. Se trata de una evaluación basada en las habilidades de los RCMs para la simulación del periodo de control (1961-1990), a escala mensual.

La fórmula de Weibull (Makkonen, 2006) para posiciones de graficación fue utilizada para calcular los cuantiles de las CDFs. Como se ha comentado, dos medidas 
cuantitativas fueron empleadas para evaluar la bondad de ajuste de las CDFs. La primera de ellas es el $p$ del test de bondad de ajuste Smirnov-Kolmogorov para dos muestras (en adelante $p$ del TSSK, Sheskin, 2000; Gibbons y Chakraborti, 2003). Mientras la segunda se refiere a la métrica propuesta por Perkins et al. (2007), que mide el área común bajo dos curvas PDF (en adelante Sscore). Las ecuaciones de ambas métricas se presentan en los Anejos A y B, respectivamente.

Los valores de $R_{i}$ se estimaron en todos los sitios identificados desde la malla definida por los RCMs (906 celdas para España). Estos valores fueron interpolados (utilizando la técnica de kriging), y las distribuciones espaciales de los factores de confiabilidad se obtuvieron para cada RCM. Los ráster Pm se calcularon utilizando los mapas interpolados de $R_{i}$. Los mapas $P m$ permiten construir los ensembles PDF en sitios en los que no se disponía de datos.

Por último, las ensemble PDF se construyeron para el período 1961-2050 en toda España considerando como factor de ponderación el valor de $P m$ calculado para cada modelo. Mayor peso fue dado a RCMs con alto valor del factor de confiabilidad normalizado, utilizando técnicas de bootstrapping (Efron y Tibshirani, 1993; Giraldo y García, 2013). El procedimiento bootstrapping se usa para ensamblar diferentes distribuciones de probabilidad. La distribución ensemble depende del factor de ponderación y de la distribución de probabilidad de cada RCM miembro del ensemble.

Se ha aplicado la metodología propuesta para generar ensembles multimodelo de las variables precipitación, temperatura máxima, mínima y media a escala mensual. A modo de ejemplo, se presenta de forma detallada el análisis de sensibilidad del caso específico de la variable precipitación media a escala mensual

\subsection{Evaluación de sensibilidad del factor de confiabilidad: caso de estudio precipitación}

Distintos autores han estudiado la incertidumbre asociada a la aplicación de técnicas y métricas en la modelización climática, a modo de ejemplo Giraldo y García (2013) estudiaron la incertidumbre asociada a las dos métricas utilizadas en la construcción de ensembles PDF de valores de longitud máxima anual de rachas secas de precipitación. Otros autores, como Xu et al. (2010), emplearon seis diferentes formulaciones variando las ponderaciones del método REA que podrían ser usadas en diferentes contextos.

En la presente Tesis, con intención de evaluar e identificar la metodología más robusta 
para la construcción de ensembles de RCMs, se realizó un ejercicio de sensibilidad del factor de confiabilidad $R_{i}$ a la selección de la métrica y del método de construcción de ensembles.

Se consideraron cuatro combinaciones diferentes que se presentan en la Tabla 5.1, correspondientes a las dos nuevas metodologías de estimación de $R_{i}$ (Método 1 Ecuación 3 y Método 2 Ecuación 4), y las dos métricas seleccionadas ( $p$ del TSSK y Sscore). En la combinación 1.1 se utiliza la Ecuación 3 con la métrica $p$ del TSSK, mientras, la combinación 1.2 considera la Ecuación 3 con la métrica Sscore. La combinación 2.1 corresponde a la Ecuación 4 y la métrica $p$ del TSSK, y finalmente, en la combinación 2.2 se utiliza la Ecuación 4 con la métrica Sscore.

Los resultados obtenidos desde las distintas combinaciones, son presentados $\mathrm{y}$ analizados en el capítulo de análisis de resultados.

Tabla 5.1. Diferentes combinaciones para analizar la sensibilidad del factor de confiabilidad $\left(R_{i}\right)$.

\begin{tabular}{cl}
\hline Combinaciones & Parámetros \\
\hline 1.1 & $R_{i}$ método 1 y métrica $p$ del TSSK \\
1.2 & $R_{i}$ método 1 y métrica Sscore \\
2.1 & $R_{i}$ método 2 y métrica $p$ del TSSK \\
2.2 & $R_{i}$ método 2 y métrica Sscore \\
\hline
\end{tabular}




\section{Modelización hidrológica: Modelo Témez}

El objetivo de la Tesis consiste en no solo obtener proyecciones climáticas confiables, sino también mejorar las proyecciones hidrológicas. Basado en ello, se considera importante seleccionar un modelo hidrológico distribuido que presente el mínimo número de parámetros posibles, pero sin sacrificar la representación de los procesos más importantes que se presentan a escala de cuenca. De este modo, se logra reducir las incertidumbres asociadas, puesto que a las incertidumbres de la modelización climática se deberían adicionar las correspondientes a la parametrización hidrológica.

Uno de los modelos hidrológicos de amplia aplicación en España es el modelo Témez (Témez, 1977). Este modelo ha sido mejorado e incluido en otras herramientas de modelización tales como el Sistema SIMPA (Estrela y Quintas, 1996; Ruiz, 1999; Cabezas et al., 1999; Álvarez et al., 2005). Témez es un modelo hidrológico de simulación continua, conceptual, que simula los flujos medios mensuales en régimen natural en cualquier punto de una red hidrográfica.

El modelo opera realizando balances de humedad entre los distintos procesos que tienen lugar en un sistema hidrológico, desde el instante en que comienza a llover hasta el momento en que se genera escorrentía, y la posterior descarga de los acuíferos a los ríos. La siguiente figura (Figura 6.1) representa un diagrama de flujo esquemático del funcionamiento del modelo.

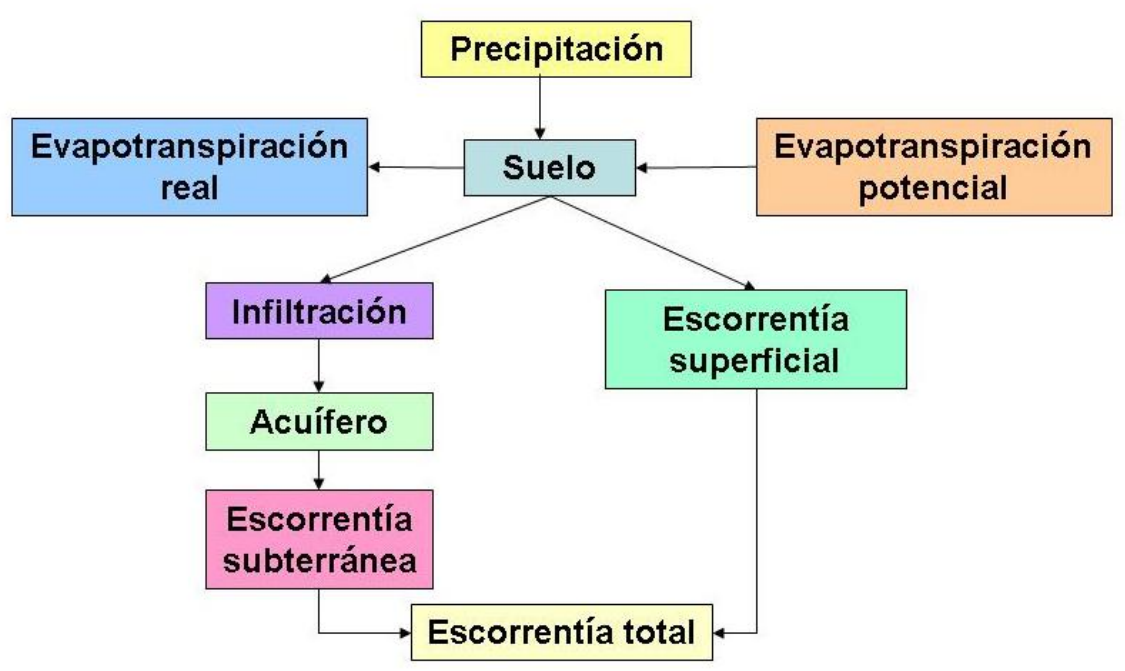

Figura 6.1. Esquema simplificado del modelo Témez. 
El modelo reproduce los procesos esenciales de transporte de agua que tienen lugar en las diferentes fases del ciclo hidrológico, plantea el principio de continuidad y establece, a escala mensual, leyes de reparto y transferencias de agua entre los distintos almacenamientos.

Las entradas al modelo corresponden a datos de precipitación $(\mathrm{P})$ y evapotranspiración potencial (ETP). Otra información que precisa el modelo son datos sobre topología y clasificación de las subcuencas consideradas (Quintas, 1996), y los mapas de unidades hidrogeológicas.

Las ecuaciones básicas del modelo Témez se presentan en el Anejo C. Éstas se han integrado de forma distribuida en el SIG GRASS. Otros autores, han presentado aplicaciones de formulaciones de Témez en entornos SIG como Potenciano y Villaverde (2010).

\subsection{Metodología de calibración y validación}

\section{Estimación inicial de parámetros}

Existen diferentes versiones del modelo Témez con diferente grado de detalles y por tanto distinto número de parámetros, siendo cuatro el número mínimo. En la presente Tesis se ha trabajado con el modelo Témez de cuatro parámetros, ya que como se comentó, se intenta reducir al máximo el número de parámetros a calibrar y en consecuencia las incertidumbres asociadas. Se debe recordar que sencillez es equivalente a robustez, según el Principio de Parsimonia estadístico.

Por tanto, se trabajó con los siguientes parámetros: $H_{m a ́ x}, C, I_{m a ́ x}$ y $\alpha$. La capacidad máxima de almacenamiento de humedad en el suelo $\left(H_{m a ́ x}\right)$ y el coeficiente de excedente (C) regulan el almacenamiento en el suelo, la capacidad máxima de infiltración ( $\left.I_{\text {máx }}\right)$ impacta en la proporción de escorrentía superficial y subterránea, mientras el coeficiente de recesión de los acuíferos $(\alpha)$ regula el drenaje subterráneo. También se precisó la definición de las condiciones iniciales de la simulación, correspondientes a humedad inicial en el suelo $\left(\left(H_{0}\right) \mathrm{mm}\right)$ y almacenamiento inicial en el acuífero $\left(V_{0}=Q_{0} / \mathrm{\alpha} \mathrm{hm}^{3}\right)$.

Tratándose de un modelo distribuido, sus parámetros no son escalares, sino matrices representativas de los distintos atributos territoriales considerados.

Los mapas de capacidad máxima de almacenamiento de humedad en el suelo, capacidad 
máxima de infiltración y coeficientes de agotamiento de los acuíferos se obtuvieron de forma distribuida, para todo el territorio, a partir de características físicas de la cuenca (tales como usos de suelo, litología, etc.) y de los acuíferos.

Como se ha comentado previamente, la cuenca de la Fuensanta es considerada como cuenca de estudio al momento de generar y analizar las proyecciones hidrológicas. Los valores iniciales de los parámetros de ajuste del modelo de Témez en la cuenca de estudio se establecieron de acuerdo a los siguientes criterios:

a) Infiltración máxima $\left(I_{\max }\right)$. Los valores iniciales de calibración del mapa de infiltración máxima se han establecido en función de la litología, según las equivalencias reflejadas en la Tabla 6.1 (Estrela et al., 1999). Para ello se reclasificó bajo el SIG GRASS el mapa geológico Nacional del IGME obtenido previamente para la zona.

Tabla 6.1. Regionalización de la capacidad máxima de infiltración a partir de la litología. (Estrela et al., 1999)

\begin{tabular}{lc}
\hline \multicolumn{1}{c}{ Litología } & Infiltración máxima (mm) \\
\hline Mat. Aluvial de origen indiferenciado & 400 \\
Calizas y dolomías & 1000 \\
Margas & 85 \\
Margas yesíferas & 75 \\
Yesos & 64 \\
Materiales arenosos & 450 \\
Materiales gravo-arenosos & 500 \\
Calcarenitas & 250 \\
Arcosas & 150 \\
Rañas & 95 \\
Granitos & 65 \\
Rocas metamórficas & 20 \\
Gneiss & 55 \\
Pizarras & 40 \\
Rocas volcánicas & 275 \\
\hline
\end{tabular}

Los valores de infiltración máxima que se han estimado tras la calibración, se presentan en la Figura 6.2a siguiente. 


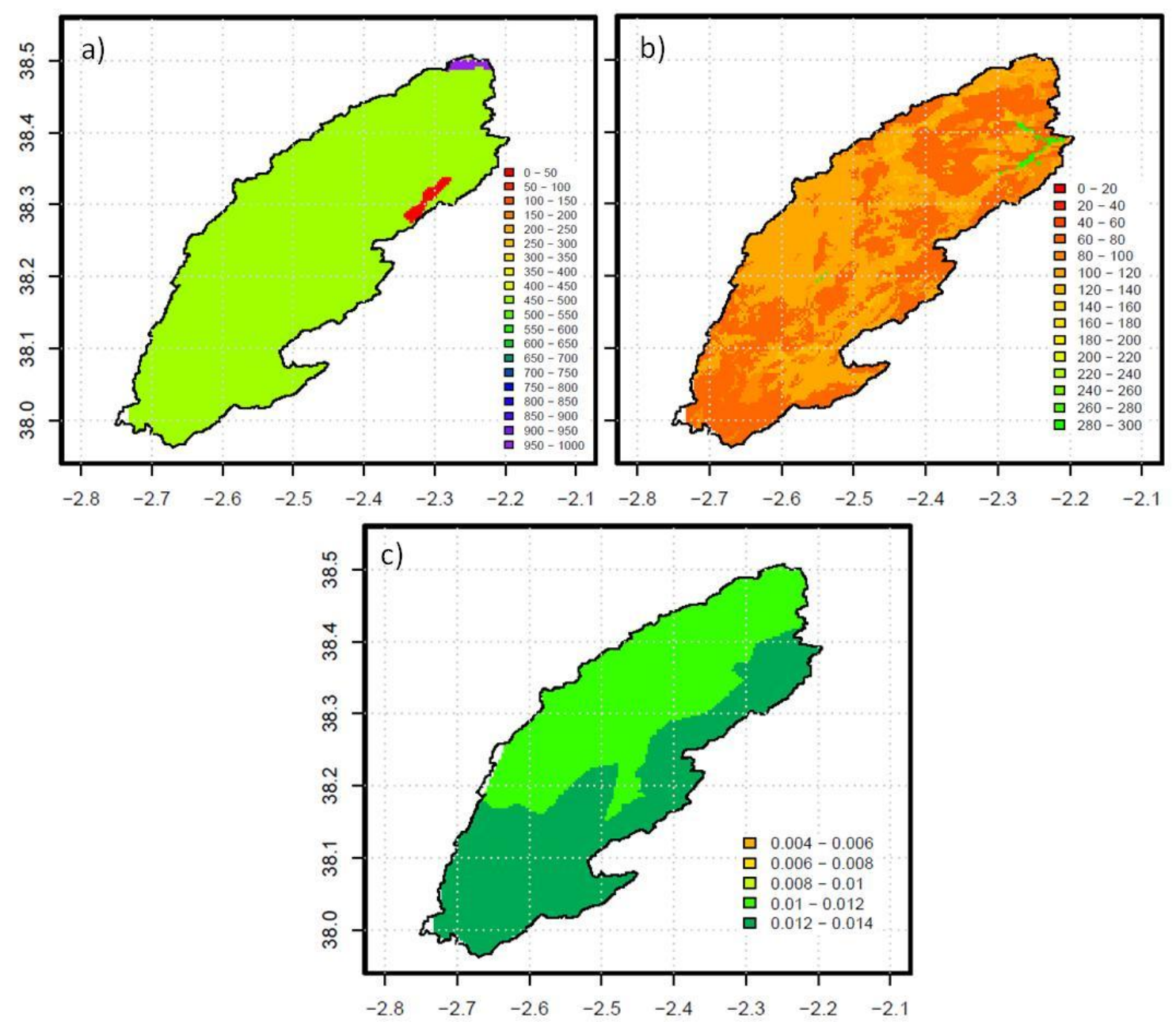

Figura 6.2. Mapa de la cuenca de estudio de: a) Infiltración del suelo (mm); b) Capacidad máxima de humedad del suelo ( $\mathrm{mm})$; y c) Mapa de coeficiente de agotamiento del acuífero $\left(\right.$ mes $\left.^{-1}\right)$.

b) Capacidad máxima de almacenamiento de agua en el suelo $\left(H_{\max }\right)$. Los valores iniciales de este parámetro se establecieron en función de los usos del suelo según las equivalencias reflejadas en la Tabla 6.2 (Estrela et al., 1999). Para ello se reclasificó bajo el SIG GRASS el mapa de usos del suelo obtenido para la zona de estudio desde el proyecto CORINE Land Cover (IGN, 2010). 
Tabla 6.2. Regionalización de la capacidad máxima de humedad del suelo en mm a partir de los usos del suelo (Estrela et al., 1999)

\begin{tabular}{lc}
\hline \multicolumn{1}{c}{ Usos del suelo } & $\begin{array}{c}\text { Capacidad máxima de } \\
\text { humedad del suelo (mm) }\end{array}$ \\
\hline Superficies artificiales & 40 \\
Espacios con poca vegetación & 100 \\
Tierras de labor en secano & 155 \\
Tierras de labor en regadío & 215 \\
Praderas y pastizales naturales & 150 \\
Sistemas agrícolas heterogéneos & 195 \\
Cultivos permanentes & 210 \\
Vegetación arbustiva & 135 \\
Bosque mixto & 220 \\
Bosque de frondosas y coníferas & 230 \\
Zonas húmedas, superficies de agua y & 300 \\
artificiales & \\
\hline
\end{tabular}

El mapa con los valores de capacidad máxima de humedad del suelo que finalmente se ha empleado en el modelo Témez tras la calibración, se presenta en la Figura 6.2b.

c) Coeficiente de agotamiento del acuífero $(\alpha)$. Los valores iniciales de este parámetro se han establecido en función de los empleados por CHG (2010) en la Propuesta de Proyecto de Plan Hidrológico de la Demarcación Hidrográfica del Guadalquivir. Se han obtenido a partir del conocimiento cualitativo del funcionamiento de los acuíferos, de sus propiedades hidrodinámicas (si son conocidas), y fundamentalmente, de las curvas de agotamiento de los acuíferos observadas desde los registros de las estaciones foronómicas. Para la obtención del mapa del coeficiente de recesión del acuífero de la cuenca se reclasificó bajo el SIG GRASS, el mapa de unidades hidrogeológicas provisto por la Confederación Hidrográfica del Segura.

Los valores de $\alpha$ que han sido finalmente utilizados en la modelización hidrológica, se han ajustado en fase de calibración (Figura 6.2c).

d) Coeficiente de excedente $(C)$. Los valores iniciales de este parámetro se definieron de acuerdo a los considerados por Murillo et al. (2011): 0.30 para las cuencas altas con acuíferos carbonatados, suelos poco desarrollados, pendientes elevadas, escasa vegetación e importante red de drenaje; 0.35 para cuencas con pendientes y desarrollo de la red de drenaje, vegetación y suelo de tipo medio; y 
0.50 para las cuencas bajas ligadas a acuíferos detríticos, escasa pendiente, suelos muy desarrollados y numerosos campos de cultivo. Según Témez (1977), toma valores del orden de 0.3 . Finalmente, en el presente trabajo se consideró un valor de 0.2 para toda la cuenca.

e) Valores iniciales. El parámetro de humedad inicial en el suelo $\left(H_{0}\right)$ se ha considerado nulo dado que las simulaciones se realizan para al menos un año hidrológico completo y se inician y finalizan con el estiaje. El almacenamiento inicial en el acuífero $\left(Q_{0}\right)$ también se ha considerado nulo, pues el efecto de los valores iniciales se reduce a medida que transcurre el tiempo, por lo que estos resultan poco significativos.

\section{Calibración}

La calibración del modelo se llevó a cabo para el periodo 2000-2005 (6 años), siendo los usos del suelo considerados los provistos por el proyecto CORINE Land Cover 2006. Se trata de un periodo representativo, debido a que presenta tanto años secos como años húmedos, con fluctuaciones máximas y mínimas de los caudales. Se debe recordar que en los años 2004-2006 se registró una sequía considerable. Por lo tanto este periodo permitirá obtener parámetros efectivos más robustos capaces de representar tanto años húmedos como secos. Se efectuó el ajuste de los parámetros minimizando las diferencias entre las aportaciones observadas (provistas por la CHS) al Embalse de Fuensanta y las simuladas por el modelo.

La comparación de las series de aportaciones observadas y las estimadas por el modelo Témez se realizó mediante el Coeficiente de Eficiencia de Nash-Sutcliffe (Nash y Sutcliffe, 1970), comúnmente usado como la medida de eficiencia en los modelos hidrológicos. Este coeficiente es una herramienta para evaluar la capacidad predictiva de un modelo hidrológico. El Coeficiente de Nash-Sutcliffe contempla una eficiencia entre 0 y 1, como se puede observar en la Tabla 6.3, siendo 1 el ajuste perfecto entre el caudal observado y el simulado. Este coeficiente es calculado utilizando la siguiente ecuación:

$$
N S E=1-\frac{\sum_{t=1}^{T}\left(Q_{0}^{t}-Q_{m}^{t}\right)^{2}}{\sum_{t=1}^{T}\left(Q_{0}^{t}-\bar{Q}_{0}\right)^{2}}
$$


donde $N S E$ es el Coeficiente de Nash-Sutcliffe, $Q_{0}$ es el caudal observado, $Q_{m}$ es el caudal simulado y $\overline{Q_{0}}$ es el promedio del caudal observado.

Tabla 6.3. Criterio para la evaluación de la bondad de ajuste de Nash-Sutcliffe (Molnar, 2011)

\begin{tabular}{cccccc}
\hline Indicador & Excelente & Muy Bueno & Bueno & Satisfactorio & Insuficiente \\
\hline NSE & $>0,8$ & $0,6-0,8$ & $0,4-0,6$ & $0,2-0,4$ & $<0,2$ \\
\hline
\end{tabular}

Se debe destacar que en la fase de calibración, el criterio de selección de la mejor solución de los parámetros propuestos ha sido el NSE más alto.

\section{Validación}

Una limitación de los modelos hidrológicos es su grado de capacidad de predicción, es decir, no se puede asegurar que un modelo obtenga buen rendimiento cuando se emplea en condiciones diferentes a las del periodo de calibración (Gan y Burgues, 1990). Por lo tanto, el proceso de validación demuestra la capacidad de predicción de un modelo, su rendimiento y la confiabilidad alcanzada (Senarath et al., 2000). En este trabajo, la validación se realizó para el periodo 2006-2012 (6 años) evaluando el ajuste brindado por los parámetros. Se debe destacar que para el periodo de validación, no se consideraron cambios en los usos del suelo.

Nuevamente, el grado de ajuste entre aportaciones observadas y simuladas se estimó mediante el Coeficiente de Eficiencia de Nash-Sutcliffe.

\subsection{Estimación de las entradas al modelo}

Los datos meteorológicos de entrada al modelo corresponden a las distribuciones espaciales mensuales de precipitación y ETP. Los mapas de temperatura máxima, mínima y media son requeridos para la estimación de la las distribuciones espaciales de ETP mensual.

Se ha trabajado con series temporales mensuales desde diferentes fuentes, tanto para el periodo histórico como para el futuro:

- Período histórico: Se emplean datos observados, tanto de precipitaciones como de temperaturas, procedentes de la base de datos Spain02 (período 1950-2007) e interpolados desde las distintas estaciones meteorológicas de la cuenca del 
Segura (periodo 2008-2013), como ya se detalló. El periodo que se ha considerado como referencia ha sido 1961-1990.

- Período futuro. Los ensembles de RCMs (precipitaciones y temperaturas) generados desde la aplicación de la novedosa metodología propuesta en esta Tesis, son usados para generar los escenarios futuros (2021-2050).

\section{Estimación de Evapotranspiración Potencial}

El cálculo de las series temporales de evapotranspiración potencial a escala de cuenca, se estimaron mediante la aplicación del método de Hargreaves modificado (Ecuación 7) integrado en el Toolbox EXTREMES bajo el SIG GRASS. La ecuación de Hargreaves (Hargreaves y Samani, 1985; Samani, 2000) (Ecuación 6) es a menudo empleada en situaciones donde los datos son insuficientes para calcular la evapotranspiración mediante el método de Penman o Penman-Monteith (Allen et al., 1998).

$$
E T_{0}=C \cdot R_{e x} \cdot\left(T_{m}+17.78\right) \cdot\left(T_{\max }-T_{\min }\right)^{0,5}
$$

donde $E T_{0}$ es la evapotranspiración ( $\left.\mathrm{mm} \mathrm{dia}^{-1}\right), C$ es un coeficiente con valor $0.0023, T_{m}$ es la temperatura media $\left({ }^{\circ} \mathrm{C}\right)$ calculada como la media de $T_{\max }$ y $T_{\min }$, $T_{\max }$ es la temperatura máxima media mensual $\left({ }^{\circ} \mathrm{C}\right), T_{\min }$ es la temperatura mínima media mensual $\left({ }^{\circ} \mathrm{C}\right)$ y $R_{e x}$ es la radiación extraterrestre diaria media mensual $\left(\mathrm{MJ} \mathrm{m}^{-2} \mathrm{~d}^{-1}\right)$.

La ecuación de Hargreaves fue ajustada por Maestre et al. (2013) para la cuenca del Segura, en cuanto al coeficiente $C$ como sigue:

$$
E T_{0}=0.00285 \cdot R_{e x} \cdot\left(T_{m}+17.78\right) \cdot\left(T_{\max }-T_{\min }\right)^{0,5}
$$

La estimación de las distribuciones espaciales de evapotranspiración potencial se llevó a cabo tanto desde los datos históricos observados (Spain02), así como desde los ensembles de temperaturas máximas, mínimas y medias generados desde los RCMs. Para ello, se construyeron los ensembles multimodelo de las variables termométricas mencionadas a escala mensual aplicando la metodología de generación de ensembles que se demostró más apropiada en el periodo de evaluación. 


\section{Análisis de resultados y discusión}

El capítulo de presentación, análisis de resultados y discusión se estructura en tres apartados.

En el primero de ellos, se presenta el análisis de sensibilidad que se llevó a cabo en función de las dos metodologías de construcción de ensembles de RCMs, y de las dos métricas usadas. Sólo se presentará el análisis de sensibilidad con simulaciones de precipitación, a modo de ejemplo.

En el segundo apartado, se lleva a cabo un análisis de las tendencias a nivel de España, tanto para las precipitaciones, como para la temperatura máxima y mínima.

Mientras que en el tercer apartado, el modelo hidrológico es aplicado para una subcuenca de la cuenca del Segura, para finalmente, generar escenarios hidrológicos futuros a partir de los resultados del modelo.

\subsection{Análisis de sensibilidad probabilístico a la metodología de construcción de ensembles PDF y a la métrica de proyecciones de precipitación}

\subsubsection{Evaluación de metodologías propuestas para generación del ensemble de precipitación}

Como se ha explicado anteriormente (apartado 6.2), se consideraron dos metodologías para la estimación del factor de confiabilidad $R i$.

En este apartado se lleva a cabo una evaluación de la sensibilidad de las metodologías propuestas para la generación de las distribuciones espaciales tanto del $R_{i}$ como del factor de confiabilidad normalizado $P m$, a la selección de la métrica. Se debe destacar que un primer paso en el contraste de ambas metodologías es fijar la métrica.

Las distribuciones espaciales obtenidas del factor $R_{i}$ para cada uno de los RCMs utilizados mediante la aplicación del Método 1 y la métrica $p$ del TSSK (combinación 1.1 desde Tabla 5.1) se presentan en la Figura 7.1. Mientras, la Figura 7.2 presenta las distribuciones espaciales del factor $R_{i}$ computado con el Método 2 y la misma métrica (combinación 2.1 desde Tabla 5.1). 


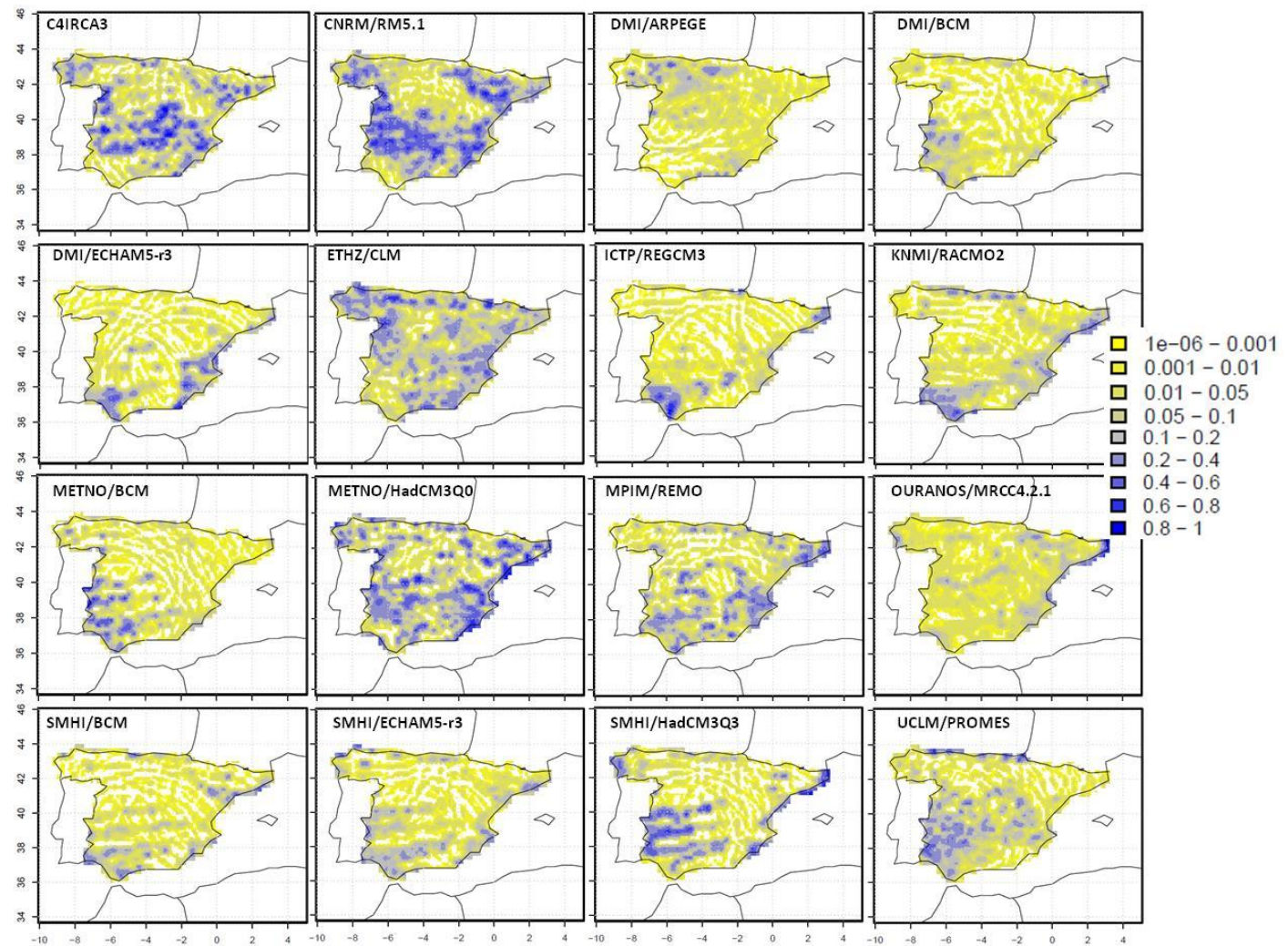

Figura 7.1. Mapas de los valores de $R_{i}$ estimados con la combinación 1.1 (Método 1 y métrica $p$ del TSSK) de cada RCM para la precipitación.

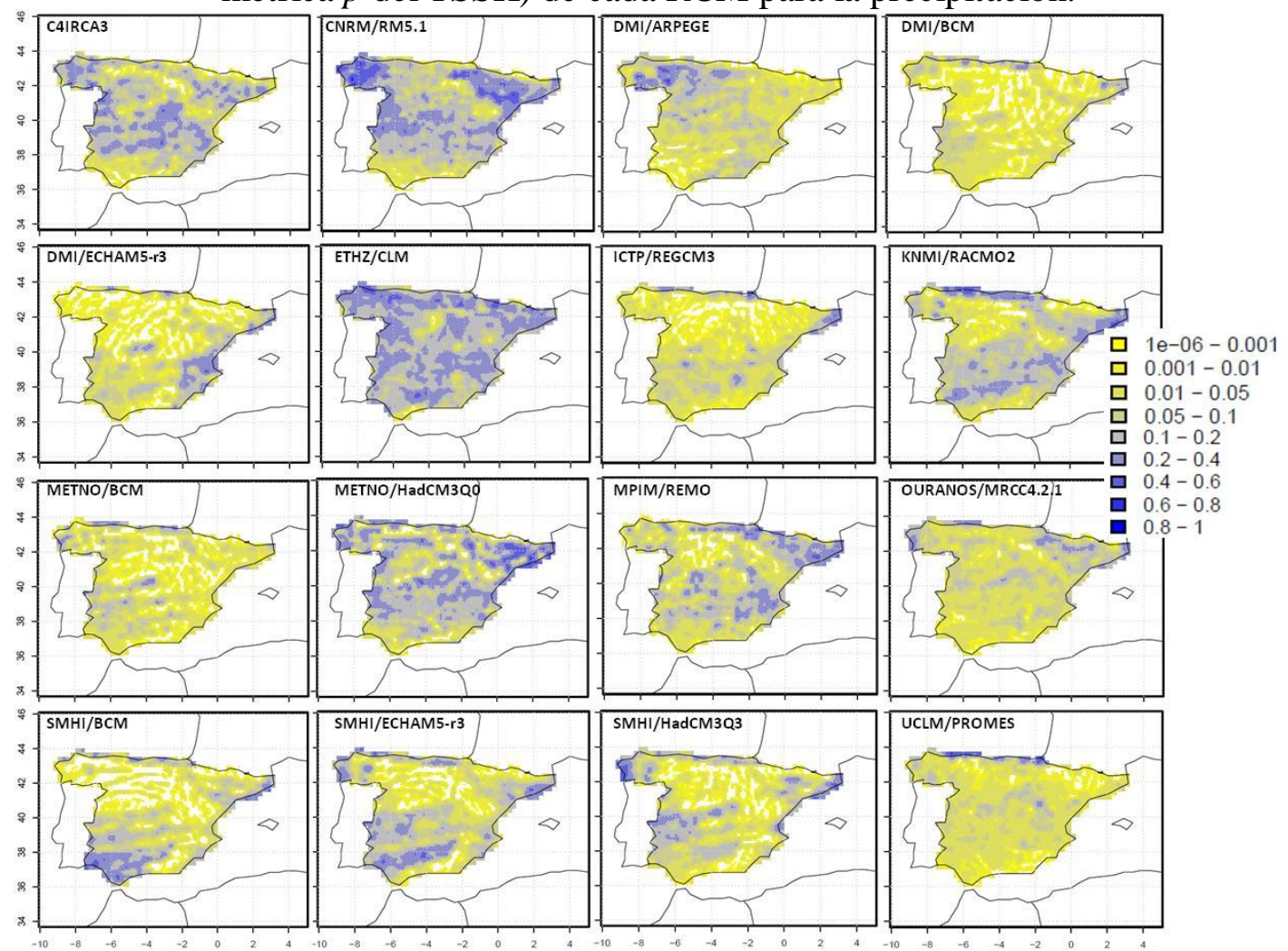

Figura 7.2. Mapas de los valores de $R_{i}$ estimados con la combinación 2.1 (Método 2 y métrica $p$ del TSSK) de cada RCM para la precipitación. 
Se debe destacar que estos mapas presentan de forma espacial las fortalezas y debilidades de cada RCM para representar los datos observados. Los resultados se muestran en azul oscuro cuando se identifica un buen rendimiento, o en amarillo si el rendimiento no es satisfactorio. El hecho de que los valores se repartan en varias escalas hace más perceptible las zonas en las que, en general, el conjunto de modelos presenta un desempeño bueno o deficiente.

Desde ambas Figuras 7.1 y 7.2, se identificaron cuatro RCMs con mejor habilidad para simular $R_{i}$ desde datos observados: C4IRCA3, CNRM/RM5.1, ETHZ/CLM y METNO/HadCM3Q0, pero con diferencias para las distintas formulaciones.

Los valores de $R_{i}$ para la combinación 1.1 (Figura 7.1) demuestran mayor dispersión que los mapas de la combinación 2.1 (Figura 7.2). En este último caso, el rango de valores abarca desde menos de 0.001 hasta 0.6, y excepcionalmente valores superiores. Sin embargo en la Figura 7.1, los valores llegan a ser mayores de 0.8 en los RCMs con mejor rendimiento.

Desde la Figura 7.1, los modelos identificados como de pobre desempeño cuando se trabaja con el Método 1 serían: DMI/ARPEGE, DMI/BCM, SMHI/BCM, SMHI/ECHAM5-r3 y OURANOS/MRCC4.2.1.

Si se emplea el Método 2 (Figura 7.2), los RCMs con resultados menos satisfactorios son: DMI/BCM, ICTP/REGCM3, METNO/BCM y UCLM/PROMES. En conclusión, el Método afecta al rendimiento de los distintos RCMs.

A continuación se evaluaron ambos Métodos propuestos, pero usando la métrica Sscore. Las distribuciones espaciales de factor $R_{i}$ obtenidos con el Método 1 y la métrica Sscore (combinación 1.2 en la Tabla 5.1), se presentan en la Figura 7.3. La Figura 7.4 presenta las distribuciones espaciales del factor $R_{i}$ estimado con el Método 2 y la métrica Sscore (combinación 2.2 en la Tabla 5.1). Esta métrica utiliza prácticamente todos los miembros, dando pesos ligeramente mayores a los mejores modelos. 


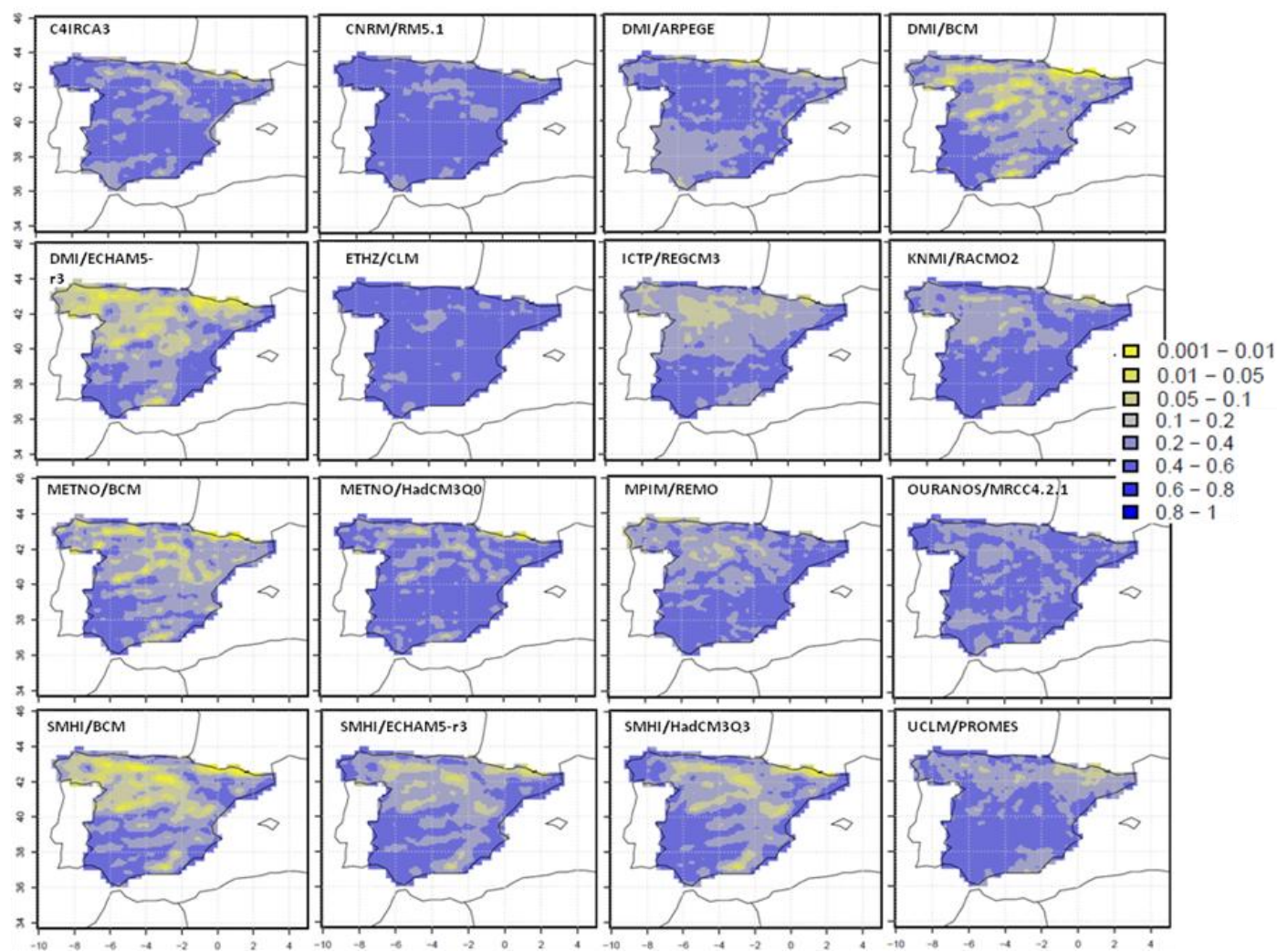

Figura 7.3. Mapas de los valores de $R_{i}$ estimados con la combinación 1.2 (Método 1 y métrica Sscore) de cada RCM para la precipitación.
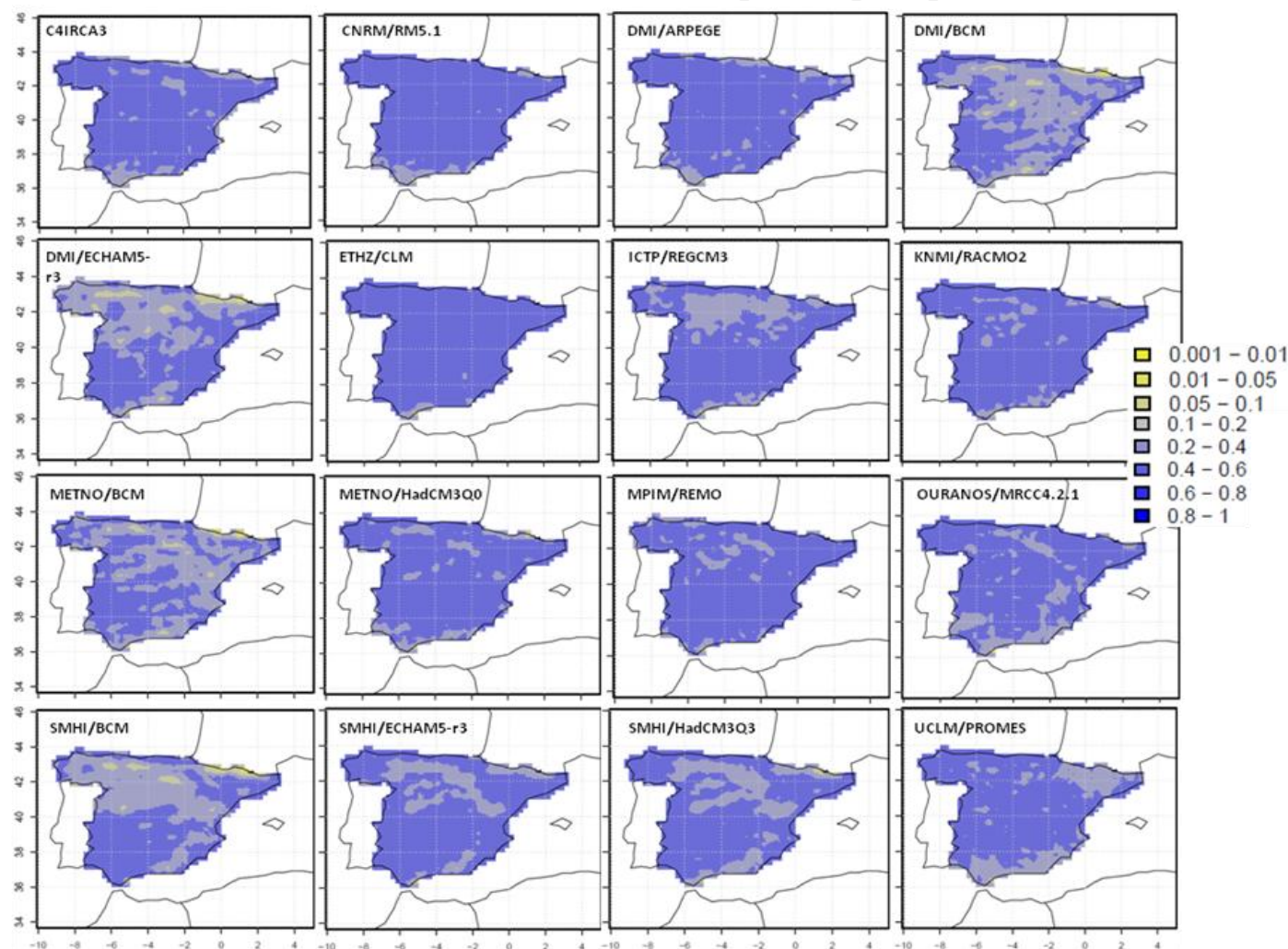

Figura 7.4. Mapas de los valores de $R_{i}$ estimados con la combinación 2.2 (Método 2 y métrica Sscore) de cada RCM para la precipitación. 
A la vista de las dos últimas figuras (Figuras 7.3 y 7.4), se observa que la diferencia en el desempeño de los distintos RCMs para representar los datos observados no es muy apreciable.

Sin embargo, cuando se emplea el Método 1 (combinación 1.2), al igual que ocurre con los mapas de la métrica $p$ del TSSK, en la mayoría de modelos se observa una mayor dispersión de los valores (DMI/BCM, DMI/ECHAM5-r3, METNO/BCM, SMHI/BCM, SMHI/ECHAN5-r) que cuando se emplea el Método 2 (combinación 2.2).

A modo de resumen, la Figura 7.5 presenta las distribuciones espaciales de los valores medios de $R_{i}$ obtenidos mediante la aplicación de los Métodos 1 y 2, considerando ambas métricas. Estos mapas permiten identificar el método más robusto (mayores valores de $R_{i}$ ) y combinación adecuada, para generar los ensembles de precipitación en este caso. Deben tenerse en cuenta las diferentes escalas de los valores obtenidos con las métricas (Sscore y $p$ del TSSK), que se han explicado anteriormente.

a)

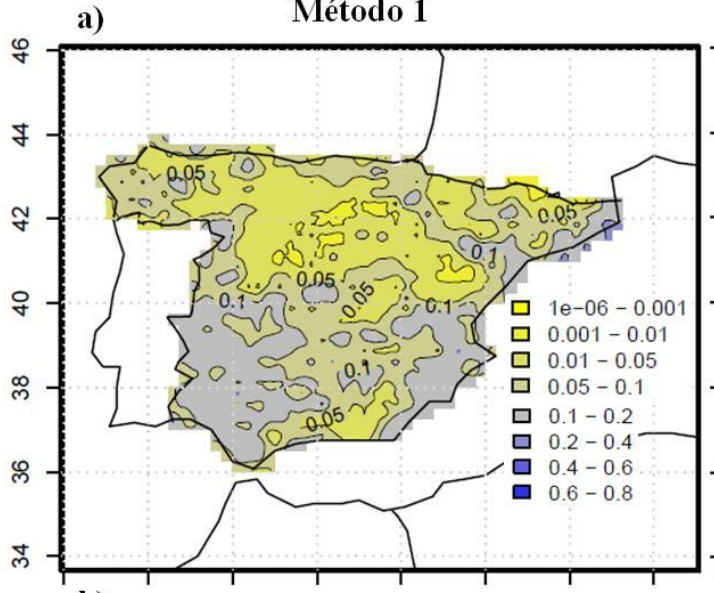

b)

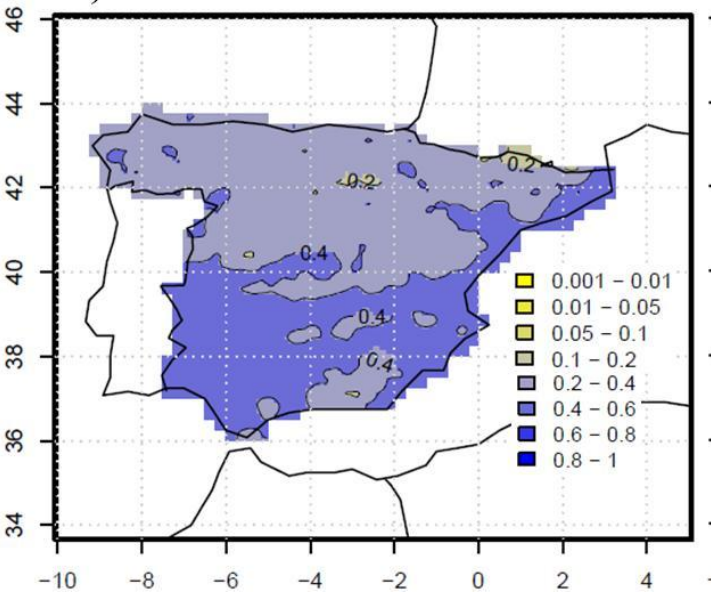

Método 2
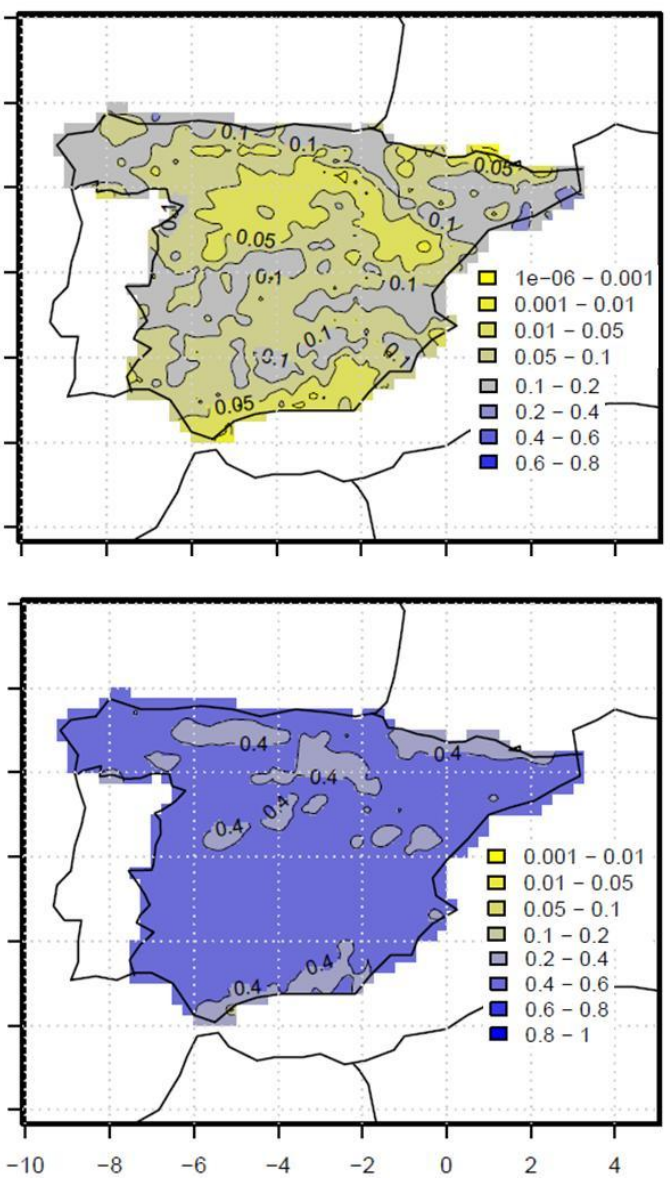

Figura 7.5. Mapas de valores medios del factor de confiabilidad para el Método 1 y 2 , evaluados usando las métricas: a) $p$ del TSSK; y b) Sscore 
Como se puede observar (Figura 7.5a), los mapas de valores medios de $R_{i}$ evaluados con la métrica $p$ del TSSK demuestran una distribución espacial similar para ambos métodos, si bien en el caso del Método 1 se obtienen en general valores más elevados (sobre todo en la mitad Sur) del factor de confiabilidad $R_{i}$.

En el caso de los mapas de $R_{i}$ evaluados con Sscore (Figura 7.5b), cuando se emplea el Método 2, el mapa presenta valores más altos en la mitad Norte de España, lo que indica que el conjunto de modelos presenta un menor sesgo en este área. Sin embargo, esta métrica no permite discernir claramente el desempeño de los modelos, puesto que asigna pesos similares a todos los modelos (no penaliza adecuadamente los pobres rendimientos).

Pero esta evaluación si bien es adecuada, no se considera concluyente para determinar que metodología es la más robusta. Por ello, se procedió al análisis de los mapas del factor de confiabilidad normalizado $\mathrm{Pm}$. Estos mapas representan la contribución final de cada RCM al ensemble PDF.

Las distribuciones espaciales del factor $P m$ de ambos métodos para la métrica $p$ del TSSK, se presentan en la Figura 7.6 y Figura 7.7, respectivamente. Como puede observarse, el $p$ del TSSK es una métrica que penaliza el pobre desempeño de una forma más acusada que la métrica Sscore, ya que $p$ del TSSK sólo tiene en cuenta los mejores modelos para construir el ensemble PDF. 

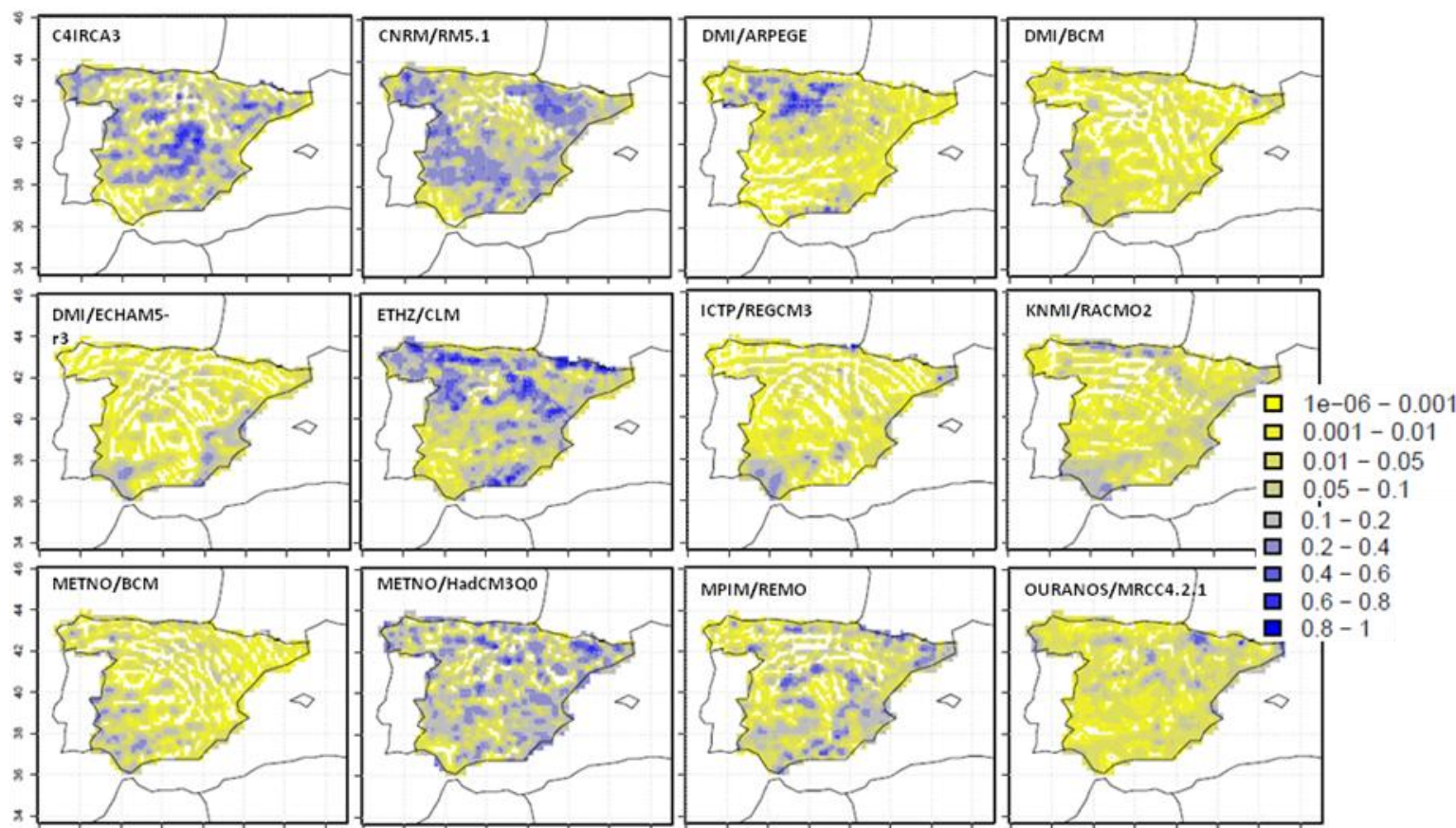

$0.01-0.05$

ㅁ $0,05-0.1$

ㅁ $0.1-0.2$
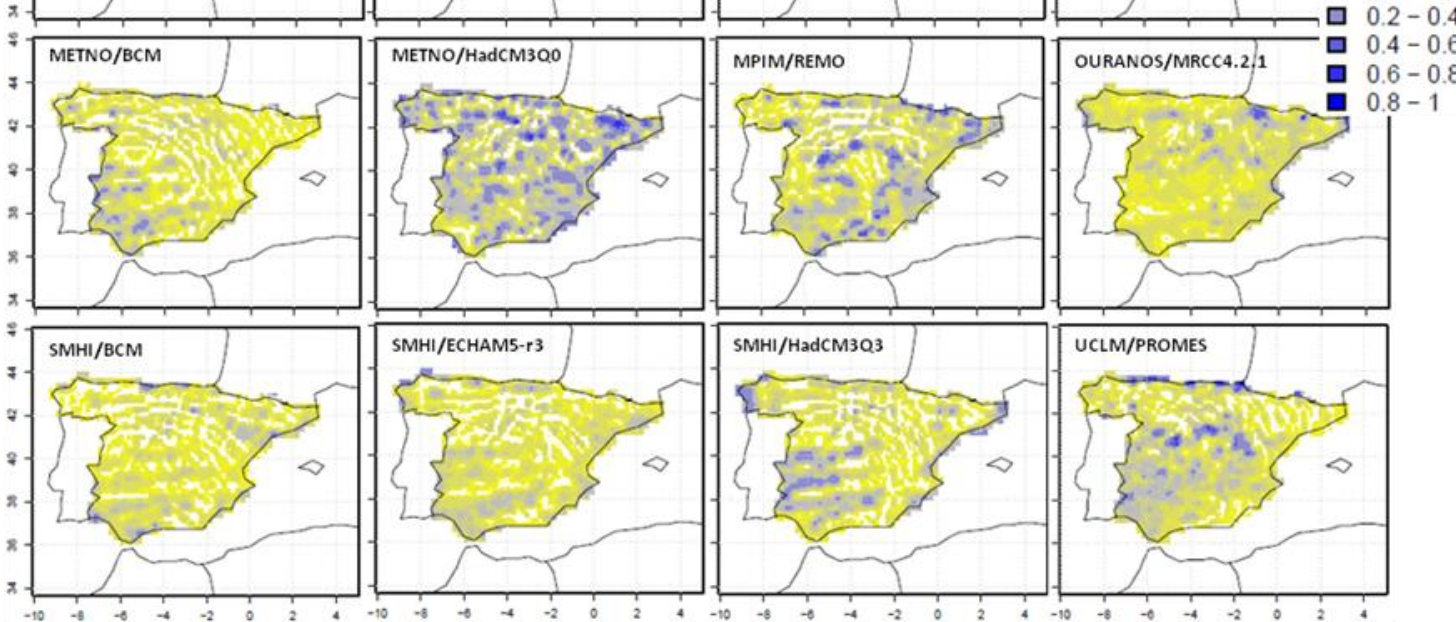

Figura 7.6. Mapas de los valores de Pm estimados con la combinación 1.1 (Método 1 y métrica $p$ del TSSK) de cada RCM para la precipitación.

Si se contrastan ambas figuras (Figura 7.6 y Figura 7.7), se puede observar que cuando se emplea el Método 1 (Figura 7.6), los mejores modelos (C4IRCA3, CNRM/RM5.1, ETHZ/CLM y METNO/HadCM3Q0) muestran un mejor desempeño. Aunque, estos RCMs exhiben distribuciones espaciales con valores no satisfactorios en el Suroeste de Andalucía y Sistema Ibérico. 

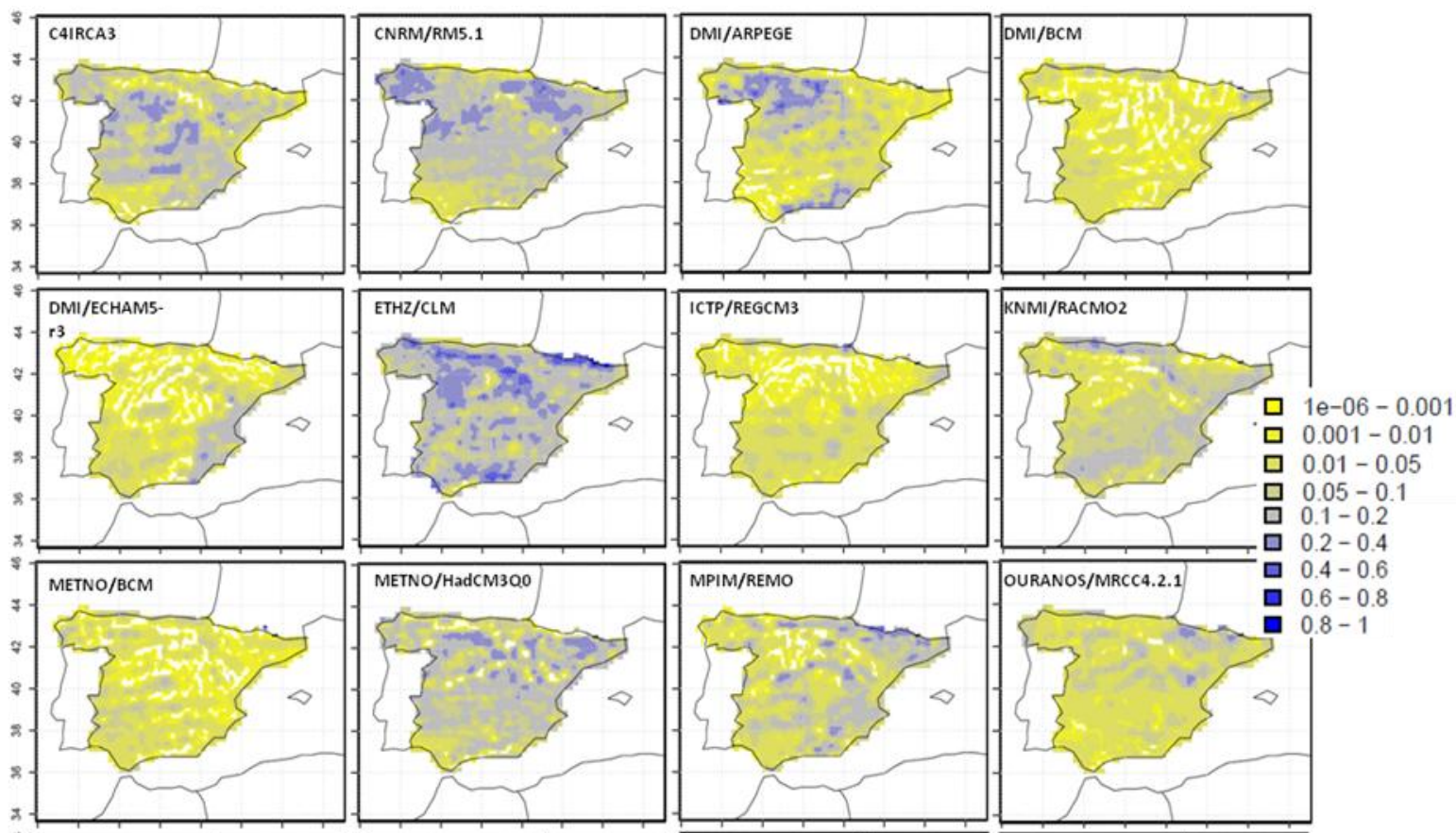

$\square 0.01-0.05$

무 $0.05-0.1$
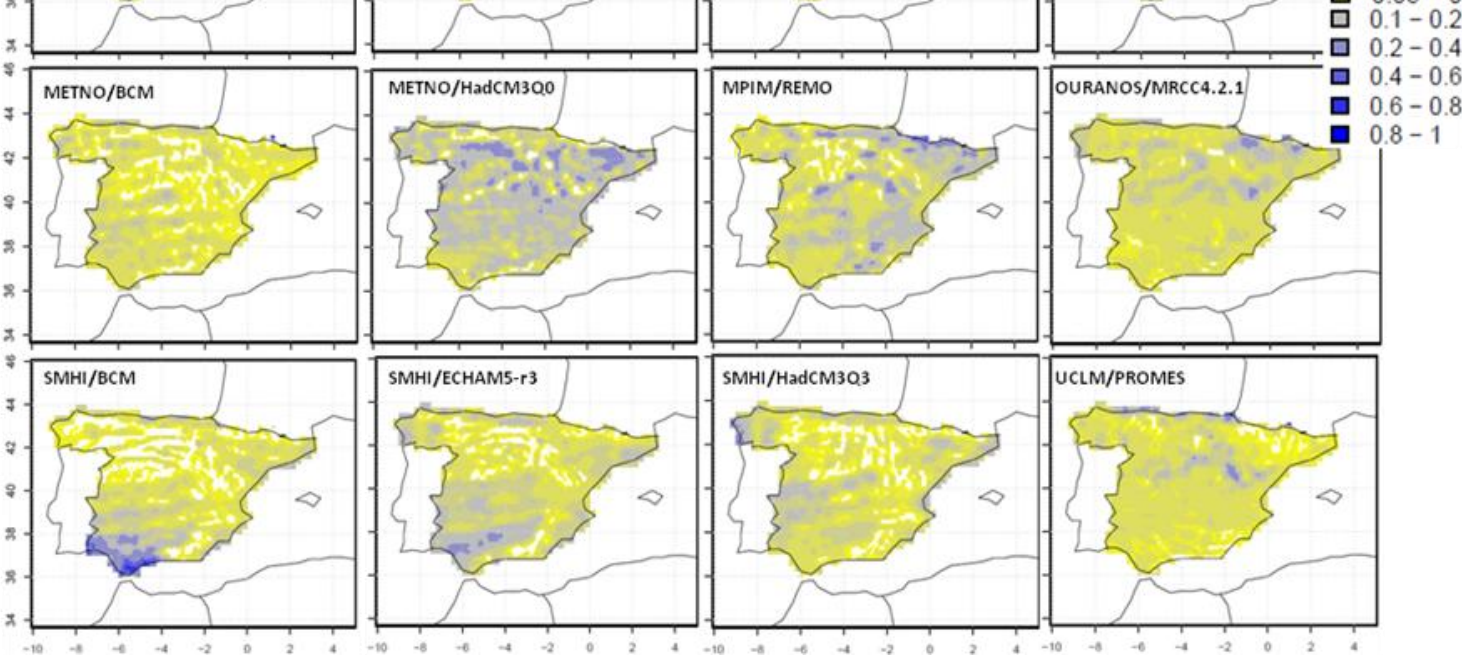

Figura 7.7. Mapas de los valores de Pm estimados con la combinación 2.1 (Método 2 y métrica $p$ del TSSK) de cada RCM para la precipitación.

Por último, y para comprobar qué metodología es más robusta, y si es independiente de la métrica, se evaluaron las distribuciones espaciales del factor $P m$ desde ambos métodos para la métrica Sscore (Figura 7.8 y Figura 7.9, respectivamente). 


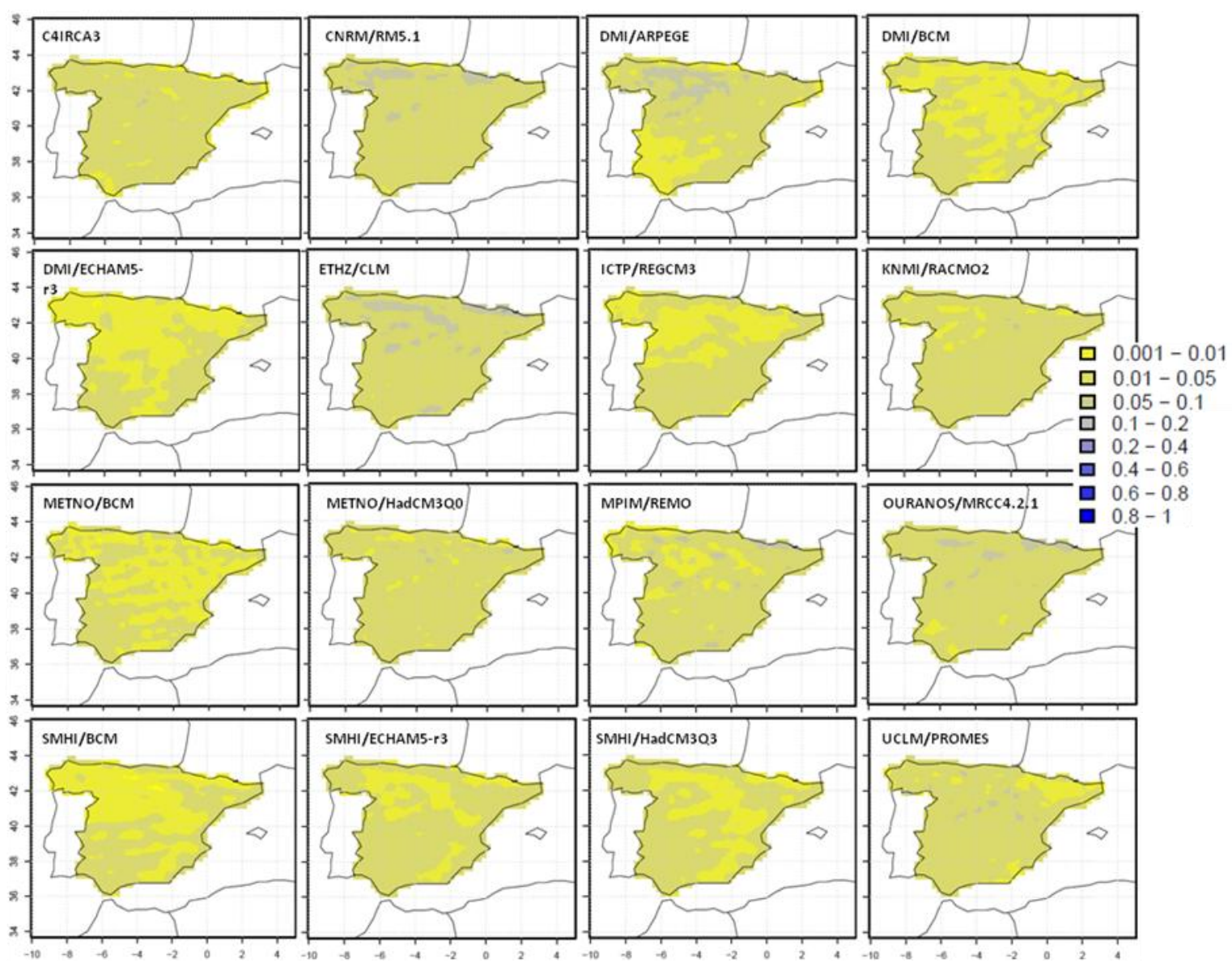

Figura 7.8. Mapas de los valores de Pm estimados con la combinación 1.2 (Método 1 y métrica Sscore) de cada RCM para la precipitación.

En primer lugar, se observa tanto en la Figura 7.8 como en la Figura 7.9, que desde ambos métodos el desempeño de los modelos es bajo, teniendo casi todos los RCMs la misma ponderación. Sin embargo, cuando se emplea el Método 1 (Figura 7.8), se aprecian mayores dispersiones, con valores de $P m$ desde 0.001 a 0.2 , mientras que con el Método 2 los valores varían de 0.001 a 0.1 .

En resumen, desde el análisis presentado se demuestra que el método de construcción del ensemble, independientemente de la métrica usada, genera variaciones apreciables en los valores de $R_{i}$ y $P m$. Se aprecian mayores valores de $R_{i}$ en el caso del Método 1 que es estimado en base a CDFs estacionales y anuales. 

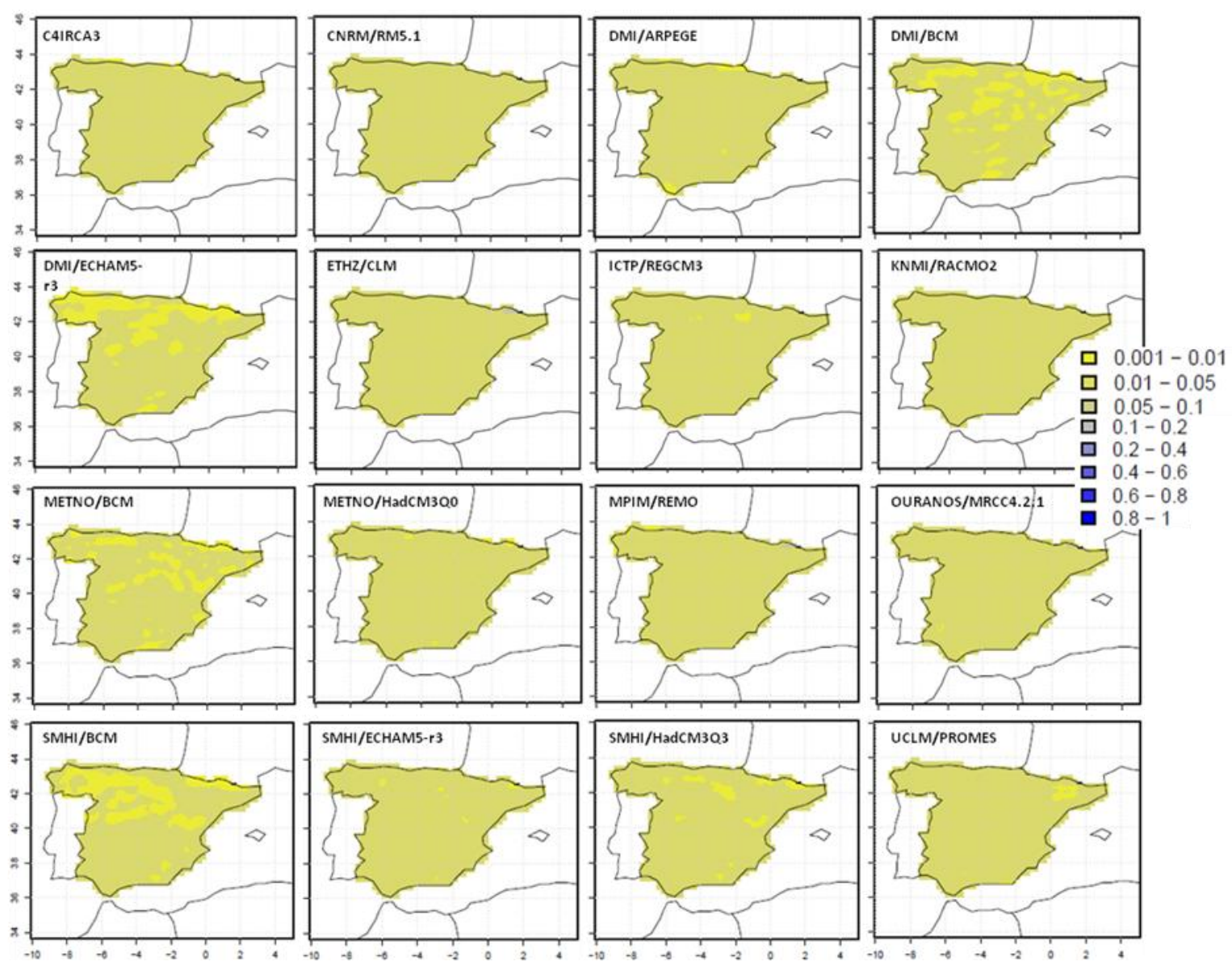

Figura 7.9. Mapas de los valores de Pm estimados con la combinación 2.2 (Método 2 y métrica Sscore) de cada RCM para la precipitación.

\subsubsection{Evaluación de la sensibilidad del ensemble a la selección de la métrica}

Dos métricas diferentes se han seleccionado para evaluar la bondad del ajuste de las CDFs: el $p$ del TSSK y la métrica Sscore. En este apartado se ha evaluado la sensibilidad del ensemble a la selección de la métrica.

De los 906 sitios que se han estudiado en la España Peninsular, fueron seleccionados 6 con diferente régimen hidroclimático, para llevar a cabo un análisis detallado. La Figura 7.10 representa los sitios seleccionados: 53, 224, 295, 490, 679, y 899. 


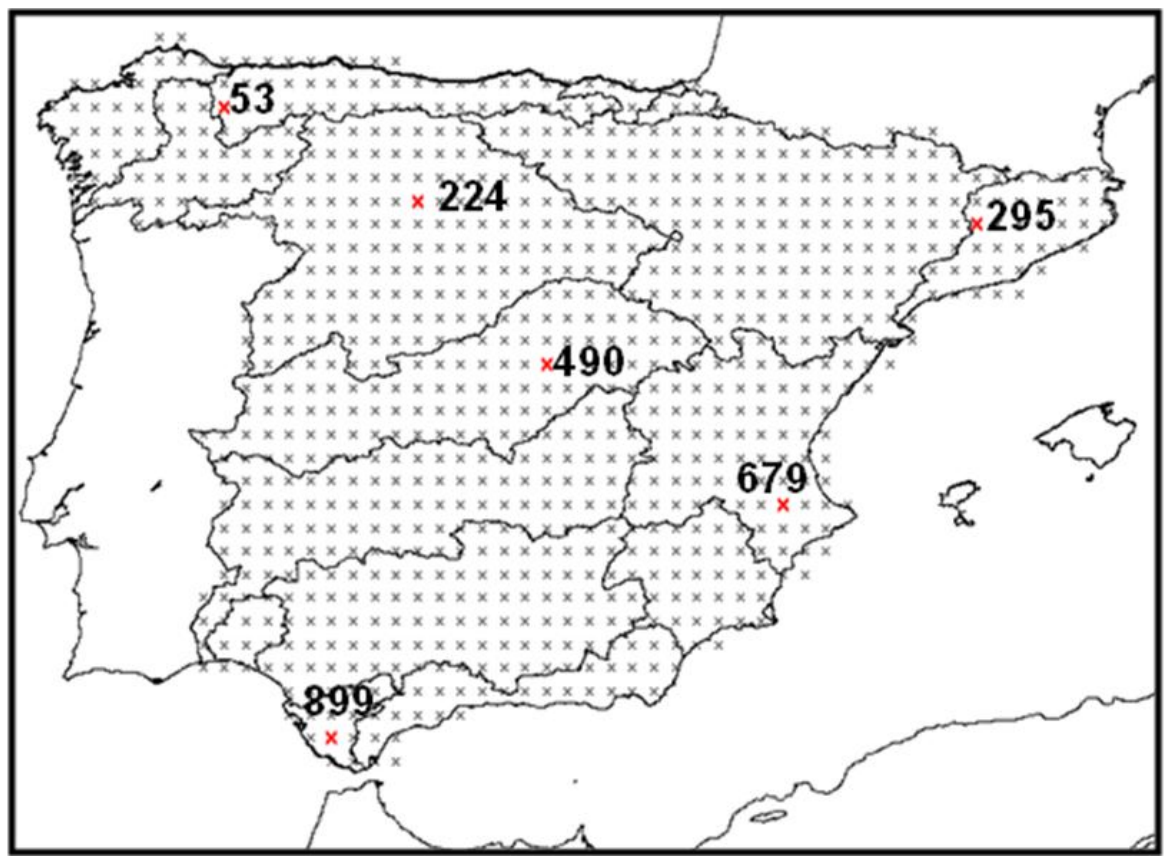

Figura 7.10. Ubicación de los 906 sitios, cuencas y sitios de estudio seleccionados en la España continental.

Los parámetros utilizados para calcular las ponderaciones de miembros en el ensemble PDF ( $p$ del TSSK y Sscore) presentan valores entre [0,1], con la unidad que significa un acuerdo perfecto entre las PDFs empíricas.

Considerando este hecho, en la Tabla 7.1 se presenta el $p$ del TSSK y Sscore que evalúan la similitud distribucional entre los datos ensemble y los observados para las combinaciones 1.1 y 1.2 , basadas en CDFs estacionales y anuales para el periodo de referencia 1961-1990. Como ya se analizó en el apartado anterior, el $p$ del TSSK (combinación 1.1) presenta valores a través de diversas escalas, mientras que los valores de Sscore (combinación 1.2) están contenidos en una escala comparable general.

Tabla 7.1. $p$ del TSSK y Sscore para las combinaciones 1.1 y 1.2 en el período 19611990.

\begin{tabular}{cccccccccccccc}
\hline & \multicolumn{1}{c}{ Site 53 } & \multicolumn{2}{c}{ Site 224 } & \multicolumn{2}{c}{ Site 295 } & \multicolumn{2}{c}{ Site 490 } & \multicolumn{2}{c}{ Site 679 } & \multicolumn{2}{c}{ Site 899 } \\
\hline & $p$ & Sscore & $p$ & Sscore & $p$ & Sscore & $p$ & Sscore & $p$ & Sscore & $p$ & Sscore \\
Invierno & 0.081 & 0.401 & 0.015 & 0.256 & 0.099 & 0.28 & 0.524 & 0.379 & 0.321 & 0.291 & 0.884 & 0.427 \\
Primavera & 0.901 & 0.179 & 0.757 & 0.276 & 0.083 & 0.211 & 0.546 & 0.331 & 0.194 & 0.24 & 0.571 & 0.471 \\
Verano & 0.058 & 0.342 & 0.034 & 0.269 & 0.809 & 0.338 & 0.756 & 0.371 & 0.254 & 0.383 & 0.409 & 0.404 \\
Otoño & 0.147 & 0.379 & 0.004 & 0.248 & 0.385 & 0.327 & 0.077 & 0.24 & 0.041 & 0.236 & 0.589 & 0.331 \\
Anual & 0.241 & 0.2 & 0.09 & 0.033 & 0.415 & 0.181 & 0.409 & 0.184 & 0.398 & 0.393 & 0.608 & 0.413 \\
\hline
\end{tabular}

Según los resultados presentados en la Tabla 7.1, por un lado el sitio 899 (que se 
encuentra en el Sureste de Andalucía), presenta la mejor bondad de ajuste para el período 1961-1990 con ambas métricas. Por otra parte, el sitio 224 (en el Norte de la submeseta), es el que menor bondad de ajuste presenta para ambas métricas.

Hay que tener en cuenta, que valores de $p$ del TSSK inferiores o similares a los valores Sscore no implican un peor acuerdo entre las PDFs empíricas, como se va a demostrar seguidamente.

A continuación, se estudiaron las CDFs anuales, estacionales y mensuales de las cuatro combinaciones en los diferentes sitios de España. Las CDFs anuales de datos observados, del ensemble, y de cada RCM obtenidos tanto con la métrica $p$ del TSSK, como con Sscore se presentan en la Figura 7.11 para los 6 sitios seleccionados (teniendo en cuenta las combinaciones 1.1 y 1.2, basadas en CDFs estacionales y anuales).

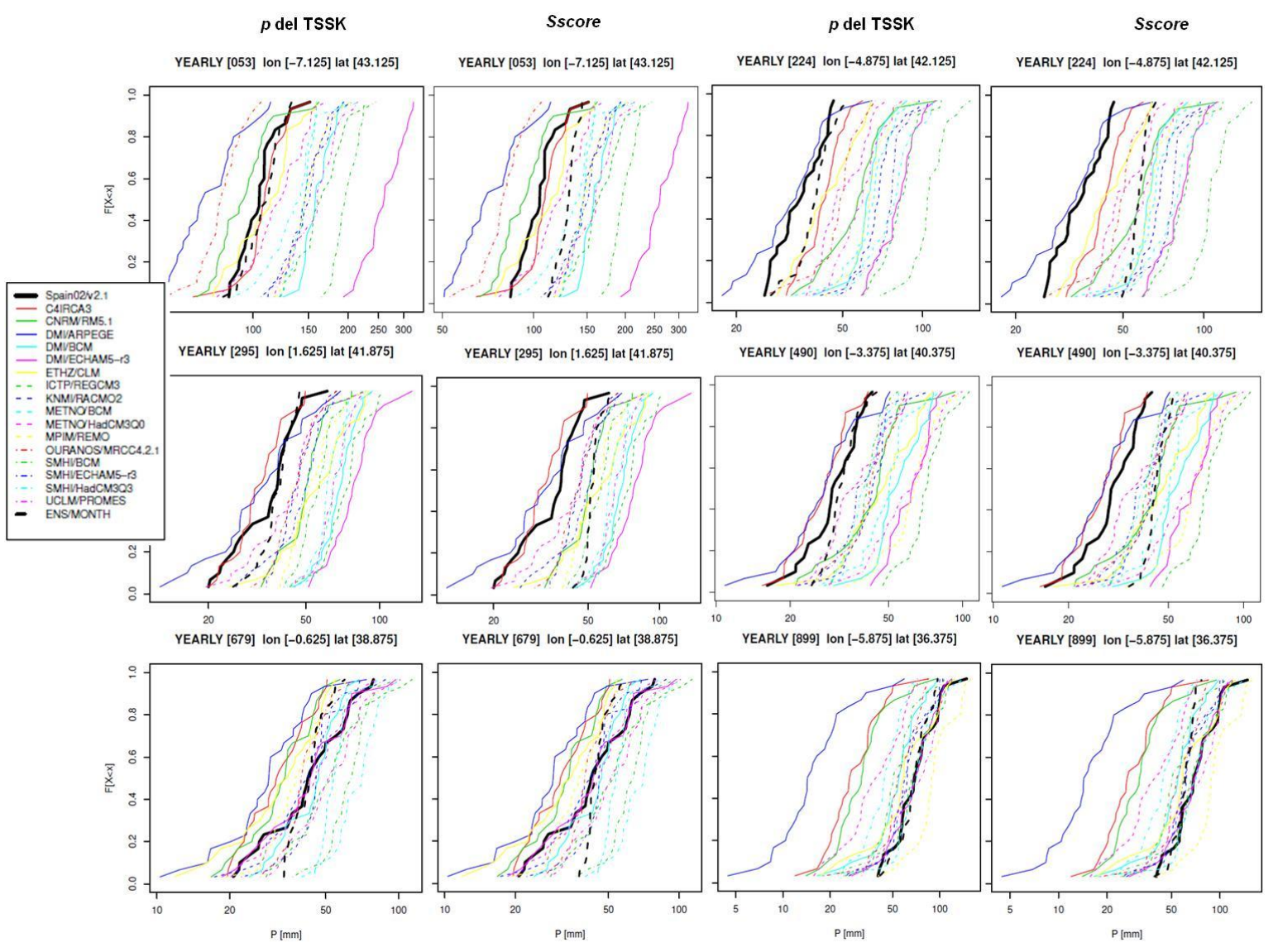

Figura 7.11. CDFs anuales de precipitación de datos observados (en negro), RCMs (en color) y ensemble de RCMs (negro discontinua) en seis sitios diferentes para el período 1961-1990

Como se aprecia desde la Figura 7.11 previa, cuando la métrica utilizada es $p$ del TSSK 
(combinación 1.1), las CDFs de datos observados (línea negra continua) y de ensembles de RCMs (línea negra discontinua) presentan una notable similaridad distribucional en la mayoría de los sitios. Sin embargo, si la métrica utilizada es Sscore (combinación 1.2), este buen ajuste no se observa.

Por ejemplo, si se analizan las CDFs del sitio 53 (Figura 7.11), cuando se usa la métrica p del TSSK los modelos con mejor rendimiento son CNRM / RM5.1 (línea verde), C4IRCA3 (línea roja) y ETHZ/CLM (línea amarilla). Sin embargo, desde las CDFs resultantes con la métrica Sscore no se puede identificar un RCM con el mejor rendimiento. Ello ya fue mencionado al analizar los mapas de $R_{i}$ y $P m$ del apartado anterior.

Una vez calculados los ensembles de RCMs, para completar el estudio de las métricas, se construyeron mapas de diferencias de medias anuales y estacionales, utilizando el test $t$ con datos de precipitaciones observados y ensembles de RCMs (Figuras 7.12 y 7.13). Las Figuras 7.12 y 7.13 presentan la distribución espacial de las diferencias de medias anuales y estacionales en todos los sitios de la malla para el período de referencia 19611990, y para ambas métricas y métodos. Los mapas fueron evaluados aplicando la ecuación $\left[100 *\left(\right.\right.$ mapa $_{E n s}-$ mapa $\left._{O b s}\right) /$ mapa $\left.a b s\right]$.

Mientras la columna derecha presenta los mapas construidos con la métrica Sscore, la columna izquierda enmarca los mapas construidos con $p$ del TSSK.

Los mapas de la Figura 7.12 fueron calculados usando precipitaciones ensemble con los factores de confiabilidad en base a CDFs estacionales y anuales (Método 1), mientras que los mapas de la Figura 7.13 se obtuvieron con ensembles de RCMs calculados con factores de confiabilidad en base a CDFs mensuales (Método 2).

Las áreas sombreadas, en ambas figuras, representan diferencias significativas con un intervalo de confianza del $95 \%$. 


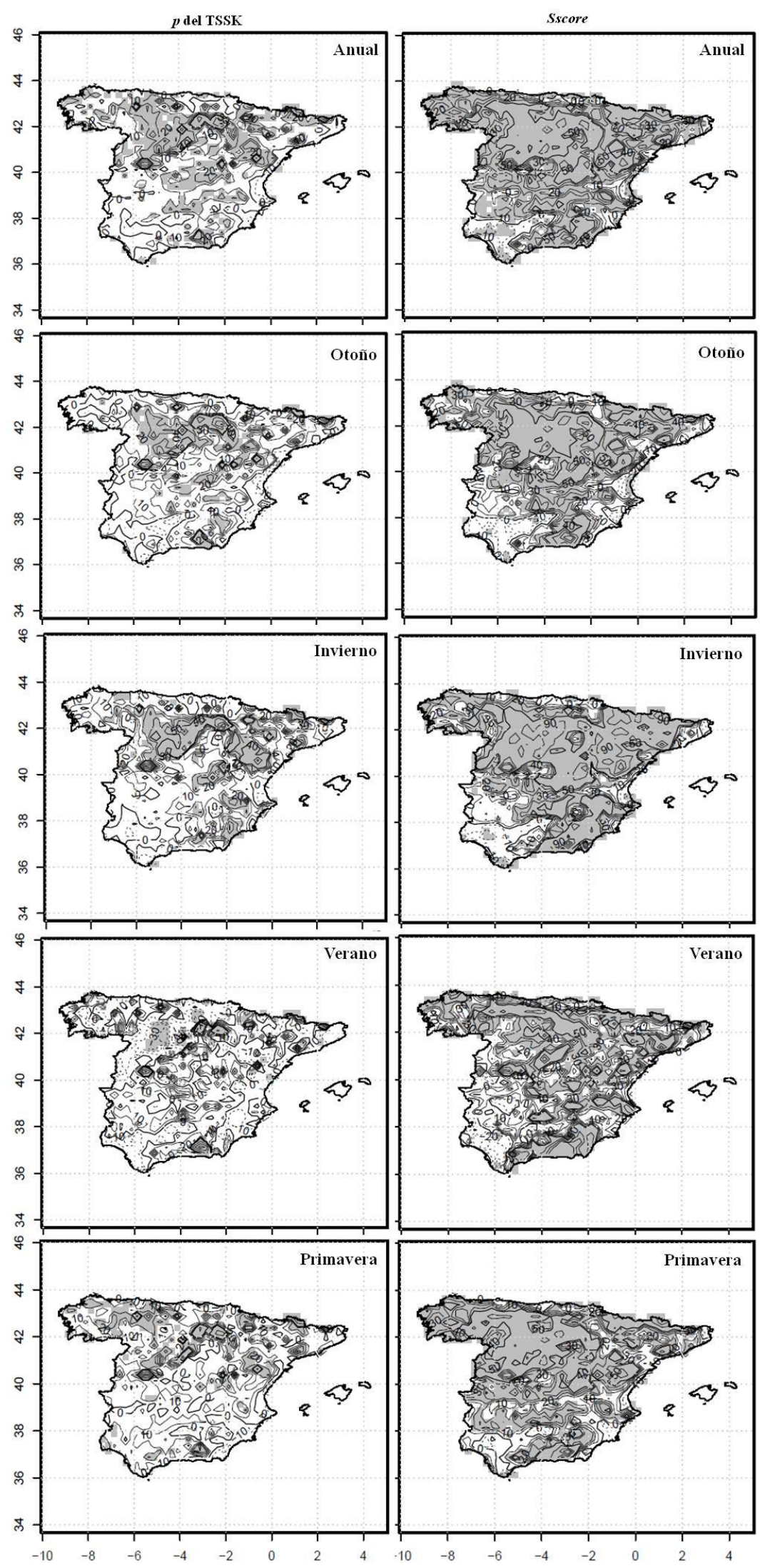

Figura 7.12. Mapas de diferencias de medias de precipitaciones calculados para el período 1961-1990. Los mapas ensembles fueron construidos con el Método 1 usando: Sscore (derecha) y $p$ del TSSK (izquierda). 


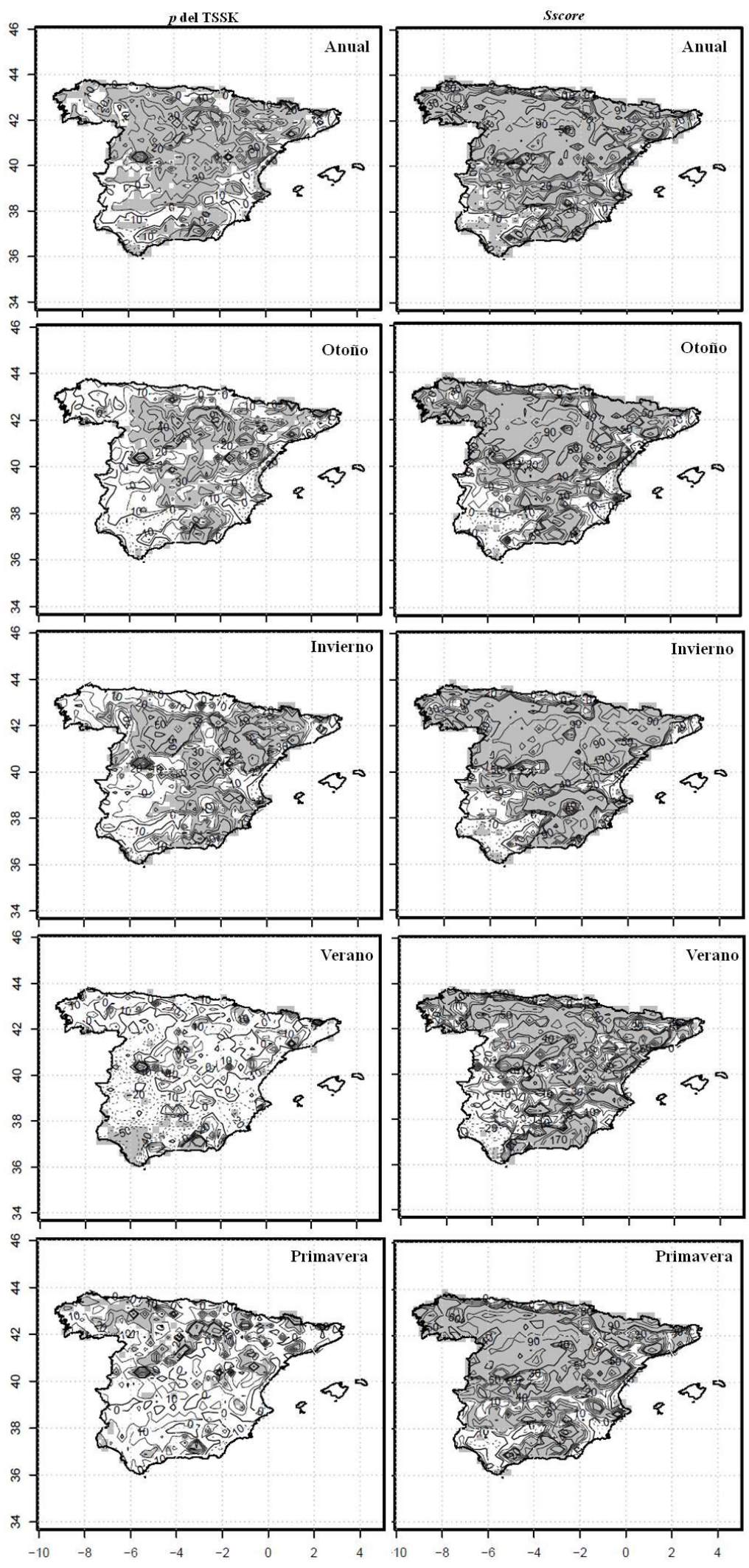

Figura 7.13. Mapas de diferencias de medias de precipitaciones calculados para el período 1961-1990. Los mapas ensembles fueron construidos con el Método 2 usando: Sscore (derecha) y $p$ del TSSK (izquierda). 
Como ya se podía prever cuando se estudiaron las CDFs del ensemble, y existía una mejor bondad de ajuste al emplear la métrica $p$ del TSSK, en la Figuras 7.12 y 7.13 este mejor rendimiento se ha podido demostrar para toda España, y de forma anual y estacional.

De acuerdo a las Figuras 7.12 y 7.13, los mapas de diferencias en los que se trabajó con el ensemble de precipitaciones calculadas con la métrica Sscore presentaron diferencias mayores (en \%) en todo el territorio español. Además, y como era de esperar, las áreas donde las diferencias entre el ensemble y los datos observados son significativas (áreas sombreadas), fueron mucho mayores cuando el ensemble se evaluó con Sscore.

A pesar de las diferencias entre los mapas para cada métrica y método, todos los enfoques concluyeron que el verano es la estación en la que se obtuvieron diferencias menos significativas, y los mapas anuales mostraron las mayores diferencias.

Según la Figura 7.12, cuando se emplean mapas ensembles calculados con $p$ del TSSK y el Método 1, las diferencias significativas se concentran en el cuadrante Noreste de la Península Ibérica (submeseta Norte, Sistema Ibérico y la depresión del Ebro), y en menor medida en el Sureste.

Observando la Figura 7.13, en la cual se obtienen los ensembles con el Método 2, usando la métrica Sscore, nuevamente se exhibe un pobre acuerdo entre los datos observados y el ensemble de los modelos, exceptuando en el Sureste de Andalucía. Mientras que usando la métrica $p$ del TSSK, los mapas de diferencias calculados anuales, de otoño e invierno presentan mayores zonas con diferencias significativas que cuando se emplea el Método 1 (Figura 7.12).

En general, estos resultados indican la capacidad de un conjunto de RCMs para reproducir la precipitación media con ambos métodos y métricas en España durante el período de referencia.

En vista de estos resultados, la métrica con la que se obtiene el mejor conjunto de RCMs y que mejor se ajusta a la precipitación media observada es $p$ del TSSK. Mientras, la métrica Sscore presenta pobres desempeños para el ensemble de RCMs. Estos resultados están de acuerdo con los obtenidos por Giraldo y García (2013), trabajando con la variable longitudes de sequías máximas anuales.

Además, teniendo en cuenta los resultados que se obtuvieron en la sección anterior, y las distribuciones espaciales de las diferencias de medias, se puede concluir que aplicando el Método 1 para el cálculo del factor de confiabilidad junto con la métrica $p$ 
del TSSK (combinación 1.1), se obtiene el ensemble más robusto al momento de simular la precipitación observada para el periodo 1961-1990 en la región de interés. Este hecho se justifica debido a que el Método 1 está considerando la variabilidad tanto de datos anuales como estacionales al momento de construir el ensemble de precipitaciones.

\subsection{Análisis de tendencias de precipitación, temperatura máxima y temperatura mínima}

En la sección anterior se demostró que las diferentes formulaciones para evaluar $R_{i}$ proporcionan diferentes resultados en los ensembles de RCMs.

En vista de los resultados obtenidos, se escogió la combinación 1.1 (Método 1 y métrica $p$ del TSSK) como la metodología más robusta para generar escenarios futuros tanto de precipitaciones como de temperaturas máximas y mínimas, para toda la España Peninsular.

En las Figuras 7.14, 7.15 y 7.16 se presentan los mapas de las proyecciones climáticas desde los ensembles de RCMs de precipitación, temperatura máxima y temperatura mínima medias anuales para el periodo 2021-2050 frente a los escenarios históricos 1961-1990 y 1971-2000, respectivamente. 
Observados 1961-1990

Observados 1971-2000
Ensembles 2021-2050

Ensembles 2021-2050
Diferencia Ens-Obs

Diferencia Ens-Obs

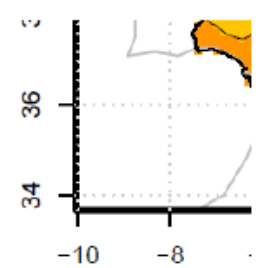

Figura 7.14. Mapas de precipitación media anual (mm) y variación de la precipitación (\%) para 2021-2050 en contraste para dos periodos distintos de datos observados (1961-1990 y 1971-2000). 
Observados 1961-1990

Observados 1971-2000
Ensembles 2021-2050

Ensembles 2021-2050
Diferencia Ens-Obs

Diferencia Ens-Obs

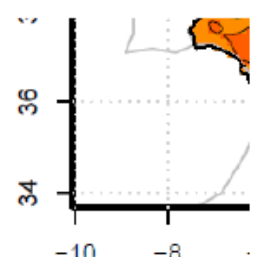

Figura 7.15. Mapas de temperatura máxima media anual $\left({ }^{\circ} \mathrm{C}\right)$ y variación de la temperatura máxima (\%), para 2021-2050 en contraste para dos periodos distintos de datos observados (1961-1990 y 1971-2000). 
Observados 1961-1990

Observados 1971-2000
Ensembles 2021-2050

Ensembles 2021-2050
Diferencia Ens-Obs

Diferencia Ens-Obs

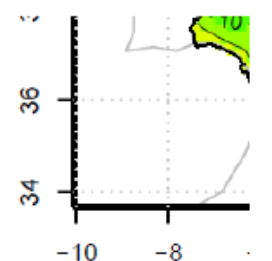

Figura 7.16. Mapas de temperatura mínima media anual $\left({ }^{\circ} \mathrm{C}\right)$ y variación de la temperatura mínima (\%), para 2021-2050 en contraste para dos periodos distintos de datos observados (1961-1990 y 1971-2000). 
Mediante un análisis de las precipitaciones desde la Figura 7.14, se identifica un gradiente decreciente hacia el Sureste, con valores máximos de las precipitaciones medias en el Norte del territorio español a partir de los mapas para los periodos 19611990, 1971-2000 y 2021-2050. Si se analizan los mapas de diferencias, en ambos se prevén disminuciones del valor medio de precipitación en el horizonte futuro de un 5 a un $10 \%$ en el Noroeste, la costa cantábrica y en la costa mediterránea, llegando a un 20 $\%$ en algunas zonas del Suroeste español, cuando se considera como periodo de referencia 1971-2000. Sin embargo, se debe tener en cuenta que estas reducciones varían dependiendo del periodo observado escogido. Cabe señalar, que las áreas donde se prevén incrementos en las precipitaciones (Submeseta Norte, Sistema Ibérico, depresión del Ebro y el Sureste peninsular) son las zonas que mostraron diferencias significativas en los mapas de diferencias de medias de la combinación seleccionada (Figura 7.12).

En la Figura 7.15, correspondiente a temperatura máxima, los resultados de ambos periodos históricos son similares. Las temperaturas máximas son menores en la mitad Norte de España, en relación a la mitad Sur. Si se observan los mapas de diferencias, en ambos la temperatura máxima aumentará de un 10 a un $15 \%$ en la zona Norte, de un 5 a un $10 \%$ en la zona Sur, mientras que en la costa mediterránea se prevén aumentos de hasta un $5 \%$. Se observa así un aumento en casi toda la España Peninsular.

Por último, si se analizan las temperaturas mínimas obtenidas para la España Peninsular (Figura 7.16), al igual que ocurre en la figura anterior, en los mapas de datos históricos las temperaturas mínimas son menores en el Norte que en el Sur. En ambos mapas de diferencias se observa un aumento de las temperaturas mínimas en toda España, lo cual es esperable debido a la proyección del aumento de las temperaturas máximas. Se prevé un aumento de la temperatura entre un 20 y un $30 \%$ para toda España, exceptuando en los Pirineos y el Sistema Ibérico, donde se prevén aumentos de hasta un $100 \%$, y zonas de la costa mediterránea y Andalucía, donde se prevén aumentos de un $10 \%$.

Luego, de manera general y a la vista de los resultados, se puede concluir que se han obtenido proyecciones climáticas con aumentos en las temperaturas máximas y mínimas para todo el país, mientras que las precipitaciones medias se prevé que aumenten o disminuyan dependiendo de la zona analizada. 


\subsection{Resultados: Modelización hidrológica en la cuenca de la Fuensanta}

En la modelización hidrológica de la cuenca de la Fuensanta se ha evaluado la producción de escorrentía, con la finalidad de generar escenarios hidrológicos futuros. Esta cuenca ha sido escogida por ser la que contribuye con la descarga natural más alta de toda la cuenca del Segura, y por ello el aumentar el conocimiento de los impactos plausibles del cambio climático en el régimen hidrológico ayudará al desarrollo de planes y medidas de adaptación.

\subsubsection{Fase calibración y validación histórica}

La Figura 7.17 presenta el contraste entre el hidrograma observado y el simulado a la salida de la cuenca por el modelo Témez, para el período 2000-2005, en fase de calibración. La calibración se efectuó en este periodo debido a que se consideran los usos del suelo provistos por el proyecto CORINE Land Cover 2006.

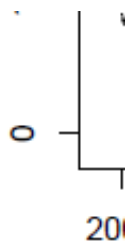

Figura 7.17. Resultados de la calibración del modelo de Témez. Periodo 2000-2005. 
La eficiencia conseguida por el índice $N S E$ es muy buena (0.71), según la Tabla 6.3.

Además, se realizó la validación del modelo en el periodo 2006-2012 (Figura 7.18) antes de generar proyecciones hidrológicas. Se obtuvieron resultados satisfactorios, con un valor de NSE de 0.68 para ese periodo.

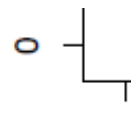

Figura 7.18. Validación del modelo. Aportaciones simuladas y observadas $\left(\mathrm{hm}^{3}\right)$ con el modelo de Témez para el periodo 2006-2012.

Si bien es verdad que la eficiencia conseguida en la fase de validación fue menor, se debe tener en cuenta que en el proceso de calibración realizado se ha llevado a cabo una hipótesis de estacionariedad o invarianza de los parámetros en el periodo de simulación. Esto supone admitir, consecuentemente, la invarianza en los usos de suelo, lo que en la práctica puede no ser así, aunque los periodos considerados son de 6 años cada uno. No obstante, se destaca que en el caso de análisis a largo plazo de la variabilidad de las aportaciones históricas es importante estudiar el impacto del cambio del uso del suelo junto al impacto del cambio climático. 


\subsubsection{Fase generación de escenarios hidrológicos futuros}

La generación de escenarios hidrológicos se ha llevado a cabo con el modelo Témez distribuido espacialmente, una vez validado, para estudiar el comportamiento de la cuenca de la Fuensanta. Esta modelización a escala mensual se realizó considerando la información derivada del ensemble de RCMs y la parametrización previa.

La aplicación del modelo Témez proporciona la escorrentía total en régimen natural en la cuenca hidrológica. La Figura 7.19a presenta una comparación de la variabilidad mensual identificada entre la escorrentía observada, la escorrentía simulada del modelo forzado por el escenario histórico, y la escorrentía simulada por el modelo forzado por el ensemble de RCMs, para el período de calibración 2000-2005. La variabilidad y la mediana identificadas a partir de los resultados hidrológicos obtenidos mediante el forzamiento con el ensemble de RCMs son mayores que los valores observados de escorrentía y la escorrentía simulada por el modelo forzado por el escenario histórico.

En la Figura 7.19b se presentan las anomalías de las proyecciones de precipitación y escorrentía para el período 2021-2050 en relación a la media del periodo 1961-1990. Se demuestra que la escorrentía simulada es principalmente forzada por la variabilidad de la precipitación, mientras se proyectan decrecimientos de esta variable (Figura 7.19b).
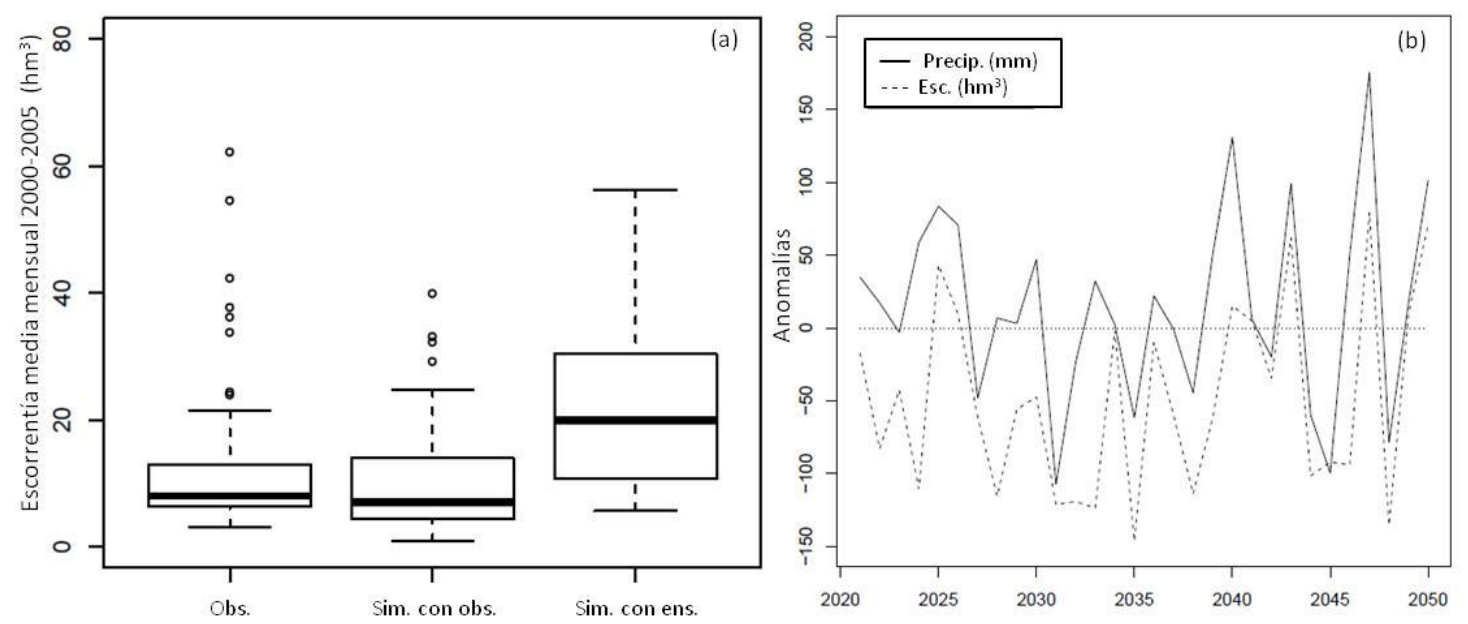

Figura 7.19. (a) Diagrama de cajas de la escorrentía media mensual para el período 2000-2005 desde datos observados, simulada a partir de datos históricos y simulada con ensembles de RCMs; y (b) anomalías proyectadas para 2021-2050 de las precipitaciones y escorrentía en relación con la media del periodo 1961-1990.

Se realizó un contraste de los resultados de aportaciones medias anuales simuladas desde las proyecciones con el ensemble de RCMs para el periodo 2021-2050, y las 
obtenidas con datos históricos para el periodo control de 1961-1990, y el periodo 19712000 (Tabla 7.2).

Tabla 7.2. Datos de aportaciones medias anuales en la cuenca de aporte al embalse de Fuensanta

\begin{tabular}{llcc}
\hline Datos & Periodo & Aportación $\left(\mathbf{h m}^{3}\right)$ & Cambio (\%) \\
\hline Observados (CHS) & $1961-1990$ & 258 & \\
Ensemble RCMs & $2021-2050$ & 209 & -20 \\
Observados (CHS) & $1971-2000$ & 204 & \\
Ensemble RCMs & $2021-2050$ & 209 & 2.5 \\
\hline
\end{tabular}

Desde la Tabla 7.2 se puede observar que, cuando se usa como periodo de referencia el periodo 1961-1990, se prevé que las aportaciones medias anuales en la cuenca disminuyan un $20 \%$ con respecto a las aportaciones simuladas con los ensembles para el periodo 2021-2050. Sin embargo, al considerar el periodo histórico 1971-2000 como periodo de control, se predice un aumento de la escorrentía del orden del $2.5 \%$. En conclusión, se identifican tendencias contrarias dependiendo del periodo de referencia (o de control) considerado. Por lo que se destaca la incertidumbre e influencia en los resultados que puede generarse al seleccionar el periodo de contraste.

A continuación, se procedió a analizar las distribuciones espaciales de las proyecciones climáticas de precipitación y evapotranspiración, así como las proyecciones de aportaciones medias anuales (Figuras 7.20, 7.21 y 7.22) del escenario futuro 2021-2050 considerando los periodos de control 1961-1990 y 1971-2000 a partir de los escenarios históricos. 
Observados 1961-1990

Observados 1971-2000
Ensemble 2021-2050

Diferencia Ens-Obs

Ensemble 2021-2050

Diferencia Ens-Obs

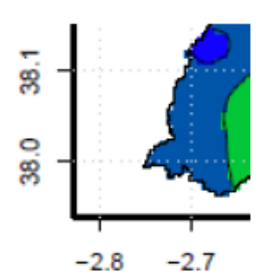

Figura 7.20. Mapas de precipitación media anual ( $\mathrm{mm})$ y variación de la precipitación (\%) en la cuenca de la Fuensanta, para el escenario 2021-20150 en contraste con dos periodos distintos de datos observados 1961-1990 y 1971-2000. 
Observados 1961-1990

Observados 1971-2000
Ensemble 2021-2050

Ensemble 2021-2050
Diferencia Ens-Obs

Diferencia Ens-Obs

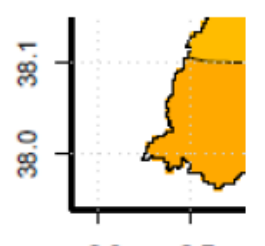

Figura 7.21. Mapas de evapotranspiración potencial media anual ( $\mathrm{mm})$ y variación de la evapotranspiración (\%) en la cuenca de la Fuensanta, para el escenario 2021-20150 en contraste con dos periodos distintos de datos observados 1961-1990 y 1971-2000 


\section{Observados 1961-1990}

\section{Observados 1971-2000}

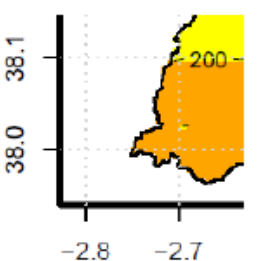

Ensemble 2021-2050

Diferencia Ens-Obs
Ensemble 2021-2050
Diferencia Ens-Obs

Figura 7.22. Mapas de aportación media anual (mm) y variación de la aportación (\%) en la cuenca de la Fuensanta, para el escenario 202120150 en contraste con dos periodos distintos de datos observados 1961-1990 y 1971-2000. 
Si se analizan las precipitaciones desde la Figura 7.20, se puede observar que cuando se emplea como periodo de referencia 1961-1990, se prevé, que las precipitaciones disminuyan hasta un $10 \%$ en la zona Este de la cuenca, llegando a aumentar hasta un 20 $\%$ en el resto. Sin embargo, cuando el periodo de referencia escogido es 1971-2000, se prevé un escenario plausible de aumento de las precipitaciones en la mayor parte del área de la cuenca (un $11 \%$ de media), llegando incluso a aumentar en un $20 \%$ en alguna zona.

Por otro lado, desde la Figura 7.21, correspondiente a ETP, los resultados de los mapas de diferencias para ambos periodos de referencia son similares. Si se observa la Figura 7.21, la ETP aumentará en casi toda la cuenca en un pequeño porcentaje (4 \% de media, para ambos casos), disminuyendo en algunas pequeñas zonas de un 0 a un $5 \%$.

Por último, si se analizan las aportaciones obtenidas en la cuenca (Figura 7.22), se observa un comportamiento similar al identificado en el caso de las precipitaciones. Considerando el periodo de referencia 1961-1990, se prevé en la mayor parte de la cuenca una reducción de las aportaciones, llegando en algunas zonas a ser del $50 \%$. En el caso de las aportaciones proyectadas en contraste con el periodo de referencia histórico 1971-2000, se identifican tendencias contrarias en signo. El escenario plausible de aportaciones corresponde a un aumento en la mayor parte de la cuenca hasta en un $40 \%$, lo que es esperable dada la proyección del aumento de las precipitaciones. Si bien, en el Norte de la cuenca se identifica una zona donde se prevé que se reduzcan las aportaciones hasta en un $50 \%$.

Para completar el estudio, se analizó la variabilidad estacional a escala de cuenca de la precipitación, ETP, temperatura media y escorrentía, para los dos periodos considerados como de control (1961-1990 y 1971-2000) y el período futuro (2021-2050). Los resultados se presentan comparativamente en las Figuras 7.23, 7.24, 7.25 y 7.26. 


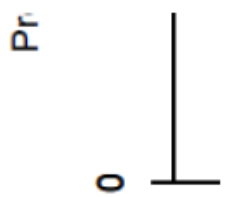

Otoño Invierno Verano Primavera

Figura 7.23. Diagrama de cajas de la precipitación media mensual $(\mathrm{mm})$ a escala de cuenca para cada estación, simulada para el período 2021-2050 y para los periodos de control 1961-1990 y 1971-2000.

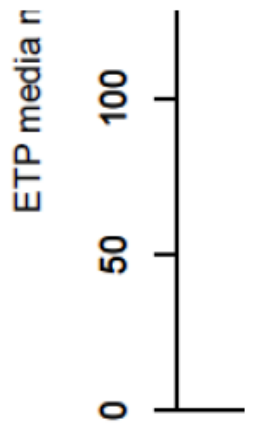

Otoño Invierno Verano Primavera

Figura 7.24. Diagrama de cajas de la ETP media mensual $(\mathrm{mm})$ a escala de cuenca para cada estación, simulada para el período 2021-2050 y para los periodos de control 19611990 y $1971-2000$. 


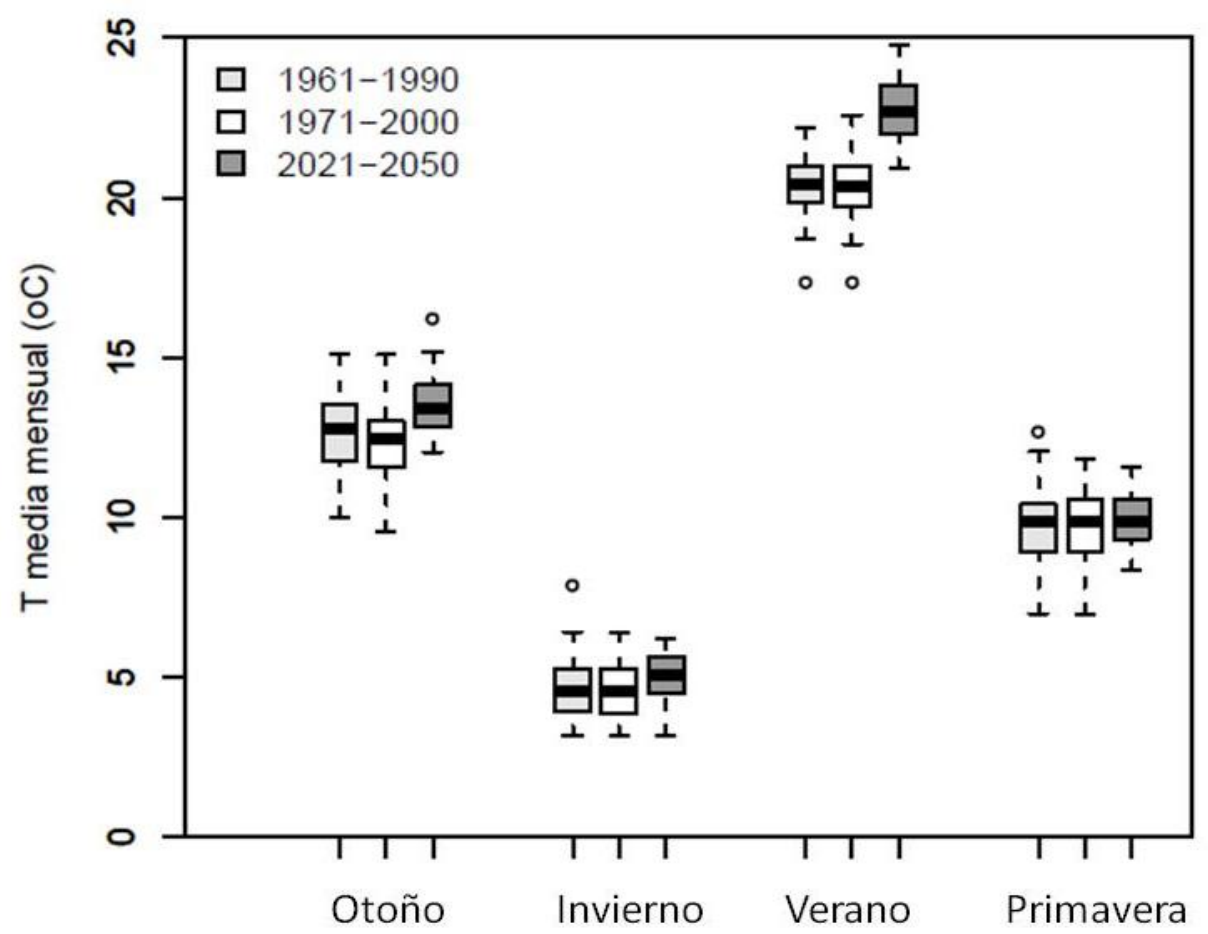

Figura 7.25. Diagrama de cajas de la temperatura media mensual $\left({ }^{\circ} \mathrm{C}\right)$ para cada estación a escala de cuenca, simulada para el período 2021-2050 y para los periodos de control 1961-1990 y 1971-2000.

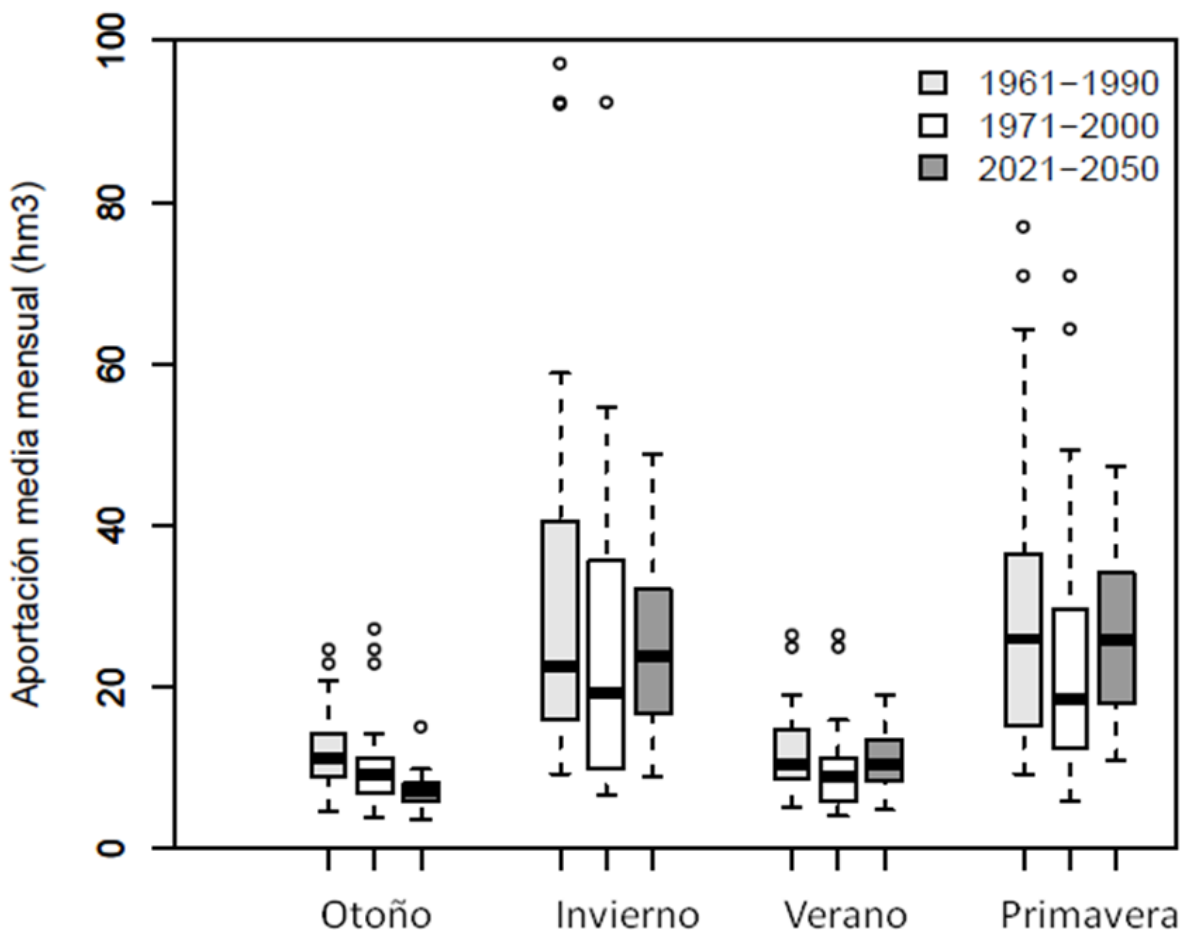

Figura 7.26. Diagrama de cajas de la aportación media mensual $\left(\mathrm{hm}^{3}\right)$ para cada estación simuladas a escala de cuenca para el período 2021-2050 y para los periodos de control 1961-1990 y 1971-2000. 
En la Figura 7.23 se puede observar que la precipitación media para el periodo 20212150 , en todas las estaciones, presenta un rango más estrecho de la variabilidad en comparación con los dos períodos de datos observados o de control (1961-1990 y 19712000). Se identifican disminuciones de la precipitación máxima y del tercer cuartil para cada estación en el período futuro. En contraste, se observan aumentos de la precipitación mínima y del primer cuartil en el período 2021-2050, con respecto a los dos periodos históricos. Si se contrastan las medianas de la precipitación estacional siempre aumentan en el periodo futuro, pero las diferencias son mayores si se contrasta con el periodo histórico 1971-2000.

Si se analiza la Figura 7.24, se aprecia nuevamente que la variabilidad de la ETP para el periodo futuro es menor, en contraste con los dos periodos observados. De esta figura se debe destacar que, tanto en otoño como en verano, la mediana es mayor para el periodo futuro frente a los periodos históricos. Esto significa que se prevén aumentos en la ETP en ambas estaciones. Para invierno y primavera, las medianas se prevén muy igualadas entre el periodo 2021-2050 y ambos periodos de datos observados. Estos aumentos previstos para otoño y verano en el periodo 2021-2050, son debidos a los potenciales aumentos que se prevén de la temperatura media mensual en ambas estaciones, con respecto a ambos periodos históricos, como se observa en la Figura 7.25.

Cabe destacar los resultados de la Figura 7.26, con respecto a las aportaciones en cada estación. Los valores máximos disminuyen de forma considerable en el periodo futuro, con respecto a los dos periodos observados o de control en todas la estaciones, menos en verano. Sin embargo los valores mínimos prácticamentente se mantienen igual. Además se observan disminuciones del tercer cuartil de aportaciones en otoño y en invierno para ambos periodos históricos, y en verano y primavera, solo contrastando con el periodo 1961-1990. El hecho de que la mediana aumente en invierno, verano y primavera, si se contrasta el periodo 2021-2050 con el periodo 1971-2000, confirma los resultados ya identificados y comentados desde la Tabla 7.2, que correspondían a un aumento de las aportaciones. Si se observa la mediana, entre el periodo futuro y 19611990, esta disminuye en otoño, y se mantiene igual para el resto de estaciones, lo cual nuevamente hace prever una reducción de las aportaciones en la cuenca.

Por lo tanto, como ya se ha destacado, a la hora de analizar los resultados de las proyecciones, hay que prestar especial atención al criterio y condicionamientos al 
momento de seleccionar el periodo histórico de control, puesto que podría constituir una fuente de incertidumbre importante que condicione las conclusiones aportadas. 


\section{Conclusiones}

La variabilidad hidroclimática se debe a los efectos de las emisiones antropogénicas de gases de efecto invernadero que actualmente son las más altas de la historia (IPCC, 2014), pero también a otras actuaciones del hombre que impactan tanto en el clima como en la naturaleza (cambios de usos del suelo como intensivas reforestaciones y urbanizaciones; construcción de grandes infraestructuras hidráulicas como presas, entre otras).

En el presente trabajo de Tesis se ha ahondado en el estudio de la variabilidad hidroclimática desde la perspectiva del impacto del cambio climático en el ciclo hidrológico. La precipitación como componente clave del ciclo hidrológico, y una de las entradas principales a los modelos hidrológicos, requiere de una precisa estimación. Por lo tanto, se requieren proyecciones climáticas precisas como requisito previo para la obtención de acertadas proyecciones hidrológicas. Una forma de aumentar la confiabilidad de las proyecciones climáticas es trabajar con combinaciones (o ensembles) de RCMs.

A modo de resumen, se remarcan los principales resultados y conclusiones considerando los objetivos planteados inicialmente en la Tesis.

- El primer objetivo se orientó a proponer una metodología robusta de generación ensembles de RCMs que permitiera reducir las incertidumbres asociadas en los escenarios plausibles de precipitación mensual.

Por ello, para cumplir con este primer objetivo se propusieron y evaluaron dos diferentes y novedosas metodologías para construir ensembles de modelos climáticos (en este caso RCMs) de variables climáticas, basadas en el método REA. La metodología REA es lo suficientemente robusta como para ser considerada el punto de partida.

- El siguiente objetivo del trabajo de Tesis fue evaluar la confiabilidad de las metodologías propuestas, mencionadas anteriormente, teniendo en cuenta distintos niveles de información que consideran la variabilidad mensual de la precipitación en un caso, y la variabilidad anual y estacional de la precipitación en el otro caso, a nivel de España.

Para llevar a cabo este segundo objetivo, y realizar los ensembles de RCMs se han 
empleado dos bases de datos climáticas diferentes, una histórica (u observacional) y otra procedente del experimento RT2B del Proyecto Europeo ENSEMBLES. Con ambas bases de datos se ha evaluado la confiabilidad de las dos metodologías propuestas, el Método 1 que consideró tanto la variabilidad anual como estacional de las series temporales, y el Método 2 que se basó en la variabilidad mensual de las series temporales. Para el análisis de la similaridad distribucional se trabajó con dos métricas distintas - $p$ del Test de Smirnov Kolmogorov (TSSK) y Test de Perkins (Sscore) -, para el periodo 1961-1990, considerando los datos de precipitación mensual históricos como los de referencia. Se debe resaltar que si bien se presenta un análisis de sensibilidad y de resultados detallados en el caso de la variable precipitación mensual, el método más robusto fue aplicado también para la construcción de los ensembles de temperaturas medias, máximas y mínimas mensuales.

- El tercer objetivo consistió en identificar la metodología más robusta para la construcción de escenarios plausibles de las variables meteorológicas seleccionadas a escala de la España continental, que constituyen el input a los modelos hidrológicos.

Mediante la aplicación de una metodología de sensibilidad probabilística se ha identificado la técnica más robusta para la construcción de conjuntos multimodelo, contrastando las PDFs del ensemble de RCMs y de los datos observados.

Desde los resultados del ensemble obtenidos con la metodología basada en el Método 1 (PDF estacional y anual) se identificaron mayores habilidades de los RCMs en la reproducción de la precipitación mensual para el período de control. Si bien los resultados son en general satisfactorios, se destaca que se han identificado algunas diferencias sobre todo en la submeseta Norte, Sistema Ibérico, la depresión del Ebro y el Sureste peninsular.

Se ha evaluado el rendimiento de las dos métricas usadas en el análisis de bondad de ajuste y la definición de las ponderaciones aplicadas a cada RCM en la construcción del ensemble. La métrica Sscore ha presentado problemas ya que el número de modelos que participan en el ensemble es grande, pues este enfoque tiende a calcular factores de ponderación similares. Los resultados han mostrado que la métrica $p$ del TSSK es más robusta que el enfoque Sscore en la construcción de conjuntos de RCMs. Por lo tanto, TSSK se puede considerar como una herramienta muy útil para analizar los cambios proyectados de las variables precipitación y temperaturas en este caso. Se concluye que este trabajo de Tesis ha contribuido a reducir las incertidumbres involucradas y a 
compensar los errores sistemáticos que se identifican tanto en las proyecciones de los modelos anidados (RCMs) como en los usados como forzamiento (GCMs).

Una vez identificada, de forma justificada, la mejor combinación para la construcción de ensembles multimodelo, se han generado los correspondientes a precipitaciones, temperaturas medias, mínimas y máximas mensuales, para el horizonte 2021-2050. Como se ha descrito en el trabajo, las proyecciones de ETP fueron estimadas aplicando una metodología ajustada a la cuenca del río Segura, a partir de los ensembles de temperaturas.

Se contrastaron espacio-temporalmente los resultados obtenidos desde datos observados para dos periodos de control 1961-1990 y 1971-2000, con los generados desde los ensembles multimodelo para el horizonte 2021-2050 a escala de toda la España continental. En concordancia con otros autores, se espera un aumento plausible de tanto las temperaturas máximas como las temperaturas mínimas, en casi todo el país. Con respecto a las precipitaciones, si bien existen zonas donde se prevén reducciones de más un $10 \%$ en ambos mapas de diferencias (considerando los dos períodos históricos de análisis), se destaca que también existen zonas donde se prevén aumentos de hasta un $20 \%$. Por lo que en este último caso, las diferencias observadas no son concluyentes pues dependen del período de contraste y de la zona estudiada.

- La Tesis presentó como último objetivo el mejorar las proyecciones hidrológicas considerando los ensembles de RCMs generados de las variables precipitación, temperatura máxima, media y mínima, como entrada a un modelo hidrológico a escala de cuenca.

Se llevó a cabo una extensa revisión bibliográfica de técnicas y modelos hidrológicos utilizados en estudios de impactos del cambio climático a nivel de mesoescala y macroescala, lo que ha permitido evaluar las ventajas y limitaciones de cada aproximación. La comprensión y la proyección de los impactos del cambio climático utilizando modelos lluvia-escorrentía distribuidos basados físicamente, presenta muchas incertidumbres debido al usualmente alto número de parámetros considerados. Por lo tanto, en esta Tesis se optó por usar un modelo de simulación continua, distribuido espacialmente, con pocos parámetros, y a escala mensual, con el fin de reducir las incertidumbres involucradas. La aplicación del modelo Témez, de amplio uso en España, ha permitido modelar a escala mensual las componentes del ciclo hidrológico de una forma distribuida espacialmente en el entorno SIG GRASS. 
La cuenca de la Fuensanta, cuenca de cabecera del río Segura, ha sido seleccionada como cuenca de estudio. Los resultados obtenidos en la calibración y validación del modelo hidrológico han sido satisfactorios en ambos casos.

El modelo hidrológico ha sido forzado con el escenario 2021-2050, generado a partir de los ensembles de RCMs. Como periodos de control se han considerado los períodos históricos 1961-1990 y 1971-2000. Se han identificado diferencias apreciables en la tendencia de la escorrentía total a futuro, dependiendo del período de control con el que se contraste. Cuando se utiliza el periodo de referencia 1961-1990, se prevén reducciones importantes (20\% de media) de proyecciones de aportaciones en la mayor parte de la cuenca. Sin embargo, si se contrasta con el periodo de referencia 1971-2000, sólo se prevén reducciones de hasta un $50 \%$ en el Noreste de la cuenca, mientras que aumentos de hasta un $40 \%$ son previstos en el Suroeste de la cuenca. Este resultado ha sido respaldado por los patrones espacio-temporales de las proyecciones de precipitación en la zona, considerando los mismos periodos temporales. Se debe destacar que la disminución de la escorrentía se justifica no sólo en el patrón de las precipitaciones, sino también en la variación espacio-temporal de las evapotranspiraciones potenciales desde la que se prevé un aumento de un $4 \%$ de media en la zona (justificado en el aumento de las temperaturas dado el método empleado en su estimación).

Desde los resultados alcanzados en esta Tesis, se concluye que las fuentes de incertidumbre no se reducen sólo a los datos de partida y a las técnicas de modelización utilizadas, sino también a la selección del período histórico empleado para el contraste con la proyección futura. La longitud y selección del período de control constituye una posible fuente de incertidumbre, condicionando en cierta medida los resultados alcanzados.

\subsection{Futuras líneas de investigación}

En base a los resultados obtenidos en la presente Tesis se plantean las siguientes futuras líneas de investigación:

- El modelo Témez es una solución parsimoniosa que ha demostrado obtener buenos resultados en la modelación de cuencas del Sureste Peninsular, como la planteada en esta Tesis. Sin embargo, los resultados provistos por el modelo hidrológico se 
encuentran condicionados tanto por los parámetros utilizados durante la etapa de calibración, como por datos meteorológicos de entrada, como por ejemplo la ETP. Por lo que se plantea como una posible línea de investigación el modificar la estructura del modelo, de tal modo que pueda ser calibrado y validado mediante su forzamiento con información obtenida desde teledetección. Se prevé la modificación de los algoritmos relacionados con la estimación de evapotranspiración real (ETR), de tal modo que se considere la ETR estimada desde satélite como un input al modelo, así como la precipitación desde satélite. De este modo, se facilita la utilización de este tipo de modelización en zonas donde no se presente una densidad adecuada de redes meteorológicas terrestres, reduciendo las incertidumbres asociadas.

- Asimismo se destaca que, en algunos casos, puede ser necesario el uso de escenarios cambiantes de usos del suelo en combinación con escenarios de cambio climático. El considerar como datos de entrada al modelo las series temporales históricas de ETR obtenidas a partir de imágenes satelitales, permitirán no sólo analizar el impacto de los cambios de la cobertura vegetal en el ciclo hidrológico, sino también evaluar la variabilidad espacio-temporal de ETR. La consideración combinada de cambios de usos del suelo y cobertura vegetal, junto a la variabilidad climática, permitirá una calibración más adecuada de los modelos hidrológicos.

- Finalmente, en la presente Tesis se ha trabajado en todo momento con las proyecciones climáticas provistas por el Proyecto Europeo ENSEMBLES. Dado que la metodología desarrollada en esta Tesis puede ser replicada con otros escenarios de RCMs y de emisión de gases de efecto invernadero, un paso sugerido en esta línea de investigación sería la consideración de los RCMs provistos por la iniciativa EUROCORDEX, que presentan una mayor resolución espacial $\left(0.11^{\circ}\right)$ para distintos RCPs. Desde la bibliografía consultada, se ha sugerido que RCP 6.0 es el escenario más similar a A1B. Por lo que se propone, como futura línea de trabajo, el contraste de las proyecciones hidroclimáticas generadas desde los resultados provistos por el Proyecto ENSEMBLES para el escenario A1B, con las correspondientes a la aplicación de la metodología propuesta a partir de las proyecciones climáticas EUROCORDEX para RCP6.0. 


\section{Bibliografía}

Abanades García, J. C., Cuadrat Prats, J. M., de Castro Muñoz de Lucas, M., Fernández García, F., Gallastegui Zulaica, C., Garrote de Marcos, L., Jiménez Herrero, L.M., Juliá Brugués, R., Losada Rodríguez, I. J., Monzón de Cáceres, A., Moreno Rodríguez, J.M., Pérez Arriaga, J. I., Ruiz Hernández, V., Sanz Sánchez, M. J. y Vallejo Calzada, R., 2007. El cambio climático en España. http://www.istas.ccoo.es/descargas/CAMBIO\%20CLIM\%C3\%81TICO\%20EN\%20E SPA\%C3\%91A\%202007.pdf.

Allen, R. G., Pereira, L. S., Raes, D., y Smith, M., 1998. Crop evapotranspirationGuidelines for computing crop water requirements. FAO Irrigation and drainage paper, 56, 300(9).

Álvarez, J., Sánchez, A. y Quintas, L., 2005. SIMPA, a GRASS Based Tool for Hydrological Studies. International Journal of Geoinformatics, 1, 13-20.

Argüeso, D., Hidalgo-Muñoz, J. M., Gámiz-Fortis, S. R., Esteban-Parra, M. J. y Castro-Díez, Y., 2012. High-resolution projections of mean and extreme precipitation over Spain using the WRF model (2070-2099 versus 1970-1999). Journal of Geophysical Research: Atmospheres, 117(D12).

Arnell, N. W., 1999. Climate change and water resources, Global Environ. Change, 9, S31-S49.

ASSET, 2015. Technical report: ASSET Accounting System for Segura River and Transfer. UPCT. http://www.assetwater.eu/

Bellot, J. y Chirino, E., 2013. Hydrobal: An eco-hydrological modelling approach for assessing water balances in different vegetation types in semi-arid areas. Ecol. Model., 266, 30-41.

Best, M. J., Pryor, M., Clark, D. B., Rooney, G. G., Essery, R .L. H., Ménard, C. B., Edwards, J. M., Hendry, M. A., Porson, A., Gedney, N., Mercado, L. M., Sitch, S., Blyth, E., Boucher, O., Cox, P. M., Grimmond, C. S. B., y Harding, R. J., 2011. The Joint UK Land Environment Simulator (JULES), model description - Part 1: Energy and water fluxes. Geosci. Model Dev., 4, 677-699.

Boberg, F., Berg, P., Thejll, P., Gutowski, W. J., y Christensen, J. H., 2010. Improved 
confidence in climate change projections of precipitation further evaluated using daily statistics from ENSEMBLES models. Clim. Dynam, 35, 1509-1520.

Buser, C. M., Künsch, H. R., Lüthi, D., Wild, M. y Schär C., 2009. Bayesian multimodel projection of climate: bias assumptions and interannual variability. Clim. Dynam., 33, 849-868.

Cabezas Calvo-Rubio, F.; Estrada Lorenzo, F. y Estrela Montreal, T., 1999. Algunas contribuciones técnicas del Libro Blanco del Agua en España. Ingeniería Civil, 115, 79-96.

Candela, L., Tamoh, K., Olivares, G. y Gomez, M., 2012. Modelling impacts of climate change on water resources in ungauged and data-scarce watersheds. Application to the Siurana catchment (NE Spain). Sci. Total Environ., 440, 253-60.

CEDEX, 2012 Estudio de los impactos del Cambio climático en los recursos hídricos y las masas de agua. Madrid. Clave CEDEX: 40-407-1-001.

C.H.G., 2010. Propuesta de Proyecto de Plan Hidrológico de la Demarcación Hidrográfica del Guadalquivir. Ministerio de Medio Ambiente y Medio Rural y Marino.

CHS, 2013. Confederación Hidrográfica del Segura. https://www.chsegura.es/chs/index.html

CHS, 2014. Memoria: Plan Hidrológico de la Cuenca del Segura 2009/2015. Murcia. España.

CHS, 2015. Confederación Hidrográfica del Segura. https://www.chsegura.es/chs/cuenca/resumendedatosbasicos/

Christensen, J. H., Carter, T. R., Rummukainen, M. y Amanatidis, G., 2007. Evaluating the performance and utility of regional climate models: the PRUDENCE project. Climatic Change, 81, 1-6.

Christensen, J. H., Rummukainen, M. y Lenderink, G., 2009. Formulation of veryhigh resolution regional climate model ensembles for Europe. In ENSEMBLES: Climate change and its impacts at seasonal, decadal and centennial timescales: Summary of research and results from the ENSEMBLES project, edited by: van der Linden, P. and Mitchell, J. F. B., Met Office Hadley Centre, FitzRoy Road, UK, 47-58.

Clark, D. B., Mercado, L. M., Sitch, S., Jones, C. D., Gedney, N., Best, M. J., Pryor, M., Rooney, G. G., Essery, R. L. H., Blyth, E., Boucher, O., Harding, R. J., Huntingford, C., y Cox, P. M., 2011. The Joint UK Land Environment Simulator (JULES), model 
description - Part 2: Carbon fluxes and vegetation dynamics, Geosci. Model Dev., 4, 701-722.

de Luis, M., Brunetti, M., Gonzalez-Hidalgo, J. C., Longares, L. A. y Martin-Vide, J., 2010. Changes in seasonal precipitation in the Iberian Peninsula during 1946-2005. Global Planet. Change, 74, 27-33.

de Luis, M., González-Hidalgo, J.C., Longares, L.A. y Štepánek, P., 2009. Seasonal precipitation trends in the Mediterranean Iberian Peninsula in second half of 20th century. Int. J. Climatol, 29(9), 1312-1323.

Diallo, I., Sylla, M. B., Giorgi, F., Gaye, A. T. y Camara M., 2012. Multimodel GCMRCM Ensemble-Based Projections of Temperature and Precipitation over West Africa for the Early 21st Century. Int. J. Geophys, 2012, 1-19.

Domínguez, F., Cañon, J. y Valdes, J., 2010. IPCC-AR4 climate simulations for the Southwestern US: the importance of future ENSO projections. Clim. Change, 99, 499-514.

Domínguez, M., Romera, R., Sánchez, E., Fita, L., Fernández, J., Jiménez-Guerrero, P., Montávez, J.P., Cabos, W. D., Liguori, G. y Gaertner, M. Á., 2013. Present-climate precipitation and temperature extremes over Spain from a set of high resolution RCMs. Clim. Res., 58, 149-164.

Ducoudré, N., Laval K. y Perrier A., 1993. A new set of parameterizations of the hydrologic exchanges and the land-atmosphere interface within the LMD atmospheric global circulation model. J. Climate, 6, 248-273

Efron, B. y Tibshirani, R. J., 1993. An introduction to the bootstrap. Chapman \& Hall, New York.

El Kenawy, A., López-Moreno, J. I., McCabe, M. F., Brunsell, N. A. y Vicente-Serrano, S. M., 2015. Daily temperature changes and variability in ENSEMBLES regional models predictions: Evaluation and intercomparison for the Ebro Valley (NE Iberia). Atmospheric Research, 155, 141-157.

Engel, B.A., Srinivasan, R., Arnold, J.G., Rewerts, C. y Brown S.J., 1993. Nonpoint source (NPS) pollution modeling using models integrated with Geographic Information Systems (GIS). Water Science and Technology, 28(3-5), 685-690.

Estrela, T., Cabezas, F. y Estrada, F., 1999. La evaluación de los recursos hídricos en el Libro Blanco del Agua en España. Ingeniería del Agua,.6 (2), 125-138.

Estrela, T. y Quintas, L., 1996a. A distributed hydrological model for water resources 
assessment in large basins. Proceedings of 1st International Conference on Rivertech, 2, 861-868.

Estrela, T. y Quintas, L., 1996b. El sistema integrado de modelización precipitación aportación SIMPA. Revista de Ingeniería Civil, 104, 43-52.

European Commission, 2009. Technical report-2009-040. Common implementation strategy for the water framework directive (2000/60/EC). Guidance document. River basin management in a changing climate. European Comunities, 24, pp 134. http://ec.europa.eu/environment/water/water-framework/

Ewen, J., Sloan, W.T., Kilsby, C.G. y O’Connell, P.E., 1999. UP Modelling System for large scale hydrology deriving large-scale physically-based parameters for the Arkansas-Red River basin. Hydrology and Earth System Sciences, 3, 125-136.

Exbrayat, J.F., Viney, N. R., Frede, H.G. y Breuer, L., 2013. Using multi-model averaging to improve the reliability of catchment scale nitrogen predictions. Geosci. Model Dev., 6, 117-125.

Famiglietti, J. S. y Wood, E. F., 1994. Multiscale modeling of spatially variable water and energy balance processes. Water Resour. Res., 30, 3061-3078.

Gan, T.Y. y Burges, S.J., 1990. An Assessment of a Conceptual Rainfall-Runoff Model's Ability to Represent the Dynamics of Small Hypothetical Catchments 1. Models, Model Properties, and Experimental Design. Water Resour. Res., 26, 1595-1604.

García Galiano, S.G., 2011. Toolbox EXTREMES. Registro de Propiedad Intelectual $\mathrm{n}^{\circ}$ 08/2011/174.

García Galiano, S. G., Olmos Giménez, P., y Giraldo Osorio, J. D., 2015. Assessing nonstationary spatial patterns of extreme droughts from long-term high-resolution observational dataset on a semiarid basin (Spain). Water, 7(10), 5458-5473, doi: $10.3390 / \mathrm{w} 7105458$.

Gedney, N., Cox, P. M., Betts, R. A., Boucher, O., Huntingford, C. y Stott, P. A., 2006. Detection of a direct carbon dioxide effect in continental river runoff records. Nature, 439(7078), 835-838.

Gibbons, J. D. y Chakraborti, S., 2003. Nonparametric statistical inference fourth edition, New York.

Giraldo Osorio, J. D., 2011. Análisis de la variabilidad y tendencias de eventos extremos de precipitación en el contexto del cambio climático: desarrollo de una herramienta de seguimiento dinámico de inundaciones. Tesis. Universidad Politécnica de 
Cartagena, España.

Giraldo Osorio, J. D. y García Galiano, S. G., 2011. Building hazard maps of extreme daily rainy events from PDF ensemble, via REA method, on Senegal River Basin. Hydrol. Earth Syst. Sci., 15, 3605-3615.

Giraldo Osorio, J. D. y García Galiano, S. G., 2013. Assessing uncertainties in the building of ensemble RCMs over Spain based on dry spell lengths probability density functions. Clim. Dyn., 40, 1271-1290.

Giorgi, F. y Coppola, E., 2010. "Does the model regional bias affect the projected regional climate change? An analysis of global model projections: a letter," Climatic Change, 100 (3), 787-795.

Giorgi, F. y Mearns, L. O., 2002. Calculation of average, uncertainty range, and reliability of regional climate changes from AOGCM simulations via the "reliability ensemble averaging" (REA) method. J. Clim., 15(10), 1141-1158.

Giorgi, F. y Mearns, L. O., 2003. Probability of regional climate change based on reliability ensemble averaging (REA) method. Geophys Res Lett 30, 311-314

González-Aparicio, I. e Hidalgo, J., 2012. Dynamically based future daily and seasonal temperature scenarios analysis for the northern Iberian Peninsula. Int. J. Climatol., $32,1825-1833$.

González-Zeas, D., Garrote, L., Iglesias, A. y Sordo-Ward, A., 2012. Improving runoff estimates from regional climate models: a performance analysis in Spain. Hydrol. Earth Syst. Sci., 9, 175-214.

Goubanova, K., 2007. Extremes in temperature and precipitation around the Mediterranean basin in an ensemble of future climate scenario simulations. Global Planet Change, 57, 27-42.

Hargreaves, G.H., y Samani, Z.A., 1985. Reference crop evapotranspiration from temperature. Applied Eng. in Agric., 1(2), 96-99.

Haylock, M., Hofstra, N., Klein Tank, A., Klok, E.J., Jones, P., New, M., 2008. A European daily high-resolution gridded data set of surface temperature and precipitation for 1950-2006. J. Geophys. Res., 113 (D20119), doi: 10.1029/2008JD010201.

Herrera, S., Fita, L., Fernández, J. y Gutiérrez, J. M., 2010. Evaluation of the mean and extreme precipitation regimes from the ENSEMBLES regional climate multimodel simulations over Spain. J. Geophys. Res., 115(D21), 117. 
Herrera, S., Gutiérrez, J. M., Ancell, R., Pons, M. R., Frías, M.D. y Fernández, J., 2012. Development and analysis of a 50-year high-resolution daily gridded precipitation dataset over Spain (Spain02). Int. J. Climatol., 32, 74-85.

Houghton, J.T., Ding, Y., Griggs, D. J., Noguer, H., Van der Linden, P. J., Dai, X., Maskell, K. y Johnson, C.A., 2001. Climate Change 2001: The Scientific Basis. Cambridge University Press, UK.

Huisman, J. A., Breuer, L., Bormann, H., Bronstert, A., Croke, B. F. W., Frede, H.-G., Gräff, T., Hubrechts, L., Jakeman, A. J. y Kite, G., 2009. Assessing the impact of land use change on hydrology by ensemble modeling (LUCHEM) III: Scenario analysis. Adv. Water Resour., 32, 159-170.

Huntington, T. G., 2006. Evidence for intensification of the global water cycle: review and synthesis. J. Hydrol., 319, 83-95.

IGME, 2013. Instituto Geológico y Minero de España. http://www.igme.es/

IGN, 2010. Metodología de producción de la base de datos CLC-CHANGE 2000-2006. Ministerio de Medio Ambiente y Medio Rural y Marino.

IPCC, 2007. Climate Change 2007: Synthesis Report. Contribution of Working Groups I, II and III to the Fourth Assessment Report of the Intergovernmental Panel on Climate Change. IPCC. Pachauri, R. K y Reisinger, A.( Eds.). ISBN 92-9169-122-4. IPCC, 2013. Climate Change 2013: The Physical Science Basis. Contribution of Working Group I to the Fifth Assessment Report of the Intergovernmental Panel on Climate Change. Stocker, T.F., Qin, D., Plattner, G.-K., Tignor, M., Allen, S.K., Boschung, J., Nauels, A., Xia, Y., Bex, V., y Midgley, P.M. (Eds.). Cambridge University Press, United Kingdom and New York, pp 1535.

IPCC, 2014. Climate Change 2014: Synthesis Report. Contribution of Working Groups I, II and III to the Fifth Assessment Report of the Intergovernmental Panel on Climate Change. Pachauri, R.K. y Meyer, L.A. (Eds.). IPCC, Geneva, Switzerland, pp. 151.

IPCC SRES, 2000. Special Report on Emissions Scenarios: A special report of Working Group III of the Intergovernmental Panel on Climate Change. Nakićenović, N., y Swart, R. (Eds.). Cambridge University Press, ISBN 0-521-80081-1, 978052180081-5.

IVIA, 2013. Instituto Valenciano de Investigaciones Agrarias. http://www.ivia.gva.es/ Jacob, D., Petersen, J., Eggert, B., Alias, A., Christensen, O. B., Bouwer, L., Braun, A., 
Colette, A., Déqué, M., Georgievski, G., Georgopoulou, E., Gobiet, A., Menut, L., Nikulin, G., Haensler, A., Hempelmann, N., Jones, C., Keuler, K., Kovats, S., Kröner, N., Kotlarski, S., Kriegsmann, A., Martin, E., Meijgaard, E., Moseley, C., Pfeifer, S., Preuschmann, S., Radermacher, C., Radtke, K., Rechid, D., Rounsevell, M., Samuelsson, P., Somot, S., Soussana, J.-F., Teichmann, C., Valentini, R., Vautard, R., Weber, B. y Yiou, P., 2014. EURO-CORDEX: new high-resolution climate change projections for European impact research. Regional Environmental Change, 14, 563578.

Jiménez-Guerrero, P., Montávez, J. P., Domínguez, M., Romera, R., Fita, L., Fernández, J., Cabos, W. D., Liguori, G. y Gaertner, M.A., 2013. Mean fields and interannual variability in RCM simulations over Spain: the ESCENA project. Clim Res., 57, 201-220.

Kilsby, C. G., Tellier, S. S., Fowler, H. J. y Howels, T.R., 2007. Hydrological impacts of climate change on the Tejo and Guadiana Rivers. Hydrol. Earth Syst. Sci., 11, 11751189.

Labat, D., Goddéris, Y., Probst, J. L. y Guyot, J. L., 2004. Evidence for global runoff increase related to climate warming. Advances in Water Resources, 27(6), 631-642.

Lim, Y., Jo, S., Lee, J., Oh, H. S., Lee, S. G., Park, Y. y Kang, H. S., 2014. Multimodel ensemble forecasting of rainfall over East Asia: regularized regression approach. Int. J. Climatol., 34, 3720-3731.

Loaiza Usuga, J. C. y Pauwels, V. R.N., 2008.Calibration and multiple data set-based validation of a land surface model in a mountainous Mediterranean study area. $J$. Hydrol., 356, 223-233.

López-Franca, N., Sánchez, E., Losada, T., Domínguez, M., Romera, R. y Gaertner, M. A., 2015. Markovian characteristics of dry spells over the Iberian Peninsula under present and future conditions using ESCENA ensemble of regional climate models. Clim. Dyn., 45, 661-677.

López-Moreno, J.I., Goyette, S. y Beniston, M., 2008. Climate change prediction over complex areas: spatial variability of uncertainties and predictions over the Pyrenees from a set of regional climate models. Int. J. Climatol. 28,1535-1550.

López-Moreno, J.I., Zabalza, J., Vicente-Serrano, S.M., Revuelto, J., Gilaberte, M., Azorin-Molina, C., Morán-Tejeda, E., García-Ruiz, J.M. y Tague, C., 2014. Impact of climate and land use change on water availability and reservoir management: 
Scenarios in the Upper Aragón River, Spanish Pyrenees. Science of The Total Environment, 493, 1222-1231.

Maestre-Valero, J.F., Martínez-Álvarez, V., y González Real, M.M., 2013. Regionalization of the Hargreaves coefficient to estimate long-term reference evapotranspiration series in SE Spain. Spanish Journal of Agriculture Research, 11(4), 1137-1152.

Makhlouf, Z., Michel, C., 1994. A two-parameter monthly water balance model for French watersheds. J. Hydrol., 162 (3-4), 299-318.

Makkonen, L., 2006. Plotting Positions in Extreme Value Analysis. J. Appl. Meteor. Climatol., 45, 334-340.

Milano, M., Ruelland, D., Dezetter, A., Fabre, J, Ardoin-Bardin, S. y Servat, E., 2013. Modeling the current and future capacity of water resources to meet water demands in the Ebro basin. J. Hydrol., 500, 114-126.

Milliman, J. D., Farnsworth, K. L., Jones, P. D., Xu, K. H., and Smith, L. C., 2008. Climatic and anthropogenic factors affecting river discharge to the global ocean, 1951-2000. Global planet. change, 62(3), 187-194.

Moise, A. F. y Hudson, D. A., 2008. Probabilistic predictions of climate change for Australia and southern Africa using the reliability ensemble average of IPCC CMIP3 model simulations. J. Geophys. Res., 113 (D15), doi: 10.1029/2007JD009250.

Molnar, P., 2011. Calibration. Watershed Modelling, SS 2011. Institute of Environmental Engineering, Chair of Hydrology and Water Resources Management, ETH Zürich. Switzerland.

Multsch, S., Exbrayat, J. F., Kirby, M., Viney, N. R., Frede, H. G. y Breuer, L., 2015. Reduction of predictive uncertainty in estimating irrigation water requirement through multi-model ensembles and ensemble averaging. Geosci. Model Dev., 8, 1233-1244.

Murillo, J. M. y Navarro, J. A., 2011. Aplicación del modelo de Témez a la determinación de la aportación superficial y subterránea del sistema hidrológico Cornisa-Vega de Granada para su implementación en un modelo de uso conjunto. Boletín Geológico y Minero, 122 (3), 363-388.

Nash, J.E. y Sutcliffe, J.V., 1970. River flow forecasting through conceptual models, part I: A discussion of principles. J. Hydrol., 10, 282-290.

Osca, J., Romero, R. y Alonso S., 2013. Precipitation projections for Spain by means of 
a weather typing statistical method. Global Planet. Change, 109, 46-63.

Paeth, H., Hall, N. M. J., Gaertner, M., Alonso, M. D., Moumouni, S., Polcher, J., Ruti, P. M., Fink, A. H., Gosset, M., Lebel, T., Gaye, A. T., Rowell, D. P., MoufoumaOkia, W., Jacob, D., Rockell, B., Giorgi, F. y Rummukainen, M., 2011. Progress in regional downscaling of West African precipitation. Atmos. Sci. Let., 12, 75-82.

Palmer, T. N., Doblas-Reyes, F. J., Hagedorn, R. y Weisheimer, A., 2005. Probabilistic prediction of climate using multi-model ensembles: From basics to applications, Philos. Trans. R. Soc. London, Ser. B, 360, 1991-1998, doi:10.1098/rstb.2005.1750.

Paredes, D., Trigo, R. M., García-Herrera, R. y Franco Trigo, I., 2006. Understanding precipitation changes in Iberia in early spring: weather typing and storm-tracking approaches. J. Hydrom., 7, 101-113.

Perkins, S. E., Pitman, A. J., Holbrook, N. J. y McAneney, J., 2007. Evaluation of the AR4 climate models' simulated daily maximum temperature, minimum temperature, and precipitation over Australia using probability density functions. J. Clim., 20, 4356-4376.

Potenciano A. y Villaverde J.J., 2010. Implementación del modelo hidrológico de Témez para la evaluación de recursos hídricos con GRASS GIS. Fase superficial y subterránea. Proc en: III Jornadas de SIG libre. Servei de Sistemas D’Informació Geogràfica i Teledetecció. Universitat Girona. http://www.sigte.udg.es.

Quintas, L., 1996. La base de datos hidrológicos "HIDRO" del CEDEX. Ingeniería Civil, 104, 117-126.

Ramos, M. C., Balasch, J. C. y Martínez-Casasnovas, J. A., 2012. Seasonal temperature and precipitation variability during the last 60 years in a Mediterranean climate area of Northeastern Spain: a multivariate analysis. Theor. Appl. Climatol., 110, 35-53.

Rummukainen, M., 2010. State-of-the-art with regional climate models. WIREs Climate Change, 1, 82-96, doi: 10.1002/wcc.8

Raposo, J.R., Dafonte, J. y Molinero, J., 2013. Assessing the impact of future climate change on groundwater recharge in Galicia-Costa, Spain. Hydrogeology Journal, 21 (2), 459-479.

Rauscher, S., Coppola, E., Piani, C. y Giorgi, F., 2010. Resolution effects on Regional Climate Model simulations of seasonal precipitation over Europe. Clim. Dyn., 35, $685-711$.

Rauthe, M., Steiner, H., Riediger, U., Mazurkiewicz, A., Gratzki, A., 2013. A central 
european precipitation climatology part i: Generation and validation of a highresolution gridded daily data set (hyras). Meteorologische Zeitschrift, 22(3): 235256, doi: 10.1127/0941-2948/2013/0436.

Ruiz García, J. M., 1999. Modelo distribuido para la evaluación de recursos hídricos. Monografías Cedex, M67.

Samani, Z., 2000. Estimating Solar Radiation and Evapotranspiration Using Minimum Climatological Data. Journal of Irrigation and Drainage Engineering, 126 (4), 265 267.

Samper, J., Huguet, Ll., Ares, J. y García Vera, M.A., 1999. Manual del usuario del programa VISUAL BALAN v.1.0: Código interactivo para la realización de balances hidrológicos y la estimación de la recarga. ENRESA, 5/99, pp. 205.

Sánchez, E., Romera, R., Gaertner, M. A., Gallardo, C. y Castro, M., 2009. A weighting proposal for an ensemble of regional climate models over Europe driven by 19612000 ERA40 based on monthly precipitation probability density functions. Atmos. Sci. Lett., 10, 241-248.

Senarath, S., Ogden, F.L., Downer, C.W. y Sharif, H.O., 2000. On the calibration and verification of two-dimentional distribute, Hortonian, continuous watershed models. Water Resources Research, 36, 1495-1510.

Sheskin, D. J., 2000. Handbook of parametric and nonparametric statistical procedures. Chapman \& Hall/CRC, Boca Raton.

SIAM, 2013. Sistema de información agraria de Murcia. http://siam.imida.es/apex/f?p=101:1:689155068600146

SIAR, 2013. Servicio Integral de Asesoramiento al regante de Castilla la Mancha. http://crea.uclm.es/siar/datmeteo/

Sillmann, J., Kharin, V. V., Zhang, X., Zwiers, F. W. y Bronaugh D., 2013. Climate extremes indices in the CMIP5 multimodel ensemble: Part 1. Model evaluation in the present climate. J. Geophys. Res. Atmos., 118(4), 2473-2493.

Sitch, S. y Coauthors, 2000. LPJ-A coupled model of vegetation dynamics and the terrestrial carbon cycle. The Role of Vegetation Dynamics in the Control of Atmospheric $\mathrm{CO}_{2}$. Content, Ph.D. thesis, Lund University.

Sun, Q., Miao, C. y Duan, Q., 2015. Projected changes in temperature and precipitation in ten river basins over China in 21st century. Int. J. Climatol., 35(6), 1125-1141.

Sunyer, M. A., Madsen, H., Rosbjerg, D. y Arnbjerg-Nielsen, K., 2013. Regional 
Interdependency of Precipitation Indices across Denmark in Two Ensembles of HighResolution RCMs. J. Climate, 26, 7912-7928.

Tague, C. L. y Band, L. E., 2004. RHESSys: Regional Hydro-Ecologic Simulation System- An Object-Oriented Approach to Spatially Distributed Modeling of Carbon, Water, and Nutrient Cycling. Earth Interact., 8, 1-42.

Tanguy, M., 2012. Operational tools and applications of EO satellite data to retrieve surface fluxes in semi-arid countries. Tesis. Universidad Politécnica de Cartagena, España.

Tebaldi, C., Nychka, D. y Mearns, L. O., 2004. From global mean responses to regional signals of climate change: simple pattern scaling, its limitations (or lack of) and the uncertainty in its results. In: Procl8th Conf on Probability and Statistics in the Atmospheric Sciences. AMS Annu Meet, Seattle, WA.

Tebaldi, C. y Knutti, R., 2007. The use of the multi-model ensemble in probabilistic climate projections. Philos. Trans. R. Soc. London, Ser. A, 365(1857), 2053-2075.

Témez, J. R., 1977. Modelo Matemático de trasformación "precipitación- escorrentía”. Asociación de Investigación Industrial Eléctrica. ASINEL. Madrid. 39 pp.

Touhami, I., Chirino, E., Andreu, J.M., Sánchez, J.R., Moutahir, H. y Bellot, J., 2015. Assessment of climate change impacts on soil water balance and aquifer recharge in a semiarid region in south east Spain. J. Hydrol., 527, 619-629.

USACE, 1998. HEC-HMS user's manual. Hydrologic Engineering Center. Davis, CA. USA.

Verant, S., Laval, K., Polcher, J. y Castro, M., 2004. Sensitivity of the continental hydrological cycle to the spatial resolution over the Iberian Peninsula. $J$. Hydrometeorol., 5, 265- 283.

Viovy, N., 1996. Interannuality and $\mathrm{CO}_{2}$ sensitivity of the SECHIBA-BG coupled SVAT-BGC model. Phys. Chem. Earth, 21, 489-497

Vörösmarty, C. J., Green, P., Salisbury, J. y Lammers, R. B., 2000. Global water resources: vulnerability from climate change and population growth. Science, 289(5477), 284-288.

Xu, Y., Gao, X. y Giorgi, F., 2010. Upgrades to the reliability ensemble averaging method for producing probabilistic climate-change projections. Clim. Res., 41, 6181. 


\section{ANEJOS}

\section{A. $p$ del test de bondad de ajuste Smirnov-Kolmogorov}

El test de bondad de ajuste Smirnov-Kolmogorov (TSSK) es un test no paramétrico que evalúa la concordancia entre las distribuciones de probabilidad de dos muestras independientes. El test cuantifica la distancia máxima entre las CDF empíricas construidas desde las series. El estadístico de dos colas es el siguiente:

$D_{n 1, n 2}=\max \left|S_{n 1}(y)-S_{n 2}(y)\right|$

donde $S_{n 1}(y)$ y $S_{n 2}(y)$ son las distribuciones empíricas de las muestras independientes, y $n 1$ y $n 2$ corresponden a los tamaños de las muestras. Para la distribución asintótica de la distancia de Kolmogorov se ha probado (Gibbons y Chakraborti, 2003) como:

$$
\lim _{n 1, n 2 \rightarrow \infty} P\left[\sqrt{\frac{n 1 n 2}{n 1+n 2}} D_{n 1, n 2} \leq d\right]=L(d)
$$

con

$$
L(d)=1-2 \sum_{i=1}^{\infty}(-1)^{i-1} e^{\left(-2 i^{2} d^{2}\right)}
$$

Finalmente, el $p$ del test de bondad de ajuste se calcula con la siguiente ecuación:

$$
p(d)=1-L(d)=2 \sum_{i=1}^{\infty}(-1)^{i-1} e^{\left(-2 i^{2} d^{2}\right)}
$$




\section{B. Sscore. Métrica propuesta por Perkins}

Perkins et al. (2007) desarrollaron un método para evaluar la similaridad entre dos PDFs a través del denominado skill score (Sscore), que calcula el área común bajo las dos curvas definidas por las PDF, como se presenta en la Figura 10.1. Si las distribuciones coinciden de manera perfecta, el Sscore sería igual a la unidad.

Como la relación entre las CDF empíricas (usadas por el TSSK) y las PDF empíricas es directa, el Sscore es fácil de calcular. Su definición en el caso continuo, sería la siguiente:

Sscore $=\int_{-\infty}^{x_{0}} f_{1}(x) d x+\int_{x_{0}}^{+\infty} f_{2}(x) d x$

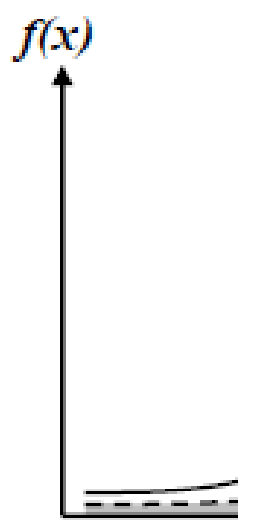

Figura 10.1 Métrica definida por Perkins et al. (2007). El Sscore es la medida del área bajo ambas curvas $f_{1}(x)$ y $f_{2}(x)$ (área sombreada). 


\section{Ecuaciones del modelo Témez}

En el modelo de Témez (1977), el agua que procede de la precipitación $\left(P_{i}\right)$ se fracciona en dos componentes. Una es la evapotranspiración $\left(E T P_{i}\right)$ y la otra, que se denomina excedente total $\left(T_{i}\right)$ es la suma de la escorrentía superficial $\left(A_{\text {sup }} i\right)$ y de la infiltración $\left(I_{i}\right)$, que tiene lugar a través del suelo y de la zona no saturada de los acuíferos. Para el instante de tiempo " $i$ " se verifica que:

$T_{i}=A_{\mathrm{sup} i}+I_{i}$

El excedente total $\left(T_{i}\right)$ se calcula según las siguientes expresiones:

$T_{i}=0$ si $P_{i} \leq P_{0}$

$T_{i}=\frac{\left(P_{i}-P_{0}\right)^{2}}{P_{i}+\delta-2 P_{0}}$ si $\quad P_{i}>P_{0}$

donde:

$\delta=H_{\text {max }}-H_{i-1}+E T P_{i}$

$P_{0}=C\left(H_{\max }-H_{i-1}\right)$

siendo en cada celda:

$P_{i}$ precipitación en el mes $i(\mathrm{~mm})$

$T_{i}$ excedente de agua en el mes $i(\mathrm{~mm})$

$H_{\max }$ capacidad máxima de almacenamiento de agua en el suelo $(\mathrm{mm})$, que depende de la textura, la pendiente del terreno y el espesor de la franja de suelo donde tienen lugar la evapotranspiración.

$H_{i-1}$ almacenamiento de agua en el suelo en el mes $i-1(\mathrm{~mm})$

$E T P_{i}$ evapotranspiración potencial en el mes $i(\mathrm{~mm})$

$C$ parámetro de excedente

Otras variables necesarias para la resolución del modelo en su fase superficial son el almacenamiento de agua en el suelo $\left(H_{i}\right)$ y la evapotranspiración real $\left(E T R_{i}\right)$ en cada celda en el mes i, y que se obtienen mediante las siguientes expresiones:

$H_{i}=\max \left[0,\left(H_{i-1}+P_{i}-T_{i}-E T P_{i}\right)\right]$ 
$E T R_{i}=\min \left[\left(H_{i-1}+P_{i}-T_{i}\right), E T P_{i}\right]$

La infiltración $\mathrm{I}_{\mathrm{i}}$ es función del excedente de agua $\left(T_{i}\right)$ y del parámetro denominado infiltración máxima $\left(I_{m a ́ x}\right)$ a través de la expresión empírica:

$I_{i}=I_{\max } \frac{T_{i}}{T_{i}+I_{\text {maz }}}$

Las relaciones más importantes entre las variables del modelo se grafican en la Figura 10.2:
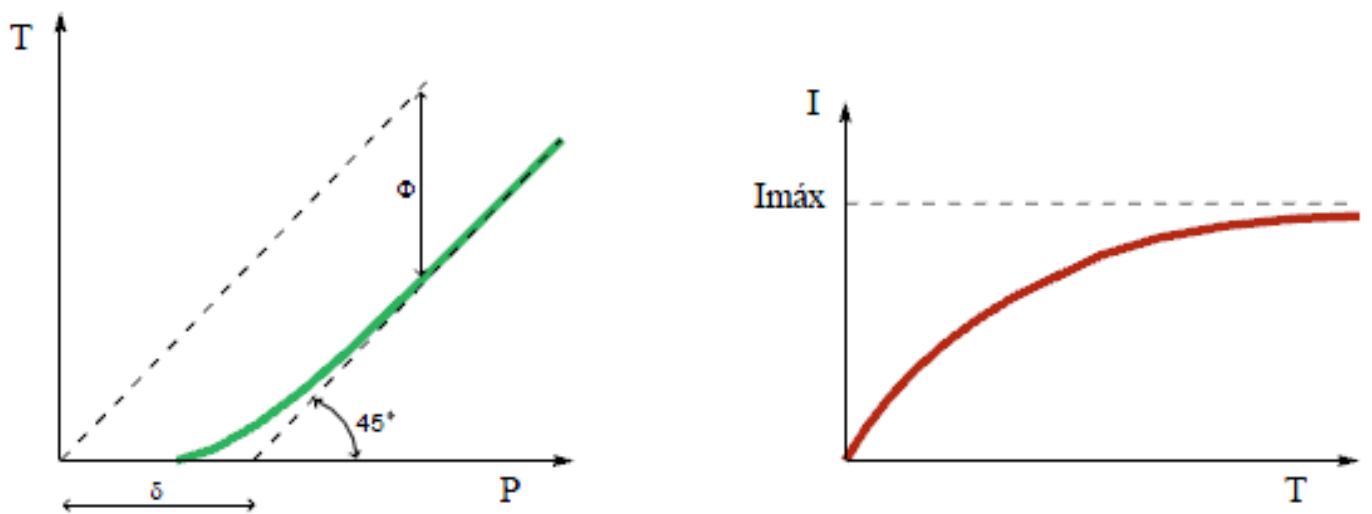

Figura 10.2. Ley de excedentes (izquierda) y ley de infiltración (derecha)

Según Témez, el modelo asume que la recarga al acuífero en cada celda coincide con la infiltración. Una vez calculada la recarga en cada una de las celdas pertenecientes a los distintos acuíferos, el modelo realiza su integración en los recintos que los definen y aplica el modelo unicelular de forma agregada.

La evolución del volumen almacenado en el acuífero y su descarga a la red de drenaje superficial o al mar se define como:

$V_{i}=V_{i-1} \cdot e^{-\alpha \Delta t}+\frac{R_{i}}{\alpha}\left(1-e^{-\alpha \Delta t}\right)$

$A_{\text {subi }}=V_{i-1}-V_{i}+R_{i}$

siendo:

$\alpha$ coeficiente de agotamiento del acuífero (meses-1)

$\Delta t$ intervalo temporal (mes)

$R_{i}$ recarga al acuífero en el mes $i(\mathrm{~mm} / \mathrm{mes})$ 
$V_{i}$ volumen almacenado en el acuífero en el mes $i(\mathrm{~mm})$

$A_{\text {subi }}$ aportación subterránea correspondiente al mes $i(\mathrm{~mm} / \mathrm{mes})$

La aportación total es igual a la parte de excedente $\left(T_{i}\right)$ no infiltrada $\left(I_{i}\right)$ más la aportación subterránea $\left(A_{s u b i}\right)$ :

$$
A_{\text {Toti }}=\left(T_{i}-I_{i}\right)+A_{\text {subi }}=A_{\mathrm{sup} i}+A_{\text {subi }}
$$

siendo:

$A_{\text {supi }}$ aportación superficial del mes $i(\mathrm{~mm} / \mathrm{mes})$

$A_{\text {Toti }}$ aportación total durante el mes $i(\mathrm{~mm} / \mathrm{mes})$. 
Evaluación de la variabilidad hidroclimática desde Modelos Climáticos Regionales a escala de cuenca 